\title{
A Multi-Frequency Acoustic Investigation of Seafloor Methane Seep Sites at Omakere Ridge, Hikurangi Margin, New Zealand
}

\author{
by \\ Thomas Vasilios Golding
}

A thesis

submitted to the Victoria University of Wellington in fulfilment of the requirements for the degree of Master of Science in Petroleum Geoscience.

Victoria University of Wellington 2012 



\begin{abstract}
Omakere Ridge is an anticlinal thrust ridge in water depths of $1100-1700 \mathrm{~m}$ on the Hikurangi Margin, east of the North Island of New Zealand, and is an area of active seafloor methane seepage associated with an extensive gas hydrate province. Methane seep sites on the Hikurangi Margin are characterised by localised buildups of authigenic carbonate and chemosynthetic seep fauna that exist on a seafloor otherwise characterised by soft, muddy sediments and provide a unique window into the workings of the gas hydrate system. Seafloor methane seeps sites on Omakere Ridge have been successfully imaged using three newly-acquired acoustic datasets: a P-Cable ${ }^{\mathrm{TM}}$ high-resolution 3D seismic reflection dataset $(60$ $\mathrm{Hz})$; a multibeam sonar backscatter dataset $(12 \mathrm{kHz})$; and a Parasound ${ }^{\mathrm{TM}}$ subbottom profiler dataset $(4 \mathrm{kHz})$.
\end{abstract}

Seafloor seismic amplitude and similarity maps have been derived from a preliminary shipboard post-stack migrated data cube. A pronounced acquisition artifact is manifest in the seafloor horizon slice as high- and low-amplitude stripes that alternate periodically in the crossline direction. This artifact has been removed from the seafloor horizon slice using 2D spatial frequency filtering, followed by direct sampling and stochastic removal of the very-low-frequency components in the spatial domain. The seismic amplitude map has then been transformed into a calibrated seafloor reflection coefficient map. Sonar backscatter mosaics have been created after correcting for beam pattern effects and angular variation in backscatter after taking into account the bathymetry. Several backscatter mosaics were incorporated into a stacked mosaic over the study area to attenuate random noise. The Parasound ${ }^{\mathrm{TM}}$ sub-bottom profiler data were processed to display instantaneous amplitude and separated into 43 lines over the study area.

Comparison of 3D seismic attributes, multibeam backscatter intensity and shallow subsurface reflection characteristics provides new insights into the previously unknown extent of authigenic carbonate build-ups, methane migration 
pathways and seep initiation mechanisms at five seep sites on Omakere Ridge. Areas of high seafloor 3D seismic reflection coefficient and high multibeam backscatter intensity are interpreted as carbonate formations of at least 6-7 $\mathrm{m}$ thickness, while areas exhibiting low seismic reflection coefficient and moderate/high sonar backscatter intensity are interpreted as areas where the carbonates are less developed. Anomalous high-amplitude subsurface reflections beneath the seeps in the Parasound ${ }^{\mathrm{TM}}$ data are interpreted as buried carbonates and may indicate a previously unknown earlier phase of seepage at Omakere Ridge, but could also be caused by gas or gas hydrates. The extent of authigenic carbonates is directly related to the duration of seepage and thus provides a new proxy for the chronology of seepage at Omakere Ridge, which has proved consistent with an existing hypothesis based on the abundance of deceased and live chemosynthetic fauna at the seep sites. 


\section{Acknowledgments}

Firstly, a big thank you to my supervisors Ingo Pecher and John Townend. I am very grateful for all the effort you have put in over the last year to maintaining regular meetings to discuss progress and results, reviewing and correcting drafts of this thesis and my AGU poster, helping me with scholarship applications, and suggesting new methods for analysing and displaying data. You have both inspired me to continue in the field of geoscience and I look forward to the future discussions we will have.

Funding for this project was provided by the Victoria University of Wellington, OMV New Zealand, the Todd Foundation, and the Geological Society of New Zealand. The Ministry of Science and Innovation programme GHR (Gas Hydrates Resources, contract number C05X0908) provided funding for me to take part in the RV-Sonne scientific cruise SO-214, to attend and present at the AGU Fall Meeting in San Francisco, and to travel to Auckland to meet with a colleague. I am very grateful for these experiences, which I consider to have been a real privilege. GNS Science also provided me with a workstation and all the software I required to complete my research.

Thank you very much to the SO-214 Scientific Party, particularly Gareth Crutchley, Jens Greinert, Cord Papenberg, Dirk Klaeschen and Joerg Bialas. Joerg allowed GNS Science to work with the 3D seismic, multibeam backscatter and Parasound $^{\mathrm{TM}}$ data from Omakere Ridge after 3D seismic surveying at Porangahau Ridge, the originally-proposed study area for this thesis, had to be abandoned due to bad weather. Without this act of generosity, this project would have been impossible. Gareth helped me to understand and interpret the 3D seismic dataset and had many useful suggestions for suppressing an acquisition artifact, and advised me on how to process the Parasound ${ }^{\mathrm{TM}}$ data. Jens' expertise in sonar 
backscatter data helped me to understand, process and interpret these data. Dirk, Cord and Gareth processed the 3D seismic data during the cruise, enabling me to begin my analysis and interpretation as soon as we returned to dry land. This thesis also benefited from many discussions with other researchers at GNS Science, including Stuart Henrys, Andreia Plaza, Bryan Davy and Dan Barker. I have learned many valuable things from each of you. Thank you to Kathy Campbell at Auckland University, who acquainted Ingo and me with the actual carbonate rocks that we had been imaging on the seafloor and in the subsurface with the acoustic datasets: this greatly helped us with our interpretations. Thank you to Andrew Gorman at Otago University, who gave me constructive feedback on results from all three datasets. I would also like to acknowledge my examiners Tim Stern and Philip Barnes for their constructive feedback, which improved this work.

Finally, thank you to my fiancée Anne, my family and my friends. Anne, you have provided constant support and inspired me every day to achieve my goals. Mum and Dad, you have always supported me in everything I have chosen to pursue. Friends, it has been great to have you there whenever I needed a break from the research. 


\section{Contents}

1 Introduction 1

1.1 Motivation and objectives ................. 1

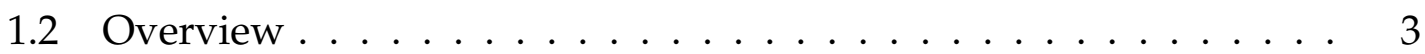

1.3 Contribution of this thesis ............... 6

1.4 Thesis structure . . . . . . . . . . . . . . . 7

2 Background 9

2.1 Seafloor hydrocarbon seep sites . . . . . . . . . . . . . . 9

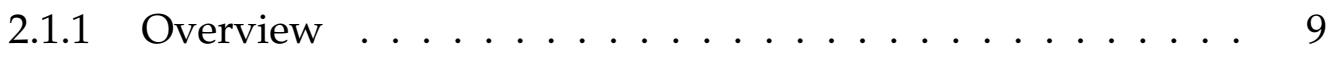

2.1.2 Gas source and migration . . . . . . . . . . . . 10

2.1 .3 Gas hydrates . . . . . . . . . . . . . . . . 10

2.1 .4 Seep carbonates . . . . . . . . . . . . . . . 12

2.1.5 Other seep-related seafloor features . . . . . . . . . . . 15

2.2 Geophysical imaging of seep sites . . . . . . . . . . . . . . . . 16

2.2 .1 Overview ..................... 16

2.2.2 Sonar backscatter from the seafloor . . . . . . . . . 16

2.2.3 3D seismic reflectivity of the seafloor $\ldots \ldots$. . . . . . 17

2.2.4 Subsurface acoustic profiling . . . . . . . . . . 18

2.3 Geological setting . . . . . . . . . . . . . . . . . . 19

2.3.1 Structure of the Hikurangi Margin . . . . . . . . . . . . . . 19

2.3.2 Gas hydrates and hydrocarbon seepage . . . . . . . . . . 20

2.3 .3 Seep carbonates . . . . . . . . . . . . . . . 22

2.3 .4 Seep fauna . . . . . . . . . . . . . . . 23

2.4 Omakere Ridge . . . . . . . . . . . . . . . . . . 24

2.4 .1 Previous studies . . . . . . . . . . . . . . 24 
3 3D Seismic Dataset 31

3.1 Acquisition and processing . . . . . . . . . . . . 31

3.2 Noise ............................... 33

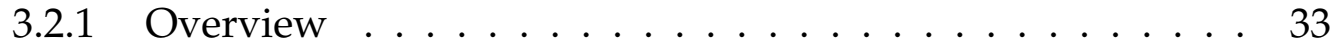

3.2.2 Time-domain characteristics of the footprint . . . . . . . 34

3.2.3 Spatial frequency characteristics of the footprint . . . . . . . 34

3.2.4 Factors contributing to the footprint . . . . . . . . . . 40

3.2.5 Footprint removal ................ . . 42

3.3 Seismic attributes . . . . . . . . . . . . . . . . . 45

3.3.1 Seafloor reflection coefficient . . . . . . . . . . 45

3.3.2 Seafloor seismic similarity . . . . . . . . . . . . . 48

3.4 Results . . . . . . . . . . . . . . . . . . . . . 49

3.4 .1 Overview ........................ 49

3.4 Bear's Paw . . . . . . . . . . . . . . . . 49

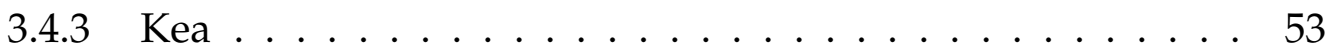

3.4 .4 Kaka ......................... 58

3.4 .5 Kakapo........................ 58

3.4 .6 Moa Reef . . . . . . . . . . . . . . . . . . . 59

4 Sonar Backscatter $\quad 61$

4.1 Sonar backscatter theory . . . . . . . . . . . . . 61

4.2 Data acquisition . . . . . . . . . . . . . . . . . 64

4.3 Data Processing . . . . . . . . . . . . . . . . . 66

4.3 .1 Overview ..................... 66

4.3 .2 Bathymetry ........................ 66

4.3 .3 Backscatter ................... 67

4.4 Results ........................ 70

4.4 .1 Overview ...................... 70

4.4 .2 Bear's Paw . . . . . . . . . . . . . 70

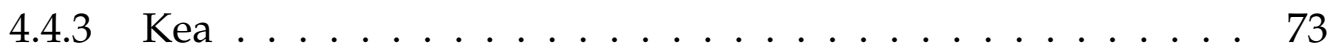

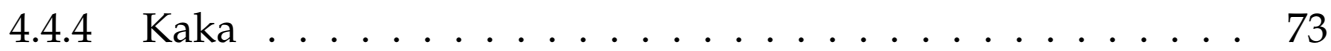

4.4 .5 Kakapo....................... 73

4.4 .6 Moa Reef . . . . . . . . . . . . . . . . . . . . . 74 
5 Parasound $\quad 75$

5.1 Acquisition . . . . . . . . . . . . . . . . . 75

5.2 Processing ......................... 76

5.3 Results ........................ 76

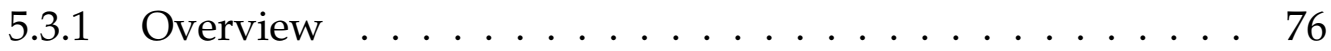

5.3 .2 Bear's Paw . . . . . . . . . . . . . . 79

5.3 .3 Kea ........................ 79

5.3 .4 Kaka ........................ 79

5.3 .5 Kakapo...................... . . 79

5.3 .6 Moa Reef . . . . . . . . . . . . . . . . . . . . . . . . 84

5.3.7 Blanked zone beneath Kea, Kaka and Kakapo .. . . . . . . 84

5.3.8 Zone of high-amplitude reflections beneath Kaka and Kakapo 84

6 Comparison of datasets $\quad 85$

6.1 Summary of results . . . . . . . . . . . . . . . . 85

6.1 .1 Bear's Paw . . . . . . . . . . . . . . . . 85

6.1 .2 Kea ...................... 87

6.1 .3 Kaka ......................... 91

6.1.4 Kakapo....................... 91

6.1 .5 Moa Reef . . . . . . . . . . . . . . . . . . . 92

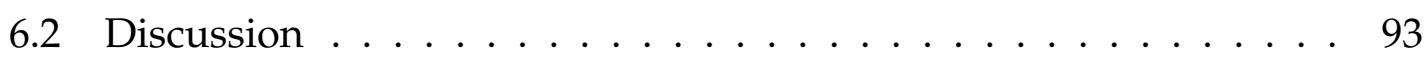

6.2.1 Bear's Paw . . . . . . . . . . . . . . . . 93

6.2.2 Kea, Kaka and Kakapo . . . . . . . . . . . . . . . . . . . . 95

6.2 .3 Moa Reef . . . . . . . . . . . . . . . . . 97

7 Conclusions $\quad 99$

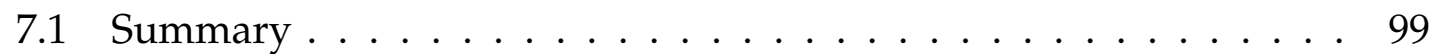

7.2 Distribution and nature of carbonates . . . . . . . . . . . . 100

7.3 Distribution of gas and migration pathways . . . . . . . . . . . . 100

7.4 Chronology of seepage . . . . . . . . . . . . . . . . . 102

7.5 Seepage initiation mechanisms . . . . . . . . . . . . . . . . 103

7.6 Proposed future research . . . . . . . . . . . . . . 103 


\section{List of Figures}

1.1 Omakere Ridge study area overview map with 3D seismic survey

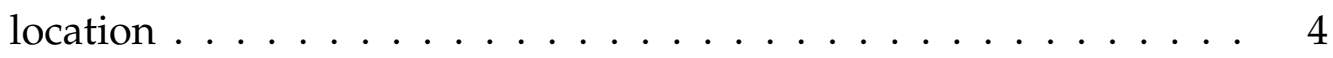

1.2 Omakere Ridge acoustic datasets . . . . . . . . . . . . . 5

2.1 Gas hydrate phase diagram . . . . . . . . . . . . . . . . 11

2.2 New Zealand seeps geological setting . . . . . . . . . . . . 21

2.3 Offshore Hawkes Bay . . . . . . . . . . . . . . . . . . . 26

2.4 Omakere Ridge study area overview map . . . . . . . . . . . 30

3.13 D seismic acquisition geometry $\ldots \ldots \ldots \ldots \ldots \ldots$

3.2 Seafloor raw seismic amplitude $(\max ) \ldots \ldots \ldots \ldots$

3.3 Raw seafloor reflection waveform . . . . . . . . . . . . . . 36

3.4 Acquisition footprint: crossline and inline wavelength spectra . . . 38

3.5 Unfiltered 2D spatial frequency spectrum . . . . . . . . . . . . 39

3.6 3D seismic shotpoints coloured by shooting direction . . . . . . . 41

3.7 Filtered 2D spatial frequency spectrum . . . . . . . . . . . . . 43

3.8 Sampling the remaining low-frequency noise in the seismic ampli-

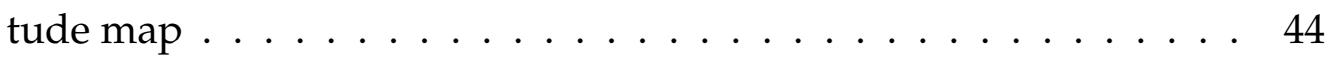

3.9 Filtering the seismic RMS amplitude map . . . . . . . . . . . . 46

3.10 Seafloor RMS reflection coefficient map . . . . . . . . . . . . 50

3.11 Reflection coefficient statistics at each seep site . . . . . . . . . 51

3.12 Seafloor reflection seismic similarity map. . . . . . . . . . . . . 52

3.13 Reflection coefficient map showing location of the key seismic inlines through the seep sites shown in Figures 3.14, 3.15 and 3.16. . . 54

3.14 Key seismic inline $1 \ldots \ldots \ldots$. . . . . . . . . . . . . . 55

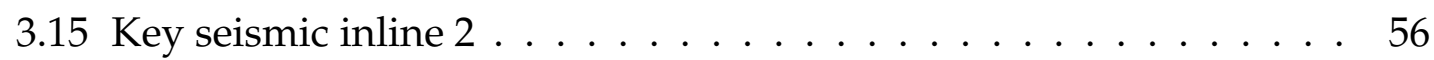

3.16 Key seismic inline $3 \ldots \ldots \ldots$. . . . . . . . . . . . . 57 
4.1 Multibeam sonar transect swath coverage . . . . . . . . . . . . 65

4.2 Raw backscatter mosaics demonstrating straight transect and ship turn transect . . . . . . . . . . . . . . . . . . 67

4.3 Backscatter mosaic stacking . . . . . . . . . . . . . . . . . 69

4.4 Backscatter with bathymetric contours . . . . . . . . . . . . . 71

4.5 Backscatter statistics at each seep site . . . . . . . . . . . 72

5.1 Parasound $^{\mathrm{TM}}$ line locations . . . . . . . . . . . . . . . . . . . . 77

5.2 Visualising Parasound ${ }^{\mathrm{TM}}$ and sonar backscatter with Fledermaus . 78

5.3 Key Parasound ${ }^{\mathrm{TM}}$ line locations . . . . . . . . . . . . . . . . . 80

5.4 Key Parasound $^{\mathrm{TM}}$ Lines 1 and $2 \ldots \ldots$. . . . . . . . . . . . . 81

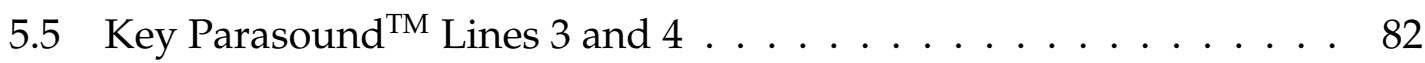

5.6 Key Parasound ${ }^{\mathrm{TM}}$ Line $5 \ldots \ldots \ldots$. . . . . . . . . . . . 83

6.1 Sonar backscatter and 3D seismics compared . . . . . . . . . . 88

6.2 Backscatter map with additional key information . . . . . . . . . . 89

6.3 Reflection coefficient map with additional key information . . . . . 90

6.4 3D perspective sonar backscatter/subsurface 3D seismics . . . . . . 94

7.1 Interpretation flow diagram . . . . . . . . . . . . . 101

7.2 Proposed drilling locations . . . . . . . . . . . . . . . . . 105 


\section{List of Tables}

6.1 Summary of results . . . . . . . . . . . . . . . 86 


\section{Chapter 1}

\section{Introduction}

\subsection{Motivation and objectives}

Seafloor methane seep sites occur globally on both passive and active tectonic margins in water depths ranging from tens of metres to abyssal depths. They can be related to conventional thermogenic hydrocarbon accumulations, microbiallygenerated gas, and gas hydrates, an unconventional hydrocarbon source (Judd and Hovland, 2007). Conventional thermogenic hydrocarbon accumulations constitute the majority of global energy production and gas hydrates could be developed in the future to contribute to global energy production (Boswell, 2009; Collett et al., 2009). This makes methane seep sites an important topic of research from a petroleum geoscience perspective.

On the Hikurangi Margin, New Zealand, many methane seep sites have been discovered over the last two decades (Lewis and Marshall, 1996; Bialas et al., 2007; Bialas, 2011) (Figure 1.1). These seep sites are related to a large gas hydrate province that stretches along the margin from $-42.5^{\circ} \mathrm{S}$ to $-38.5^{\circ} \mathrm{S}$ and across the margin from 500-600 m water depth eastward, terminating at the Hikurangi Trough (Pecher and Henrys, 2003; Barnes et al., 2010; Greinert et al., 2010) (Figure 1.1). A common occurrence at methane seep sites globally, including at Hikurangi Margin seeps, is the presence of authigenic carbonate rock structures on the seafloor and in the shallow subsurface (Campbell, 2006). These carbonates form as a direct result of methane seepage and are therefore a useful indicator of past and present seafloor methane seepage (Campbell, 2006). 


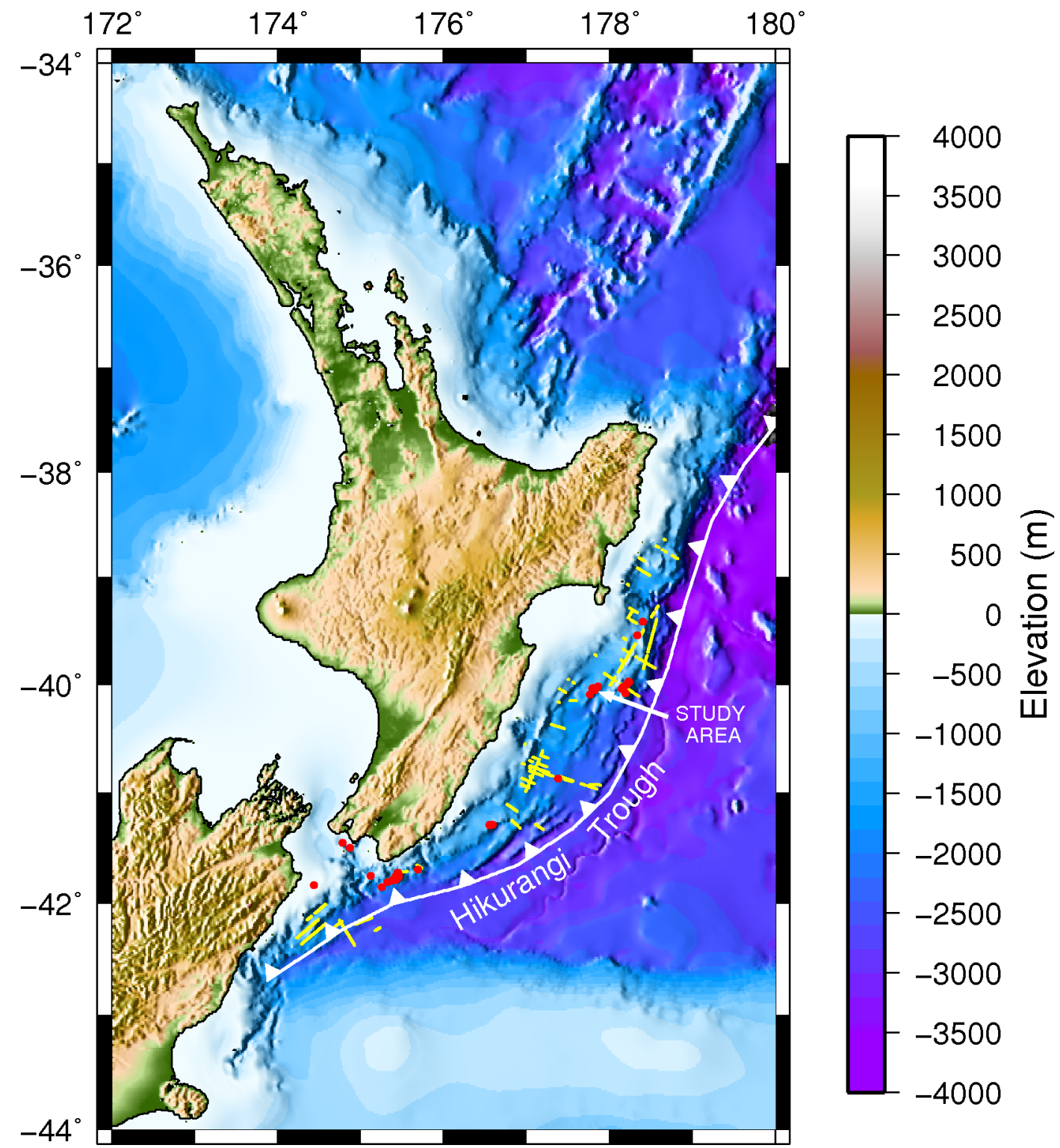

Recognising and characterising seafloor methane seep sites and better understanding how they are related to subsurface fluid migration pathways are important steps in determining the likely distributions of gas and gas hydrates in the subsurface (Roberts et al., 2006). This study investigates five methane seep sites on Omakere Ridge, Hikurangi Margin (for location see Figure 1.1), with the following goals:

- to determine the extent of authigenic carbonate build-ups at the seep sites; 
- to determine the distribution of gas in shallow sediments at the seep sites;

- to identify the shallow subsurface migration pathways of methane to the seep sites;

- to determine the relative ages of the seep sites;

- and to determine seep initiation mechanisms.

\subsection{Overview}

The data presented in this thesis were collected during the RV Sonne cruise SO214 in March 2011 (Bialas, 2011). The cruise was led by the German marine research institute IFM-GEOMAR and was a collaborative expedition, involving BGR (Germany), NIOZ (Netherlands) and GNS Science (New Zealand). A primary goal of this cruise was to image the subsurface migration pathways of methane to seafloor methane seep sites at several locations along the Hikurangi Margin, including those on Omakere Ridge offshore Hawkes Bay.

Three acoustic datasets of different source frequencies were collected simultaneously from Omakere Ridge. A high-resolution P-Cable ${ }^{\mathrm{TM}} 3 \mathrm{D}$ seismic reflection dataset was acquired with a source frequency of $60 \mathrm{~Hz}$; a Kongsberg EM120 ${ }^{\mathrm{TM}}$ multibeam sonar system was used to acquire bathymetry and backscatter data with a source frequency of $12 \mathrm{kHz}$; and a Parasound ${ }^{\mathrm{TM}}$ sub-bottom profiler dataset was collected with a source frequency of $4 \mathrm{kHz}$ (Bialas, 2011). Due to their different frequencies and source signal characteristics, each dataset was sensitive to seafloor and sub-seafloor features of different vertical and horizontal scales. Comparison of these three datasets should thus provide new insights into several aspects of the seep sites on Omakere Ridge, including the thicknesses and distribution of authigenic carbonates, relative ages of the seeps, and gas distribution and methane migration pathways to the seeps.

The SO-214 3D seismic survey covered a rectangular region approximately $6.25 \mathrm{~km}$ long and $1.625 \mathrm{~km}$ wide, oriented with the long axis in a NW-SE direction, perpendicular to the strike of the ridge (Figure 1.1). This rectangular area includes six separate seep sites: Kea, Kaka, Kakapo, Bear's Paw, Moa Reef and 


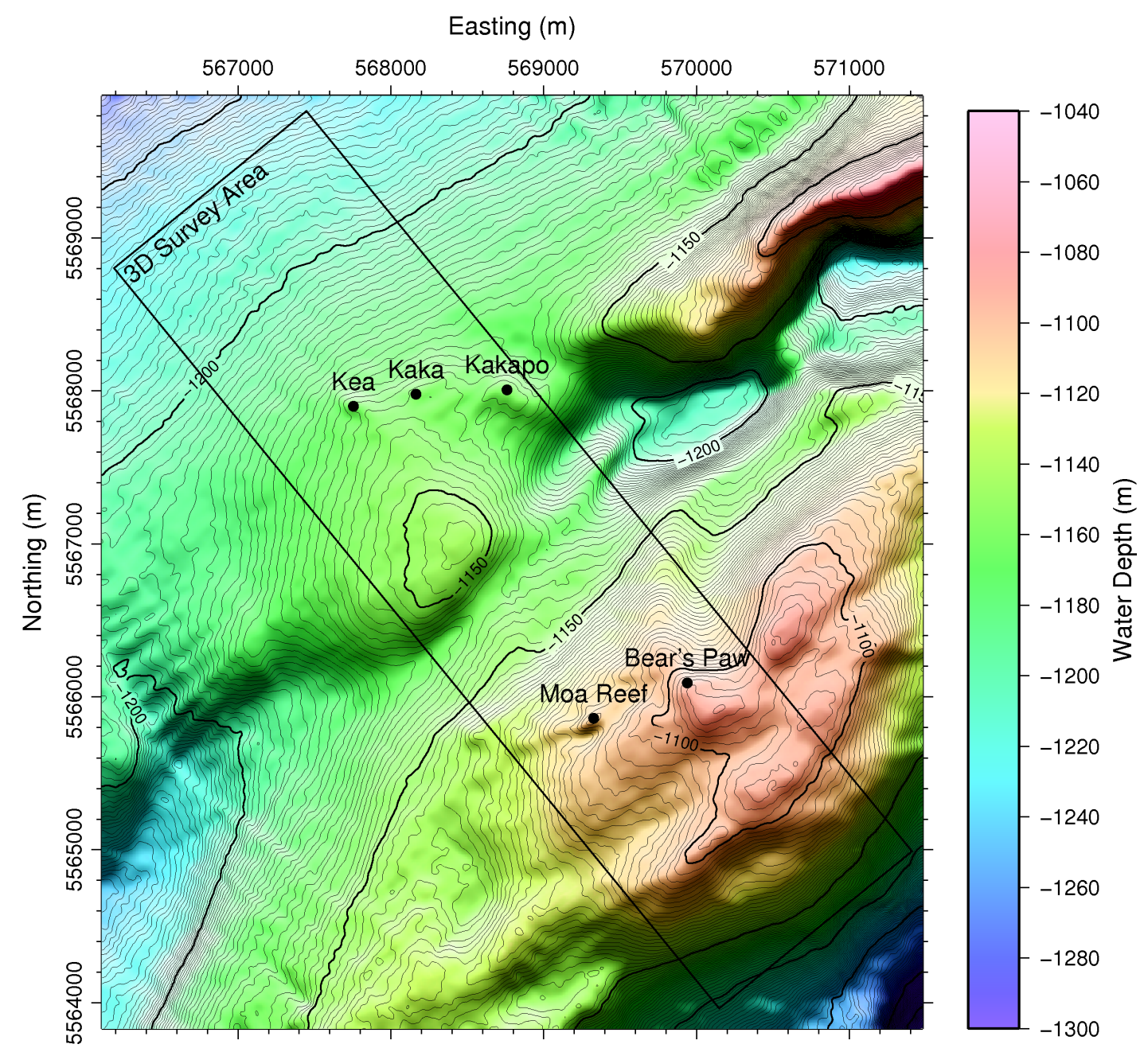

Figure 1.1: Omakere Ridge study area overview map showing seep site locations and 3D seismic survey area. The 3D seismic survey area defines the area of focus of this study. Minor contour interval is $2 \mathrm{~m}$. Refer to Figure 1.1 for the location of this study area in relation to New Zealand. 

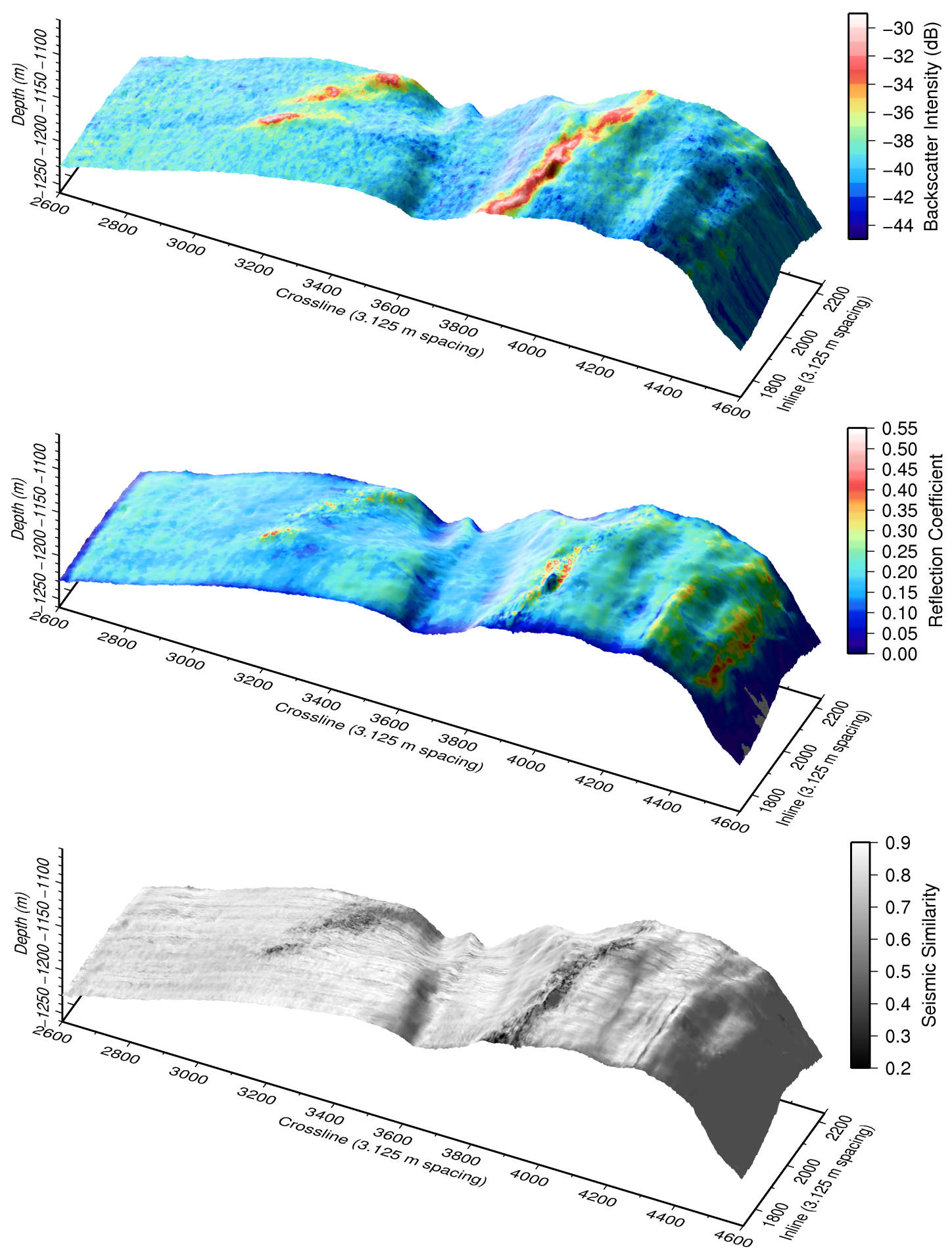

Figure 1.2: A summary of the sonar backscatter and 3D seismic results from the Omakere Ridge seafloor presented in this thesis: sonar backscatter intensity (top); seismic reflection coefficient (middle); and seismic similarity (bottom). These acoustic datasets are draped over 3D displays of the bathymetry of the 3D seismic study area shown in Figure 1.1, looking NNE. 
Moa Seep. These seep sites were first discovered by Bialas et al. (2007) during the RV Sonne cruise SO-191. As described above, the approach of this thesis is to compare sonar backscatter, 3D seismic reflectivity and shallow sub-seafloor Parasound ${ }^{\mathrm{TM}}$ reflection characteristics. Therefore the study area is defined by the $3 \mathrm{D}$ seismic survey region. For this reason, the sonar backscatter and Parasound ${ }^{\mathrm{TM}}$ reflection analyses have been restricted to the rectangular region covered by the 3D seismic survey. It should be noted that the southwestern extent of the Moa Seep is not covered by the 3D seismic survey and has therefore been excluded from analysis in this thesis. The seismic survey area lies in water depths ranging from 1060 to $1260 \mathrm{~m}$, with gently-sloping seafloor morphology dominated by two northeast-striking ridges separated by a trough, which marks the trace of an active thrust fault (Barnes et al., 2010). A prominent ridge-parallel normal fault scarp can be seen in the bathymetry on the higher, southwestern ridge. The seep sites appear as localised elevated regions (2-4 $\mathrm{m}$ ) in bathymetry data and cluster on the northwestern flanks of the two ridges in the study area (Figure 1.1). Figure 1.2 provides a preview of the results from the multibeam backscatter and 3D seismic datasets.

\subsection{Contribution of this thesis}

This thesis will contribute to a wider collection of research into gas hydrates and related phenomena in New Zealand. These studies have addressed topics such as: the distribution of gas hydrates on the Hikurangi Margin (e.g. Katz, 1981; Townend, 1997; Henrys et al., 2003; Pecher et al., 2011); the economic potential of Hikurangi Margin gas hydrates (e.g. Pecher and Henrys, 2003); how gas hydrates affect seafloor stability (e.g. Pecher et al., 2005); heat flow estimates based on gas hydrate occurrence (e.g. Townend, 1997; Henrys et al., 2003); methane seep site occurrences and their relation to large-scale geological processes (Barnes et al., 2010; Greinert et al., 2010; Jones et al., 2010); subsurface migration pathways to seep sites (e.g. Barnes et al., 2010; Crutchley et al., 2010; Netzeband et al., 2010); authigenic carbonate build-ups at modern and fossil seep sites and what information they hold about the history of seepage on the Hikurangi Margin (e.g. Campbell et al., 2010; Jones et al., 2010; Nyman et al., 2010); Hikurangi Margin seep fauna (e.g. Baco et al., 2010; Campbell et al., 2010; Jones et al., 2010); and methane concentrations in the 
water column above seep sites (e.g. Faure et al., 2010).

This thesis has been completed in conjunction with research being conducted by Andreia Plaza-Faverola at GNS Science. Plaza-Faverola's post-doctoral research will include reprocessing the Omakere Ridge 3D seismic dataset collected during SO-214 and conducting a thorough analysis and interpretation of the subsurface. A focus of Plaza-Faverola's research will be to understand how subsurface fluid migration is related to the seafloor methane seep sites at Omakere Ridge.

The findings of this thesis on the distribution of authigenic carbonates, gas distribution and migration pathways, relative ages of formation, and initiation mechanisms for the Omakere Ridge seep sites will provide new insights into the workings of the methane seep system at Omakere Ridge and contribute to many of the research topics listed above. The 3D seismic inlines presented in this thesis in Chapter 3 and Chapter 6 have undergone shipboard processing only. The interpretations drawn from them here should be considered preliminary and a more thorough investigation will follow.

\subsection{Thesis structure}

The context, motivation and goals of this thesis have been presented in this introduction. Chapter 2 provides important background information on the following topics: methane seep sites; the application of the geophysical techniques applied in this thesis to seep research; the geological setting of the Hikurangi Margin including gas hydrate and methane seep site occurrence; and Omakere Ridge and the seep sites investigated in this thesis. Chapters 3, 4 and 5 present the 3D seismic, sonar backscatter and Parasound ${ }^{\mathrm{TM}}$ data respectively, including descriptions of acquisition and processing, and the presentation of results from each dataset. Chapter 6 presents a summary of results from all three datasets for each seep site and discusses the geological implications of the results. Finally, Chapter 7 summarises the geological implications of this thesis in relation to the goals presented in this introduction and proposes future research at Omakere Ridge to further in- 
vestigate the history of methane seepage on the Hikurangi Margin. 


\section{Chapter 2}

\section{Background}

\subsection{Seafloor hydrocarbon seep sites}

\subsubsection{Overview}

Hydrocarbon seep sites have been observed globally in both active and passive tectonic settings and in both terrestrial and marine environments (Judd and Hovland, 2007). Since this thesis addresses hydrocarbon seepage in the marine environment only, this section discusses seafloor hydrocarbon seepage only. Seep hydrocarbons can be of either thermogenic or microbial origin and can range from high-order liquid hydrocarbons to methane gas (Judd and Hovland, 2007). Methane is the most common hydrocarbon in marine sediments and the most important fluid in seafloor fluid flow (Judd and Hovland, 2007). A link between gas hydrates and seafloor methane seepage has been observed in many locations (Roberts et al., 2006; Bialas et al., 2007; Judd and Hovland, 2007). Migration of buoyant hydrocarbons from reservoir to seafloor can be facilitated by both permeable faults and permeable strata (Barnes et al., 2010; Crutchley et al., 2010). Gas can also ascend through fine-grained low-permeability formations through the propagation of fractures and voids. This results in the vertical migration of gas and the formation of 'gas chimneys' (Judd and Hovland, 2007).

Hydrocarbon seepage at the seafloor results in a variety of seafloor features including authigenic carbonate build-ups of various morphologies, pockmarks and mud volcanoes with associated mudflows (Judd and Hovland, 2007). Diverse 
chemosynthetic faunal communities, often endemic, thrive on the seafloor and in the shallow subsurface at seafloor hydrocarbon seep sites (Judd and Hovland, 2007). The seafloor features and chemosynthetic communities that form at a particular seep site appear closely related to the fluid flux (Roberts et al., 2006; Campbell et al., 2010) and to the origin and nature of the fluids (Judd and Hovland, 2007).

The following sections summarise important phenomena related to seafloor hydrocarbon seepage, with a particular focus on gas migration, gas hydrates and authigenic carbonates, which are each particularly relevant to this thesis.

\subsubsection{Gas source and migration}

The hydrocarbon fluids expelled at seafloor seep sites can be the result of either thermogenic or biogenic degradation of organic matter buried in sediments (Judd and Hovland, 2007). Thermogenic hydrocarbons are generated and expelled from organic-rich source rocks buried to depths where the temperature is above approximately $60^{\circ} \mathrm{C}$ (Tissot and Welte, 1978). Biogenic methane is formed through the degradation of organic matter by microbes in shallower sediments (Whiticar et al., 1986). Hydrocarbons are buoyant with respect to pore water and therefore migrate upwards in the subsurface along whatever permeable conduits they can find, including faults, fracture networks and permeable strata (Judd and Hovland, 2007; Barnes et al., 2010; Crutchley et al., 2010; Plaza-Faverola et al., 2011). Where the upward migration of hydrocarbons is impeded by a permeability boundary, such as a low-permeability sealing lithology, hydrocarbon accumulations can form (Tissot and Welte, 1978). Seep fluids can also originate from the dissociation of gas hydrates (described in the next sections) (e.g. Greinert et al., 2001; Campbell et al., 2010).

\subsubsection{Gas hydrates}

Gas hydrates are naturally occurring solids that consist of a rigid lattice of hydrogenbonded water molecule cages, with each cage containing a molecule of natural gas, predominantly methane (Kvenvolden, 1993). Gas hydrates form under conditions of suitably high pressure and low temperature given an adequate supply of gas and water (Sloan, 1998) (Figure 2.1). They are common in marine sed- 
iments on continental margins, where the conditions required for hydrate formation are commonly present (Kvenvolden, 1993) and are widespread around the world (Kvenvolden et al., 1993). Gas hydrates typically form when the water depth exceeds 300-500 m. However, the exact minimum water depth for hydrate formation depends on the water temperature and salinity. Due to the geothermal gradient, increasing temperature overcomes the counteracting effect of increasing pressure on hydrate stability at a particular depth, below which gas hydrates cannot form (Sloan, 1998). As a result, gas hydrates are often underlain by gassaturated sediments (e.g. Bangs et al., 1993; Kvenvolden et al., 1993). The depth to the base of the gas hydrate stability zone is controlled by the water depth, water temperature, geothermal gradient, sediment density profile and salinity (Sloan, 1998).

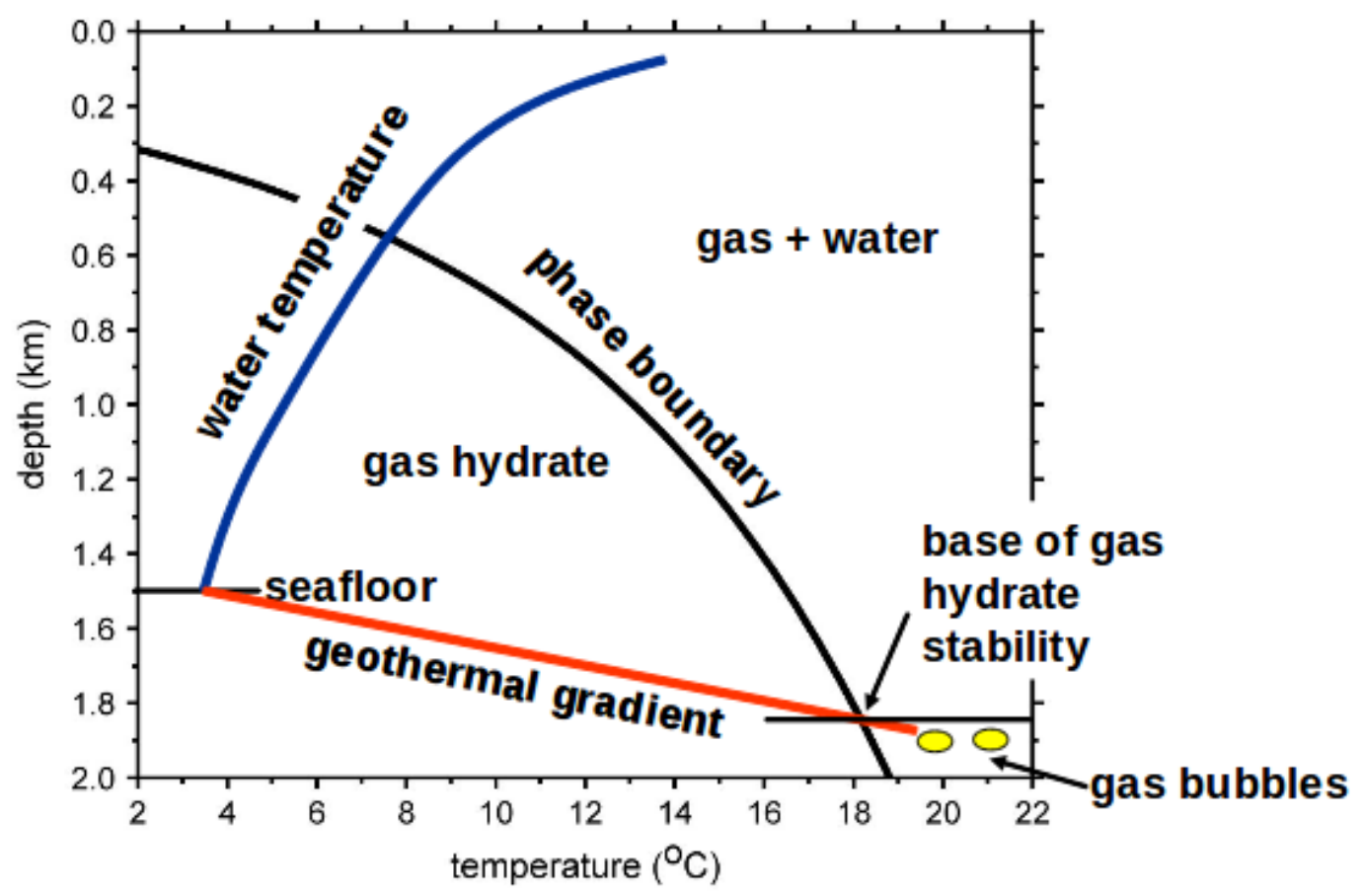

Figure 2.1: Gas hydrate phase diagram for a typical marine setting. The geothermal gradient determines how far beneath the seafloor the base of gas hydrate stability occurs. Free gas often exists below the base of gas hydrate stability. Phase boundary after Sloan (1998) and gas composition from Pecher et al. (2005), with arbitrary geothermal gradient of $40^{\circ} \mathrm{C} / \mathrm{km}$.

As a consequence of the pressure and temperature conditions required for gas 
hydrate formation, the base of gas hydrate stability roughly mimics the shape of the seafloor (Sloan, 1998). Because of the negative acoustic impedance contrast from high acoustic impedance hydrates above to free gas in the sediments below, the base of gas hydrate stability causes a distinctive negative-polarity reflection in seismic data that mimics the shape of the seafloor (Kvenvolden, 1993; Kvenvolden et al., 1993; Sloan, 1998). Such a reflection is known as a 'bottom simulating reflection' (BSR) and is considered a strong indicator for the presence of gas hydrates (e.g. Katz, 1981; Kvenvolden, 1993; Pecher and Henrys, 2003). Acoustic impedance and reflection polarity are explained in Section 2.2.

Methane seep sites in water depths deep enough to facilitate gas hydrate formation are often associated with gas hydrates in the shallow subsurface and occasionally on the seafloor (e.g. Greinert et al., 2001; Roberts et al., 2006; Bialas et al., 2007; Greinert et al., 2010; Bialas, 2011), as gas hydrate formation and seafloor fluid expulsion are related to the same fluid migration processes (Judd and Hovland, 2007). Gas hydrates are particularly abundant in the shallow subsurface and on the seafloor at sites where fluid-gas delivery to the seafloor is neither too low, nor too high. At such moderate-flux sites, chemosynthetic faunal communities are also particularly dense, suggesting that gas hydrates are an important trophic resource to these communities (Roberts et al., 2006).

\subsubsection{Seep carbonates}

Methane-derived authigenic carbonate (MDAC) is a common feature at methane seep sites globally, both in the fossil record and on the modern seafloor (Campbell, 2006). MDAC deposits of different mineralogies can occur on the seafloor and in the shallow subsurface as: slabs; crusts; lumps; breccias; cemented shell hashes; individual nodules or bands of nodules in sediment horizons; structures with large pore spaces that once contained gas hydrates; and chimney structures (e.g. Greinert et al., 2001; Campbell, 2006; Judd and Hovland, 2007; Campbell et al., 2010). These deposits can occur in various sizes and generally comprise normal seafloor sediment cemented with precipitated carbonate minerals, with a carbonate mass percentage anywhere between $0 \%$ and $100 \%$ (Campbell, 2006). 
MDAC can form at seep sites as a result of the anaerobic oxidation of methane (AOM) in the sulfate-reducing zone in the shallow subsurface, or as a result of methanogenisis in the methanogenic zone, which lies below the sulfate-reducing zone (Greinert et al., 2001; Campbell, 2006). The depth to the base of the sulfatereducing zone is typically on the scale of metres or tens of metres and can be displaced upwards by vertically migrating fluids (Mazzullo, 2000; Campbell, 2006; Paull and Ussler III, 2008). The precipitation of carbonate minerals through AOM is enabled by microbes, which utilise sulfates in the sulfate-reducing zone to anaerobically oxidise methane, producing bicarbonate:

$$
\mathrm{SO}_{4}^{2-}+\mathrm{CH}_{4} \rightarrow \mathrm{H}_{2} \mathrm{O}+\mathrm{HS}^{-}+\mathrm{HCO}_{3}^{-}
$$

The production of bicarbonate increases the pore water alkalinity, which favours the precipitation of authigenic carbonate by the following reaction:

$$
2 \mathrm{HCO}_{3}^{-}+\mathrm{Ca}^{2+} \rightarrow \mathrm{CaCO}_{3}+\mathrm{CO}_{2}+\mathrm{H}_{2} \mathrm{O}
$$

(Naehr et al., 2007).

The mineralogy and stable carbon and oxygen isotope compositions of authigenic carbonates depend on a number of factors, including temperature, degree of carbonate supersaturation, the concentration of calcium and magnesium and the concentration of sulfates (Naehr et al., 2007). Many of these factors are controlled by where the carbonate forms in relation to the sulfate-reducing and methanogenic zones (Greinert et al., 2001; Campbell, 2006; Bayon et al., 2009). Seep carbonates that form within the sulfate-reducing zone in the shallow subsurface tend to be primarily aragonite, with strongly-depleted ${ }^{13} \mathrm{C}$ owing to the anaerobic oxidation of isotopically-light biogenic or thermogenic methane (Greinert et al., 2001; Campbell, 2006). Closer to the bottom of the sulfate-reducing zone and in the methanogenic zone below, an increasing proportion of magnesium is incorporated into the carbonate over calcium, resulting in the formation of lowmagnesium and high-magnesium calcite near the base of the sulfate-reducing zone and high-magnesium calcite and dolomite in the methanogenic zone (Greinert et al., 2001; Bayon et al., 2009). Seep carbonates with higher magnesium concentrations tend to be more enriched in ${ }^{13} \mathrm{C}$ than the aragonitic carbonates, typical of 
methane produced in the methanogenic zone through methanogenisis (Greinert et al., 2001). The ${ }^{18} \mathrm{O}$ composition of seep carbonates can be used as an indicator for the source of the seep fluids (e.g. Greinert et al., 2001; Campbell et al., 2010).

A relationship between fluid flux and carbonate precipitation has been proposed from empirical evidence on the Gulf of Mexico: Roberts et al. (2006) observed larger build-ups of authigenic carbonate associated with slow methane seepage and only small nodular carbonate precipitations in the mudflows on the flanks of mud volcanoes, which are associated with rapid fluid expulsion. It has also been proposed by several studies that MDAC precipitation can reduce the methane flow to, or even seal-off previously-active seeps by clogging previouslypermeable pore space (e.g. Sager et al., 2003; Bayon et al., 2009). Both newly-active sites and sites with high methane flux at the present day seafloor might therefore be expected to be associated with less-extensive carbonate build-ups. Judd and Hovland (2007) proposed three stages of seepage related to the formation of MDAC deposits and seep sealing. In Stage 1, the seep is new and gas escapes into the water column through small vents in the seabed. In stage 2, microbial mats form in the shallow subsurface, below which gas accumulates in the sediments and occasionally seeps through holes in the mats. In Stage 3, MDAC structures form, where no seafloor gas bubbling is evident. In this stage, gas migrates to the lower part of the MDAC structures in the shallow subsurface, where carbonate cements continue to be formed. The sealing of the original seepage location by the build-up of microbial mats and carbonates in stages 2 and 3 has been hypothesised to cause the gas to migrate into the adjacent sediments (Judd and Hovland, 2007). The presence of extensive authigenic carbonate structures at seep sites is therefore indicative of long-term methane seepage.

Carbonates of various ages, mineralogies and stable carbon and oxygen isotope compositions often coexist on the seafloor at individual seepage sites, which points towards a complex history of carbonate precipitation, uplift and erosion (e.g. Campbell et al., 2010). For example, where dolomites are exposed on the seafloor, it is likely that these carbonates have been exhumed from depth, since the conditions necessary for their formation are only present deeper in the subsurface (Greinert et al., 2001; Campbell, 2006). Continual seepage in the same area during and after such exhumation can lead to later-stage aragonite structures form- 
ing very close to the seafloor in close association with the exposed dolomites (e.g. Campbell et al., 2010). The exact relationship between carbonates on the seafloor and their depth of formation is controlled by the history of sedimentation and erosion at seep locations (Paull and Ussler III, 2008).

\subsubsection{Other seep-related seafloor features}

\section{Pockmarks}

Pockmarks are shallow depressions on the seafloor that generally form in soft, fine-grained sediments. They occur in every sea and ocean and some lakes at all water depths (e.g. Davy, 1992; Hovland et al., 2005; Judd and Hovland, 2007). They are typically several tens of metres in diameter and several metres deep (Judd and Hovland, 2007), but can exist on a large range of scales, up to several kilometres in diameter (e.g. Davy et al., 2010). In some regions, pockmarks occupy a large proportion of the seafloor area, while in other regions only a few isolated pockmarks exist (Judd and Hovland, 2007). The truncation of reflections from sediment layers against pockmarks observed on seismic sections demonstrates that pockmarks are erosive features, related to the weakening of sediment layers by ascending gas or other fluids in areas where the seafloor is stable and not affected by largescale active erosion or deposition (Judd and Hovland, 2007). Gas pressure builds in a shallow porous layer below an impermeable sealing lithology. The build-up of pore pressure results in seafloor doming and eventually the yielding of seafloor sediments. The pressurised fluid erupts, ejecting gas, water and sediment into the water column and forming a depression in the seafloor (Judd and Hovland, 2007).

\section{Mud volcanoes}

Mud volcanoes are positive-relief features comprised of mud and other sediments, which vent liquid mud, including water, oil, gas and solid sediments (Judd and Hovland, 2007). They range in diameter from a few centimetres to over $1 \mathrm{~km}$, and can be tens or hundreds of metres high (Judd and Hovland, 2007). They occur in many parts of the world, in both terrestrial and marine environments, from shallow waters to continental slope depths (Milkov, 2000; Judd and Hovland, 2007). 
Mud volcanoes form in subsiding basins, in deltas and deep-water fans and in accretionary wedges, where rapid sedimentation is common (Judd and Hovland, 2007). Mud volcanoes are also commonly associated with some form of lateral tectonic compression (Milkov, 2000; Judd and Hovland, 2007). In thick sedimentary basins, low-permeability muddy sediments prevent the escape of fluids during compaction, leading to high pore fluid pressures and under-compaction of deep sediments (Milkov, 2000; Judd and Hovland, 2007). Density inversions can occur between under-compacted layers and overlying sediments, which can trigger buoyant diapiric flow of the under-compacted sediment, often along faults (Judd and Hovland, 2007). The presence of gas aids the diapiric flow of mud and can result in the formation of a mud volcano at the seafloor. The activity of mud volcanoes can range from continuous gentle emissions to discrete violent eruptions (Judd and Hovland, 2007).

\subsection{Geophysical imaging of seep sites}

\subsubsection{Overview}

Due to the presence of carbonate rock structures, gas, and gas hydrates in nearseafloor sediments, seafloor methane seep sites often cause geophysical anomalies. The particular characteristics of the geophysical response can be indicative of the amount of carbonate build up at the seep site, the fluid flux, and the likely distribution of gas hydrates at and below the seep (e.g. MacDonald et al., 2003; Roberts et al., 2006; Jones et al., 2010). The following sub-sections provide a summary of the applications of seafloor sonar backscatter, seafloor 3D seismic reflectivity, and subsurface acoustic reflection imaging to seep site imaging and characterisation. These three methods are each applied in this thesis, where the focus is on the seafloor and the shallow sub-surface (to $100 \mathrm{~m}$ below the seafloor).

\subsubsection{Sonar backscatter from the seafloor}

Sonar backscatter intensity from the seafloor is increased by both the roughness and acoustic impedance of the seafloor, and shallow subsurface heterogeneities (down to several centimetres depth) (Lurton, 2002). Acoustic impedance is equal to the product of seismic velocity and density. A detailed review of sonar backscat- 
ter theory and its application to seafloor imaging is presented in Chapter 4. Because the authigenic carbonate rock structures at seep sites are often irregular and rough in morphology, and have high acoustic impedances relative to the surrounding seafloor, seep sites are commonly characterised by high backscatter intensity in sonar data. In many locations, seafloor methane seep sites have been found to be characterised by regions of elevated sonar backscatter intensity, using both deep-towed sidescan sonars and hull-mounted multibeam sonar systems (e.g. Sager et al., 2003; Greinert et al., 2010; Jones et al., 2010).

\subsubsection{D seismic reflectivity of the seafloor}

3D seismic reflection amplitude of the seafloor is determined by the acoustic impedance of the seafloor and the source signal strength: a high acoustic impedance contrast results in a high-amplitude reflection (discussed in detail in Chapter 3). Carbonate rock structures on the seafloor and in the shallow subsurface (high acoustic impedance) and the presence of gas in the shallow subsurface (low acoustic impedance) can cause distinctive seismic amplitude responses at seep sites (e.g. Roberts et al., 2006).

Several studies of seep sites in the Gulf of Mexico that combined direct seafloor observations and sampling with seismic surveying found that methane seep sites often exhibit anomalous seismic reflectivity (MacDonald et al., 2003; Sager et al., 2003; Roberts et al., 2006). The particular characteristics of seafloor seismic reflectivity anomalies at seep sites are related to fluid flux, the distribution and nature of carbonates and the distribution of gas hydrates at and below the seep site (Roberts et al., 2006). For seeps in the Gulf of Mexico, the following relationships were established: 1) slow seepage was associated with extensive build-ups of authigenic carbonate, the presence of subsurface gas hydrates and broad areas of high seismic reflectivity; 2) moderate seepage was associated with dense chemosynthetic faunal communities, localised areas of authigenic carbonate structures, gas hydrates on the seafloor and in the shallow subsurface and highly variable seafloor reflectivity that is often fault-aligned and can exhibit phase reversals; and 3) rapid fluid expulsion was associated with mud volcanoes with nodular carbonates in the associated mudflows, gas hydrates in the subsurface of the volcano flanks and low seismic reflectivity in the expulsion centres with common 
phase reversals (Roberts et al., 2006). A phase reversal refers to when the seafloor reflection is of negative polarity rather than the normal positive polarity, which occurs when the acoustic impedance of the seafloor becomes lower than that of water. This can be caused by high gas concentrations (Roberts et al., 2006).

\subsubsection{Subsurface acoustic profiling}

Acoustic methods used to image the subsurface rely on the principle that downwardpropagating waves are reflected back towards the receiver when they encounter acoustic impedance contrasts (Sheriff and Geldart, 1995). At each acoustic impedance contrast, a portion of the seismic energy is reflected back to the receiver and a portion is transmitted deeper into the subsurface, where the process repeats at the next acoustic impedance contrast (Sheriff and Geldart, 1995). The portion of energy reflected depends on the acoustic impedance contrast. A high acoustic impedance contrast results in a large portion of the acoustic energy being reflected and only a small portion being transmitted (Sheriff and Geldart, 1995). This principle is true for all frequencies of subsurface acoustic reflection surveying, from high-frequency sub-bottom profilers $(4 \mathrm{kHz})$ to larger-scale multichannel seismic surveying (tens of hertz).

Gas, gas hydrates and authigenic carbonate in the subsurface beneath seep sites can cause anomalous acoustic reflection characteristics in the subsurface, as they each have an effect on the acoustic impedance of the host lithology (Sheriff and Geldart, 1995; Pecher et al., 2004; Crutchley et al., 2010). Sedimentary layers that have been segmented and offset by faults are also commonly detectable in subsurface acoustic datasets, where distinct reflection horizons have been segmented and offset (e.g. Barnes et al., 2010; Crutchley et al., 2010). Many studies worldwide have documented columnar zones of chaotic reflections in multichannel seismic data beneath seep sites, which are thought to be related to the vertical migration of gas to the seep sites from deeper in the subsurface (e.g. Sager et al., 2003; Pecher et al., 2004; Crutchley et al., 2010; Netzeband et al., 2010; Plaza-Faverola et al., 2011). Complex fault networks have been seismically detected beneath seep sites and are thought to play a crucial role in the migration of gas to seep sites (e.g. Barnes et al., 2010; Crutchley et al., 2010). In high-frequency sub-bottom profiler data (4 $\mathrm{kHz}$ ), seep sites are often underlain by zones of acoustic turbidity or blanking 
caused by the presence of gas in the sediments (e.g. Jones et al., 2010 Bialas, 2011).

\subsection{Geological setting}

\subsubsection{Structure of the Hikurangi Margin}

The Hikurangi subduction margin runs sub-parallel to the coastline of the eastern North Island of New Zealand from $37^{\circ} \mathrm{S}$ to $43^{\circ} \mathrm{S}$ (Figure 2.2). Here, the Australian and Pacific plates are undergoing oblique convergence at a rate of $40-45 \mathrm{~mm} / \mathrm{yr}$, which is accommodated by subduction of the Pacific plate and deformation of the overlying Australian plate (Barnes et al., 2010) (Figure 2.2). Subduction here is thought to have initiated in the early Miocene (Rait et al., 1993; Field and Uruski, 1997; Kamp and Furlong, 2006). The igneous Hikurangi Plateau is currently being subducted at the Hikurangi Trough, which has resulted in the formation of a shallow trench and a gently-dipping subduction thrust interface, with a dip of $3^{\circ}$ to at least 100 km depth (Davey et al., 1986; Wood and Davy, 1994; Barker et al., 2009). An imbricated frontal wedge is built against a backstop of Mesozoic greywacke basement to the west (Lewis and Pettinga, 1993). The frontal wedge extends offshore from the onshore coastal ranges and is up to $150 \mathrm{~km}$ in width, with a ridge and basin morphology in the offshore margin (Davey et al., 1986; Lewis and Pettinga, 1993; Barnes et al., 2010). Lewis and Pettinga (1993) proposed the wedge is comprised of the following three distinct components, all of which are undergoing deformation:

- an inner foundation of highly-imbricated late Cretaceous and Paleogene pre-subduction rocks;

- an outer wedge of late Cenozoic accreted trench-fill turbidites;

- a deforming cover sequence of Miocene to Recent shelf and slope basin sediments;

The pre-subduction inner foundation of late Cretaceous and Paleogene rocks are thought to have become highly imbricated after the initiation of subduction along the Hikurangi Margin $25 \mathrm{Ma}$ (Barnes et al., 2010). The accreted outer wedge of Cenozoic trench-fill turbidites has been overthrust from the west by the front of 
the inner foundation rocks. The deforming cover sequence can reach up to several kilometres in thickness in the slope basins of the upper margin and generally thins seaward (Barnes et al., 2010).

\subsubsection{Gas hydrates and hydrocarbon seepage}

BSRs have been observed in seismic sections from slope depths along the entire Hikurangi Margin, indicating widespread occurrence of gas hydrates in offshore marine slope sediments (e.g. Katz, 1981; Townend, 1997; Henrys et al., 2003; Pecher et al., 2004; Barnes et al., 2010) (Figure 2.2). The presence of gas hydrates on the Hikurangi Margin has been confirmed by the recovery of gas hydrates in sediment cores (Bialas et al., 2007; Greinert et al., 2010). A recent study estimated the Hikurangi Margin gas hydrate resource to be equivalent to around 800 trillion cubic feet (tcf) of natural gas, sparking interest in developing Hikurangi Margin gas hydrates as a natural resource (Pecher and Henrys, 2003). Of this total volume, 20 tcf is likely to be contained in highly concentrated zones of gas hydrate, termed gas hydrate 'sweet spots' (Pecher and Henrys, 2003).

Offshore methane seep sites occur in mid-slope depths of 700-1900 m on the crests of thrust-faulted anticlinal ridges and are widespread along the Hikurangi Margin, having been recognised in clusters at six separate areas along the margin (Figure 2.2) (Lewis and Marshall, 1996; Bialas et al., 2007; Bialas, 2011). These six locations of seepage, from north to south, are known as Builder's Pencil, Rock Garden, Omakere Ridge, Porangahau Ridge, Uruti Ridge and Opouawe Bank (sometimes referred to as Wairarapa) (Bialas et al., 2007 Bialas, 2011) and are shown in Figure 2.2. Beneath these seep areas, the BSR is commonly disturbed by the upward migration of fluids (e.g. Barnes et al., 2010; Pecher et al., 2010). Fossilised seep carbonates have been discovered in the onshore East Coast Basin, with the earliest sites dating back to the early Miocene (Campbell et al., 2008), and other sites dating from the late Miocene (Nyman et al., 2010), indicating that the methane seep system has been active since the initiation of subduction along the Hikurangi Margin.

The source rocks responsible for the fluids expelled at the seep sites and sequestered in gas hydrates could include the Cretaceous and Paleogene sequences, 


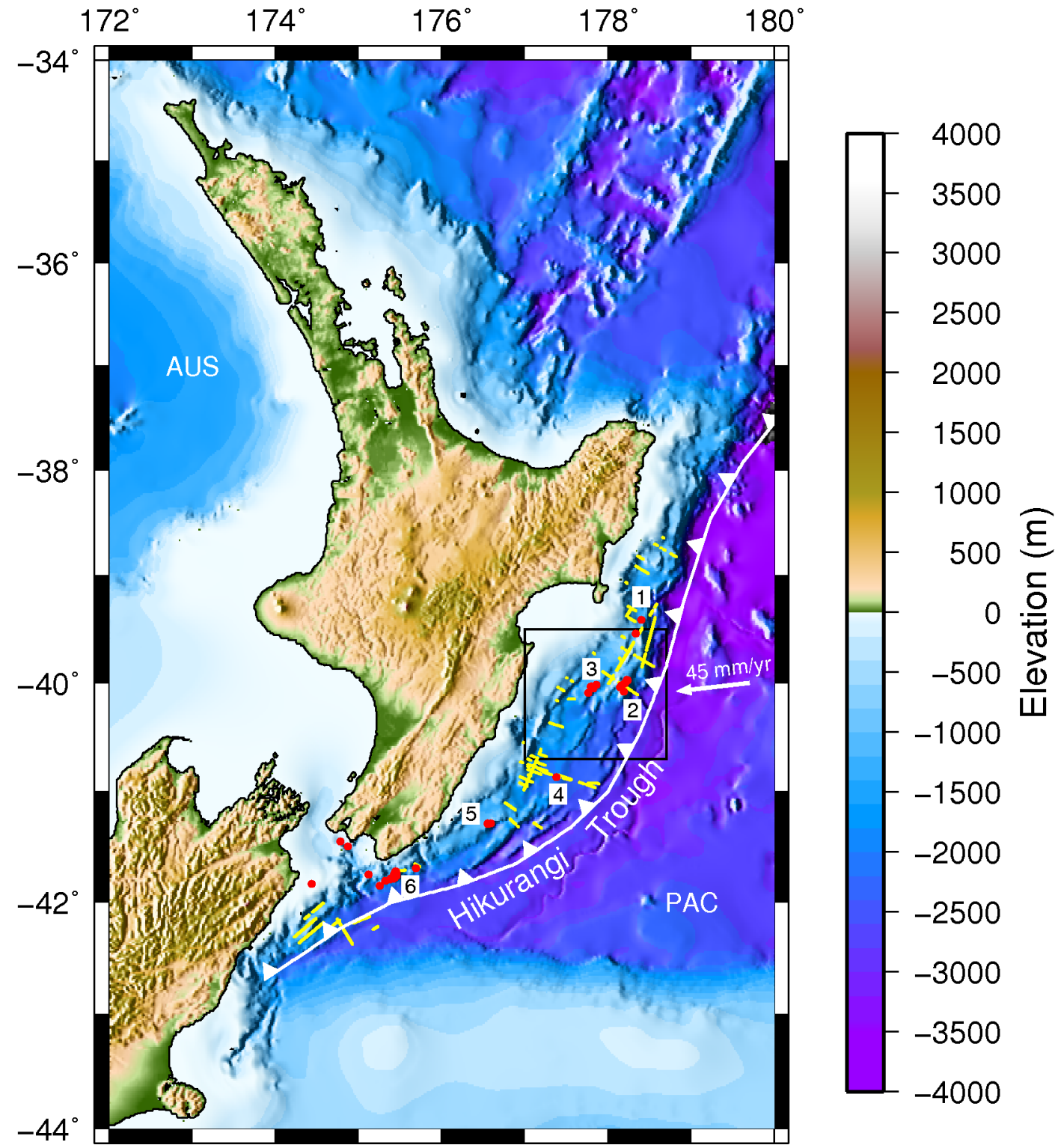

Figure 2.2: North Island New Zealand bathymetry and geological setting. Shown are the locations of all known seep sites offshore (red dots), Pacific Plate (PAC) motion vector relative to Australian Plate (AUS) and the Hikurangi Trough and deformation front. Seepage locations are numbered as follows: 1) Builder's Pencil; 2) Rock Garden; 3) Omakere Ridge; 4) Porangahau Ridge; 5) Uruti Ridge; and 6) Opouawe Bank (Wairarapa). The area enclosed by the rectangle is offshore Hawkes Bay and includes Omakere Ridge. For a detailed map of this location, see Figure 2.3. The yellow lines show the extent of all BSRs mapped on seismic data (from Pecher et al., 2011), indicating the known extent of the Hikurangi Margin gas hydrate province. 
the innermost part of the accreted trench-fill turbidites and sediments subducted beneath the inner foundation rocks and Mesozoic greywacke backstop (Barnes et al., 2010). Carbon isotope compositions of methane expelled at the seep sites have generally been consistent with a biogenic origin, but a thermogenic origin could not be discounted in all cases (Faure et al., 2010).

The seep sites are located in close proximity to major thrust faults near the eastward edge of the inner foundation rocks (Barnes et al., 2010). The low-permeability imbricated inner foundation rocks appear to focus fluid flow along their outer edge along major thrust faults and the interplate decollement (Barnes et al., 2010). However, no seep sites have been identified where major thrust faults break-out at the seafloor on the eastern flanks of the ridges. Rather, the seep fluids are syphoned from the main thrust faults upwards into shallow extensional fault networks beneath the crests of the thrust-faulted anticlines, which feed the seep sites (Barnes et al., 2010; Crutchley et al., 2010). These shallow fault networks appear to be more permeable than the main thrust faults in the upper few hundred metres of sediment.

\subsubsection{Seep carbonates}

Seep-related authigenic carbonates have been discovered at many of the seep sites along the Hikurangi Margin, including seep sites at Rock Garden, Omakere Ridge, Opouawe Bank, Uruti Ridge and Builder's Pencil (Baco et al., 2010; Campbell et al., 2010; Greinert et al., 2010; Jones et al., 2010). In fact, many of the seep sites were discovered in part as a result of high-backscatter anomalies in sonar data caused by the presence of authigenic carbonates on the seafloor (Greinert et al., 2010; Jones et al., 2010). This thesis is the first study to investigate the subsurface extent and distribution of authigenic carbonates at seep sites on the Hikurangi Margin.

Carbonates of various mineralogies and stable carbon and oxygen isotope compositions were recovered from the seafloor at many seep sites at Rock Garden, Omakere Ridge, Opouawe Bank and Uruti Ridge by Campbell et al. (2010), who collected both sediment box cores and carbonate grab samples from the seafloor. The mineralogy of the recovered carbonates ranges from aragonite, 
through low- and high-magnesium calcite, to dolomite, with carbonates of all mineralogies coexisting on the modern seafloor (Campbell et al., 2010). The physical nature of the carbonates is also highly varied, including shell content, size, siliciclastic component and morphology (Campbell et al., 2010). In box cores, Campbell et al. (2010) observed microcrystalline carbonate (micarb) cements in siliciclastic silts and sands, with micarb development ranging from scattered nodules to dense, coalesced nodular bands up to $15 \mathrm{~cm}$ thick. Seafloor grab samples included both fresh and weathered samples (Campbell et al., 2010). Fresh samples included: sandy micarbs with abundant attached or embedded shells; tubular micarbs that represent fluid conduits; porous, fibrous layers cementing dead fauna; and breccias of grey micarb intraclasts cemented with white fibrous carbonate cement (Campbell et al., 2010). The weathered grab samples were micarb slabs and blocks with an outer rind of dark reddish to brown iron and manganese staining (Campbell et al., 2010). The box core samples and fresh carbonate grab samples were found to be predominantly aragonite, with minor amounts of highmagnesium calcite in the nodular carbonates in the box cores, whereas the weathered carbonate slabs and blocks were found to be composed of microcrystalline dolomite (Campbell et al., 2010).

Stable carbon isotope compositions indicated that the aragonite samples formed through AOM in the sulfate-reducing zone, whereas the weathered dolomite samples formed from an oxidised methane pool at greater depth, possibly near the base of the sulfate-reducing zone (Campbell et al., 2010). Stable oxygen isotope compositions of seep carbonates on the Hikurangi Margin indicated a range of possible influences on the seep fluids, including gas hydrate formation and dissociation and pore fluid freshening by clay mineral dehydration (Campbell et al., 2010).

\subsubsection{Seep fauna}

The composition of seep fauna along the Hikurangi Margin at higher taxanomic levels is typical of cold seep communities in other parts of the world (Baco et al., 2010). The most commonly-observed symbiont-bearing taxa at Hikurangi Margin seeps include siboglinid tube worms, vesicomyid clams and bathymodiolin 
mussels (Lewis and Marshall, 1996; Baco et al., 2010). These taxa rely on symbiotic relationships with the microbes that perform chemosynthesis on the seep fluids (i.e. those responsible for AOM as discussed above) (Baco et al., 2010). Siboglinid tube worms are predominantly of the Lamellibrachia species, while the clams belong to the Calyptogena species (Lewis and Marshall, 1996; Baco et al., 2010). Non-symbiont-bearing taxa encountered at seep sites include various species of cold-water corals, which appear to colonise seafloor outcrops of authigenic carbonate after seepage has ceased (Baco et al., 2010; Jones et al., 2010; Liebetrau et al., 2010). Campbell et al. (2010) observed recurring associations between different seep fauna and authigenic carbonate type. Calyptogena species clam shells, which are considered to be indicative of diffuse seepage, were often incorporated into aragonitic carbonate bands (Campbell et al., 2010). Closer to active vent areas, fresh aragonitic grab samples were associated with bathymodiolin mussels and tube worms, characteristic of higher fluid fluxes (Campbell et al., 2010). The weathered dolomite slabs and blocks discussed above were often associated with cold-water corals (Campbell et al., 2010).

\subsection{Omakere Ridge}

\subsubsection{Previous studies}

Omakere Ridge is an anticlinal thrust ridge of approximately $500 \mathrm{~m}$ bathymetric relief on the Hikurangi Margin, offshore Hawkes Bay, in water approximately $1100 \mathrm{~m}$ deep and is one of the six locations on the Hikurangi Margin, mentioned above, where seafloor methane seepage has been observed (Bialas et al., 2007; Greinert et al., 2010). The main active Omakere Ridge thrust fault breaks-out at the seafloor at the toe of the steep eastern flank. A second active thrust fault branches upwards to the west of the main thrust through the crest of the ridge, where it forms a scarp of up to $100 \mathrm{~m}$ relief (Barnes et al., 2010). Deeper, inactive thrust faults lie below the main Omakere Ridge thrust fault, the tips of which are buried in sediments to the east of Omakere Ridge (Barnes et al., 2010). The ridge is thought to be comprised of 700-800 m of Miocene to Recent slope sediments that have been folded in the hanging wall of the major thrust faults, which overlie the Cretaceous and Paleogene inner foundation rocks (Barnes et al., 2010). Omakere Ridge is located one ridge to the west of the interface between the inner founda- 
tion rocks and the outer wedge of accreted late Cenozoic turbidites (Barnes et al., 2010).

Prior to the RV Sonne cruise SO-214, six methane seep sites on Omakere Ridge had been described by Lewis and Marshall (1996) and Jones et al. (2010): these seep sites are known as LM-9, Kea, Kaka, Kakapo, Moa and Bears Paw (Figure 2.4). Seep-related observations at these sites include hydroacoustic flares in the water column (Bialas et al., 2007; Jones et al., 2010); underwater video observations of dense chemosynthetic faunal communities and authigenic carbonate rock structures (Jones et al., 2010); the recovery of authigenic carbonates of various mineralogies in sediment box cores (Campbell et al., 2010); the recovery of gas hydrate in sediment cores (Bialas et al., 2007); the presence of a BSR in multichannel seismic data beneath Omakere Ridge (Greinert et al., 2010); gas-related acoustic turbidity and blanking in Parasound ${ }^{\mathrm{TM}}$ sub-bottom profiler (SBP) data beneath the seep sites (Jones et al., 2010); and high backscatter features in sidescan and multibeam sonar data (Greinert et al., 2010; Jones et al., 2010). A series of CTD (ConductivityTemperature-Depth) casts were analysed by Faure et al. (2010) to determine seawater methane concentrations above each of the seeps at Omakere Ridge, and showed elevated methane concentrations over the whole area, with the highest concentrations occurring at Bear's Paw.

The seeps appear as elevated features, generally of $2-4 \mathrm{~m}$ bathymetric relief in multibeam swath bathymetry and are all characterised by regions of high backscatter intensity on both sidescan and multibeam sonar compared to the surrounding seafloor (Greinert et al., 2010; Jones et al., 2010). Seep sites with higher population densities of live chemosynthetic organisms have been inferred to be the locations where present-day seepage is the greatest (Jones et al., 2010). Locations where significant seafloor carbonate structures exist with evidence of previouslyliving populations of chemosynthetic fauna are considered to be extinct seep sites (Jones et al., 2010). Previous research has suggested that the seep sites might be migrating eastward due to the continual eastward migration of the deformation front, based on the abundance of chemosynthetic faunal communities at the seeps (Jones et al., 2010). Summaries of previous findings at each Omakere Ridge seep site examined in this study are presented in the following sections. 


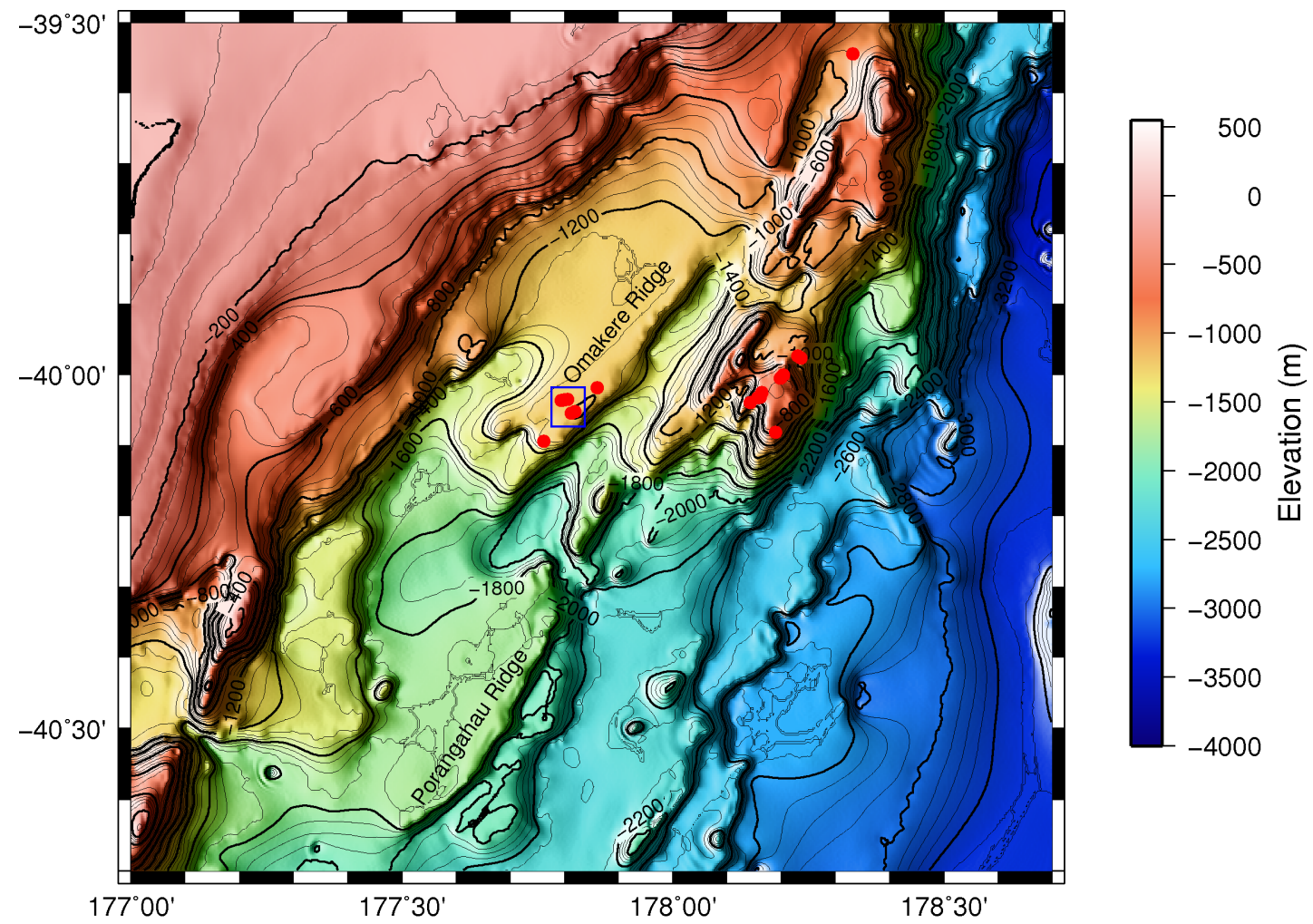

Figure 2.3: Detailed bathymetric map of offshore Hawkes Bay (for location see Figure 2.2), showing the location of Omakere Ridge and the study area for this thesis (the small blue rectangle). A detailed map of the study area is provided in Figure 2.4. 


\section{Bear's Paw}

Bear's Paw appears as a moderate sidescan sonar backscatter feature without acoustic shadows, indicating low bathymetric relief. Acoustic turbidity has been observed in SBP data to the northeast of the Bear's Paw site (Jones et al., 2010). Underwater video observation has shown that the authigenic carbonate at Bear's Paw is of moderate bathymetric relief and is interspersed with areas of sulphidic sediments and extremely high abundances of chemosynthetic fauna (Jones et al., 2010). Based on the abundance of live chemosynthetic fauna, and higher methane concentrations in the overlying water column than at any of the other sites, Bear's Paw was identified as the most active of the Omakere Ridge seep sites (Faure et al., 2010; Jones et al., 2010). Gas hydrates were recovered in a shallow sediment core from Bear's Paw in 2007 (Bialas et al., 2007). The gas hydrates were found in three separate sub-horizontal layers, one of which was $1 \mathrm{~cm}$-thick, approximately $1 \mathrm{~m}$ below the seafloor (Bialas et al., 2007).

\section{Kea}

Kea appears as a region of scattered patches of high sidescan sonar backscatter, with well-developed acoustic shadows, elongate in a WNW-ESE orientation (Jones et al., 2010). The patches of high backscatter are interspersed with areas of lower backscatter at background levels. Underwater video observations have revealed scattered carbonate coverage at Kea, with carbonate outcrops of predominantly low relief, including boulders and cobbles (Jones et al., 2010). The western end of Kea exhibited the most abundant seep fauna and extensive areas of exposed carbonate structures out of Kea, Kaka and Kakapo. Shell valves of Calyptogena species clams and patches of sulphidic sediment were present at Kea and were in high abundance at the western end of the seep (Jones et al., 2010). The carbonate structures at the western end of Kea were found to be inhabited by Bathymodiolus species mussels, Calyptogena species clams, and hexactiellid sponges. Lamellibrachia species tube worms were also present across the Kea site. Based on the abundance of live chemosynthetic fauna, Kea was determined to be the second most active seep site on Omakere Ridge, after Bear's Paw (Jones et al., 2010). 


\section{Kaka}

Like Kea, Kaka appears as a region of scattered patches of high sidescan sonar backscatter interspersed with areas of lower backscatter, with well-developed acoustic shadows, elongate in a WNW-ESE orientation. As observed at Kea, video observations have shown scattered carbonate coverage at Kaka, with carbonate outcrops of predominantly low relief and areas of boulders and cobbles. Shell valves of Calyptogena species clams and patches of sulphidic sediment were present at low abundance at Kaka. Lamellibrachia species tube worms were also present across the Kea site. Based on the abundance of live chemosynthetic fauna, Kaka was determined to be the fourth most active seep on Omakere Ridge, after Bear's Paw, Kea and the Moa Seep (Jones et al., 2010).

\section{Kakapo}

Kakapo, too, is elongate in a WNW-ESE orientation. It is characterised by moderate sidescan sonar backscatter without acoustic shadows. However, (Jones et al., 2010) noted that Kakapo was directly below the path of the sidescan towfish, adding uncertainty to the sidescan backscatter data. Chirp SBP data showed an irregular zone of increased signal intensity directly below the Kakapo seep. This was interpreted by Jones et al. (2010) to be acoustic turbidity caused by gas bubbles in the shallow sediments reflecting acoustic energy. The acoustic turbidity intersects the seafloor directly beneath the Kakapo seep and is thought to represent the migration pathway of methane to the seep site (Jones et al., 2010). Underwater video observations revealed a very similar story to that at Kaka. Kakapo is characterised by: scattered carbonate coverage with predominantly low-relief outcrops, boulders and cobbles; Calyptogena species clam shell valves; a low abundance of sulphidic sediment patches; and Lamellibrachia species tube worms. Based on the abundance of live chemosynthetic fauna, Kakapo was determined to be the fifth most active seep on Omakere Ridge, after Bear's Paw, Kea, Moa Seep and Kaka (Jones et al., 2010). 
Moa

Moa is characterised by two distinctly different sections. The northwestern section is a high-bathymetric-relief cold-water coral reef where seep activity appears to have ceased, while the southwestern section is a low-relief feature densely populated by live chemosynthetic fauna and is a location of active methane seepage (Jones et al., 2010). These two distinct sections are referred to as 'Moa Reef' and 'Moa Seep' respectively. Widespread vesicomyid clam shells at the Moa Reef show that seep activity has occurred here in the past (Jones et al., 2010).

Moa Reef is characterised by very high backscatter in the sidescan sonar data with well-developed acoustic shadows, which are indicative of high bathymetric relief. Underwater video observations have revealed that the Moa Reef is characterised by steep, high-relief authigenic carbonate colonised in many places by cold-water corals, but no live chemosynthetic fauna. Based on the absence of live chemosynthetic fauna, the Moa Reef was determined to be an extinct seep site (Jones et al., 2010).

Moa Seep is characterised by high sidescan sonar backscatter, but in contrast to Moa Reef shows no pronounced evidence of shadowing. Video observations have revealed that the authigenic carbonate at the Moa Seep is populated with live chemosynthetic fauna, which is also a contrast to the authigenic carbonate at Moa Reef, which was found devoid of live chemosynthetic fauna. Based on the abundance of live chemosynthetic fauna, Moa Seep was determined to be the third most active seep on Omakere Ridge, after Bear's Paw and Kea (Jones et al., 2010). 


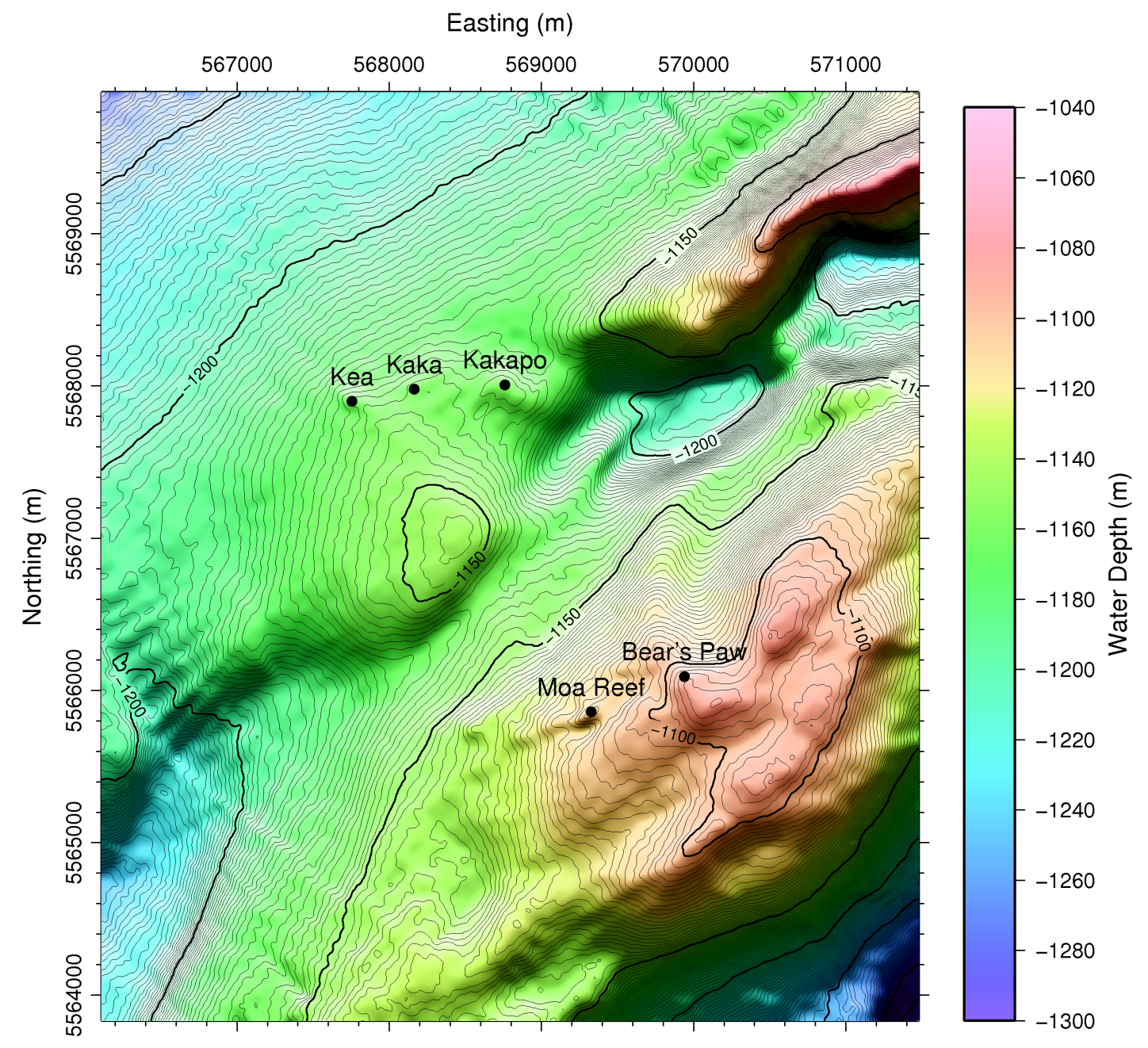

Figure 2.4: Omakere Ridge study area overview bathymetric map showing seep site locations. Refer to Figure 2.2 for the location of this study area in relation to New Zealand. 


\section{Chapter 3}

\section{D Seismic Dataset}

\subsection{Acquisition and processing}

High-resolution 3D seismic data were acquired by the RV Sonne during cruise SO-214 with a 128-channel 3D P-Cable ${ }^{\mathrm{TM}}$ system, consisting of 16 streamers towed in parallel, with eight channels per streamer at a channel spacing of $1 \mathrm{~m}$. Each streamer was connected to a data cable that was extended orthogonally to the ship's travel direction by two trawl doors, one at either end of this cross-cable. Outer-array streamers were separated by $15 \mathrm{~m}$ of cross-cable, while inner-array streamers were separated by $10 \mathrm{~m}$ of cross-cable. In plan view, the cross-cable formed a roughly parabolic shape when towed behind the ship, resulting in middlearray streamers being towed further behind the ship than the outer array streamers and an effective streamer spacing less than the length of cross-cable separating the streamers from one another. The greater cross-cable spacing of the outer-array streamers compensated for the parabolic spread of the cross-cable, resulting in more uniform effective streamer spacings (Bialas, 2011). A diagram of the acquisition system and geometry is provided in Figure 3.1.

A single GI-airgun (generator-injector) source was used, which had a volume of 4.21 and was operated at a constant pressure of 210 bar in harmonic mode, resulting in a dominant source frequency of $60 \mathrm{~Hz}$. The GI-gun was towed $20 \mathrm{~m}$ behind the ship at a depth of $2 \mathrm{~m}$, with a shot interval of six seconds. The data were recorded with a sampling interval of $0.25 \mathrm{~ms}$ (Bialas, 2011). 


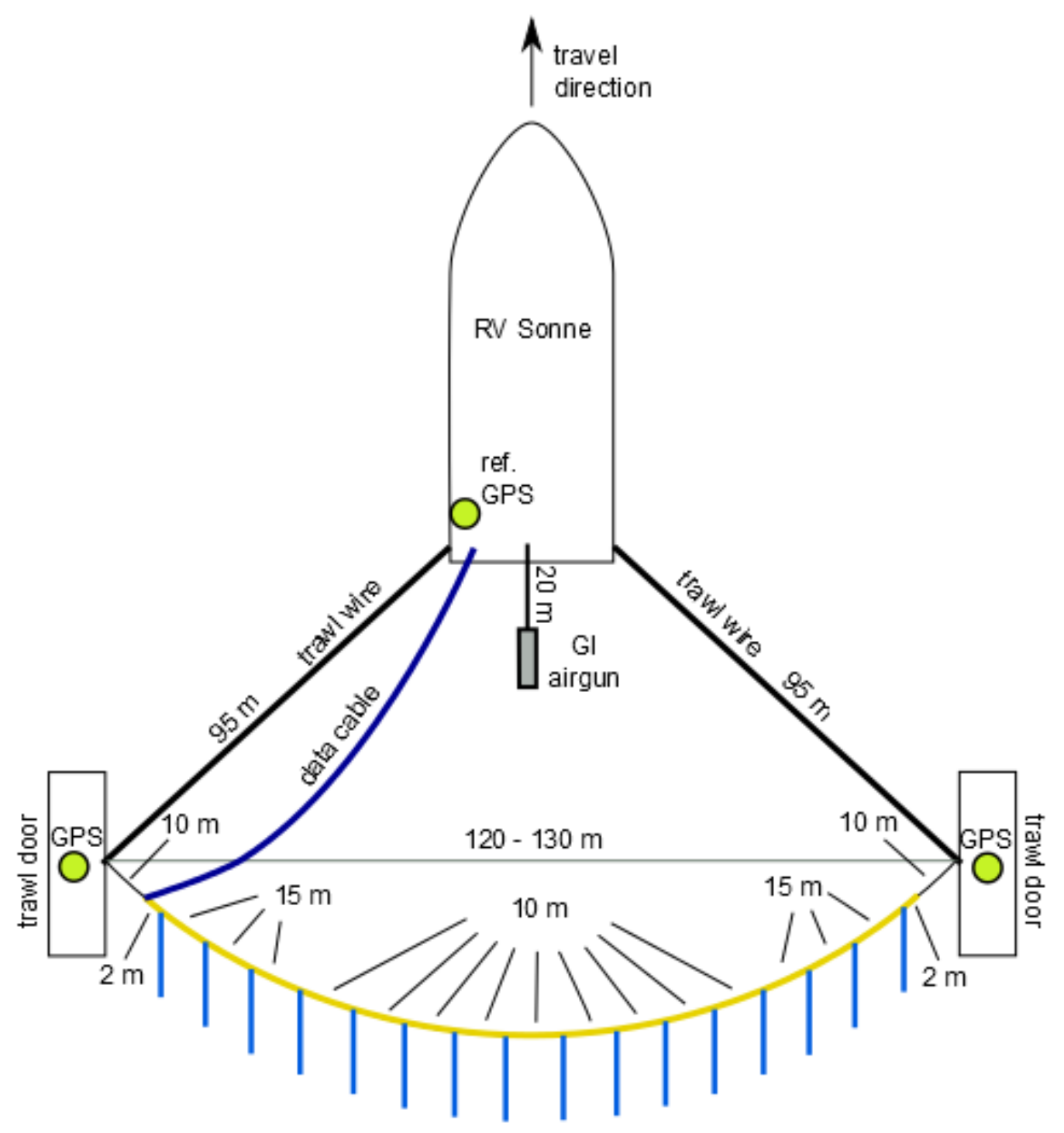

Figure 3.1: Schematic diagram of P-Cable ${ }^{\mathrm{TM}}$ 3D seismic acquisition system used during SO-214. Each of the 16 streamers (light blue) is connected to the crosscable (yellow). The middle-array streamers were separated by $10 \mathrm{~m}$ of crosscable, while outer-array streamers were separated by $15 \mathrm{~m}$ of cross-cable. This compensated for the parabolic curve of the cross-cable, resulting in more uniform streamer spacing during acquisition. The travel direction defines the inline direction. After Bialas (2011). 
The survey was completed over seven days and involved racetrack-style shooting over a rectangular area with $6.25 \mathrm{~km}$-long inlines and $1.625 \mathrm{~km}$-wide crosslines (see Figure 3.6 later in text). For the first three days of surveying, only the first seven streamers recorded any data due to technical problems with the crosscable. The rest of the surveying was completed successfully with all 16 streamers recording properly (Bialas, 2011).

The shipboard processing sequence involved CDP binning at a CDP spacing of $6.25 \mathrm{~m}$, a normal move-out correction at $1500 \mathrm{~m} / \mathrm{s}$, and along-streamer stacking. A post-stack trace interpolation algorithm was carried out to fill gaps that existed in the southwestern half of the survey. The stacked and interpolated dataset was then run through a 3D true-amplitude Kirchoff time migration at a constant velocity of $1500 \mathrm{~m} / \mathrm{s}$ (Bialas, 2011). For this preliminary shipboardprocessed dataset, everything before $1300 \mathrm{~ms}$ was clipped from the dataset (water column), as well as everything below $2800 \mathrm{~ms}$. This unfortunately resulted in the removal of the first seafloor multiple, which holds key information about the seafloor reflection coefficient, as will be discussed later in this Chapter. The data were also processed into $2 \mathrm{D}$ inlines, using the same processing parameters described above except with a 2D migration algorithm. The 2D lines include the seafloor multiple, which has enabled calculation of the seafloor reflection coefficient for the 3D dataset (see Section 3.3).

\subsection{Noise}

\subsubsection{Overview}

The Omakere seafloor seismic amplitude map (Figure 3.2) reveals that significant unwanted coherent noise exists in the 3D seismic dataset. Such noise makes it difficult to analyse and interpret the reflection characteristics of the seafloor methane seep sites. Therefore, it is important to understand the causes of the noise and to remove as much of the noise as possible before analysing and interpreting the data. Stripes of alternating high and low reflection amplitude run parallel to the northwest and southeast shooting directions of the survey. Superimposed on this striping, the southwestern half of the survey appears to be of overall higher amplitude than the northeastern half. The characteristics of the noise are typical of 
acquisition artifacts, which commonly arise in 3D seismic data due to systematic inconsistencies in the survey parameters during acquisition (Chopra and Marfurt, 2007). The characteristics of the noise have been investigated here in both the time and spatial frequency domains (in Sections 3.2.2 and 3.2.3 below). This investigation of the noise has informed the design of filtering techniques to optimally remove the stripy acquisition artifact.

\subsubsection{Time-domain characteristics of the footprint}

The stripy artifact that dominates the seafloor amplitude map shown in Figure 3.2 must have been caused by a systematic variation in the seafloor seismic reflection waveform in the crossline direction. To investigate the waveform of the seafloor reflection, several hundred individual raw shot records, such as the one shown in Figure 3.3 were investigated. On many of these shot records, including the one shown in Figure 3.3, the seafloor reflection displayed an undesirable elongation in the time domain and the emergence of a double-peak, rather than the usual single peak, accompanied by a decrease in peak amplitude. This elongation and separation of the waveform into two separate peaks is greatest for channels in streamers closer to the centre of the array, which were towed at greater depth. The same elongation, double-peaking and reduction in peak amplitude was found in the migrated 3D seismic data volume wherever low-amplitude stripes occur on the seafloor amplitude map, while high-amplitude stripes are characterised by a more compressed, single-peak reflection, confirming that this phenomenon is indeed responsible for the amplitude striping.

\subsubsection{Spatial frequency characteristics of the footprint}

The seafloor amplitude maps (Max, Min and RMS) all show significant amplitudestriping, with the stripes parallel to the inline direction. The stripes appear to have a quasi-periodic repetition in the crossline direction, and exhibit no obvious periodicity in the inline direction. To investigate the spatial frequency content of the footprint, 1D Fourier transforms of the seafloor amplitude map were calculated in both the inline and crossline directions. By plotting the power as a function of frequency, dominant spatial frequencies could be identified, allowing identification of the characteristic frequencies of the noise. As can be seen in Fig- 


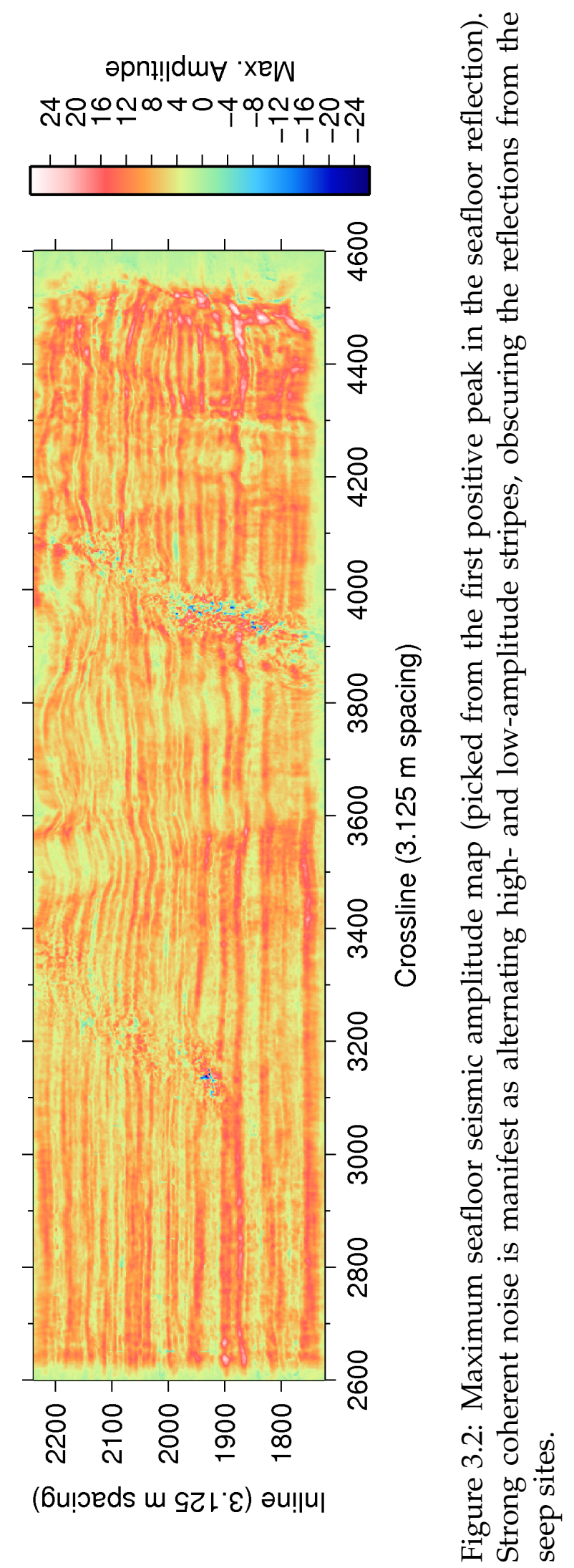




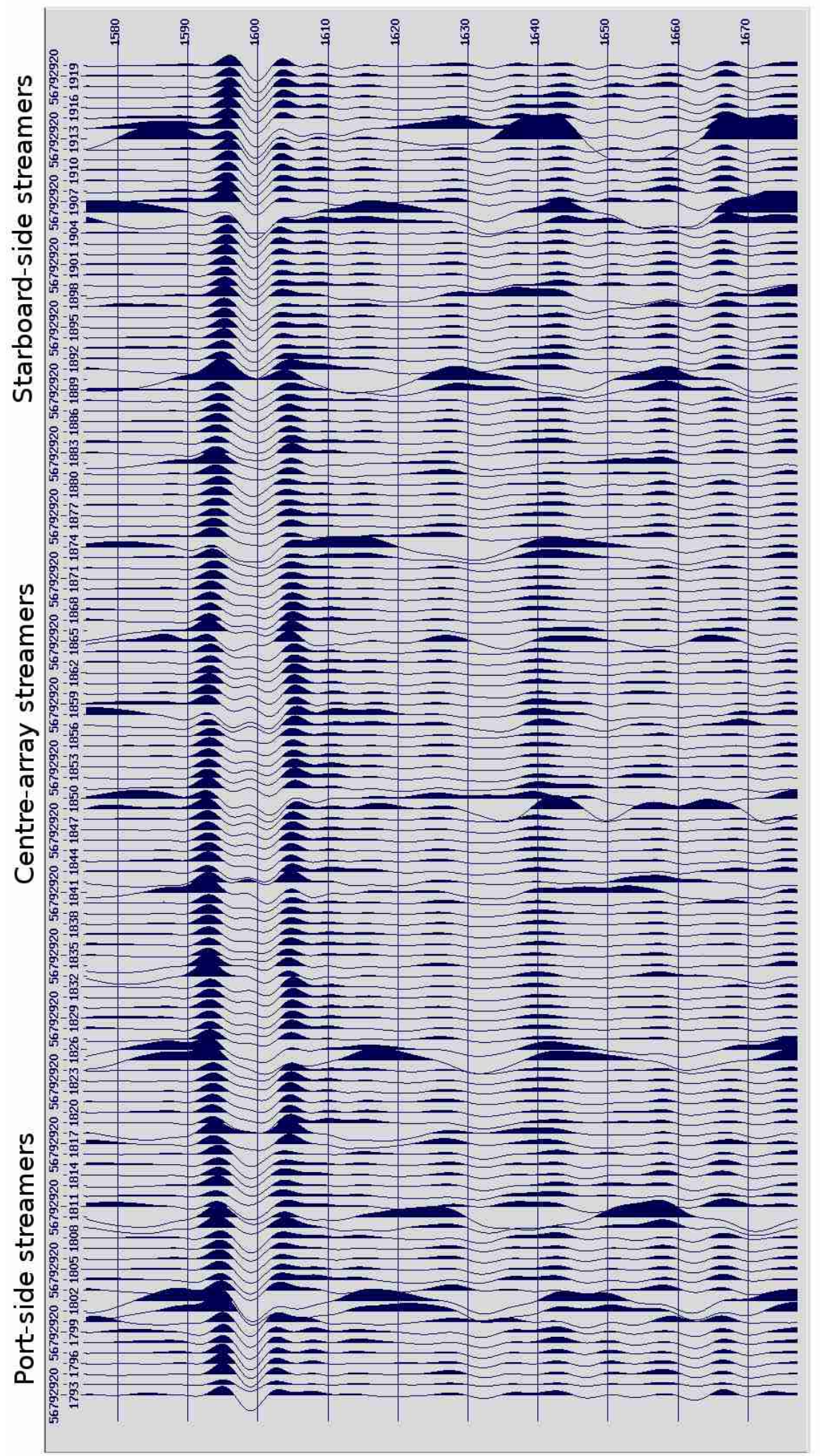

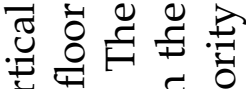
ป च क तै ह Е

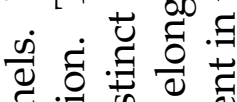

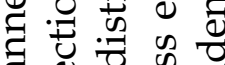

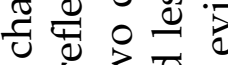

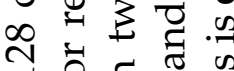
$\exists$ 월 స ॠ 60 少 20

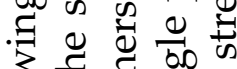
它 ज. 式

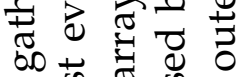

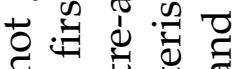
क 0 푼

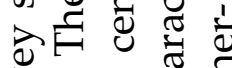

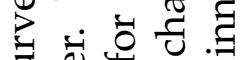
के . द्व ज्ञ

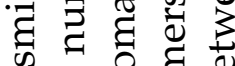

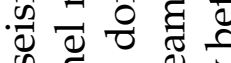

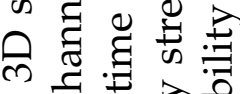
( ) 西.

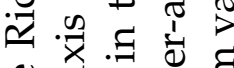

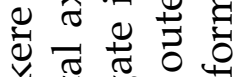

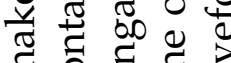

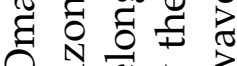
- 겅 23 는 응

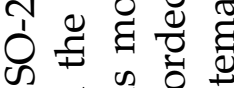
ซ

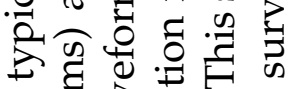

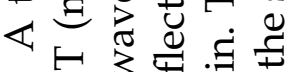

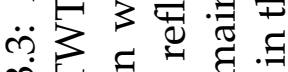
लंЕ 을 ข. 的 
ure 3.4, the power of the noise is an order of magnitude greater in the crossline direction than the inline direction. After smoothing with a Gaussian filter, a distinct power peak appears in the crossline spectrum at a wavelength of approximately $70 \mathrm{~m}$. There are no distinct peaks in the inline spectrum. The peak in the crossline spectrum confirms the hypothesis from visual investigation of the seafloor amplitude maps: the stripy artifact has a characteristic wavelength in the crossline direction. This characteristic wavelength of approximately $70 \mathrm{~m}$ is on the same order of magnitude as the array width, suggesting a link between the array width and the stripy artifact. Possible causes for this are discussed in Section 3.2.4.

To investigate the spatial characteristics of the noise in more detail, a 2D discrete Fourier transform was used to transform the amplitude map into a 2D spatial frequency map displayed as a cross-plot of $\mathrm{Kx}$ (crossline wavenumber) against $\mathrm{Ky}$ (inline wavenumber). This allowed visualisation of the frequency spectra in all azimuths. To improve visualisation of the $\mathrm{Kx}-\mathrm{Ky}$ domain, the zero frequency was shifted to the centre of the matrix. The acquisition footprint noise is characterised by high power over all wavenumbers in the crossline direction in a narrow band with low inline wavenumbers indicating that the periodic noise oscillates predominantly in the crossline direction (Figure 3.5). There is also a component of periodic noise oscillating in the inline direction over the low inline wavenumber, low crossline wavenumber range (Figure 3.5). 


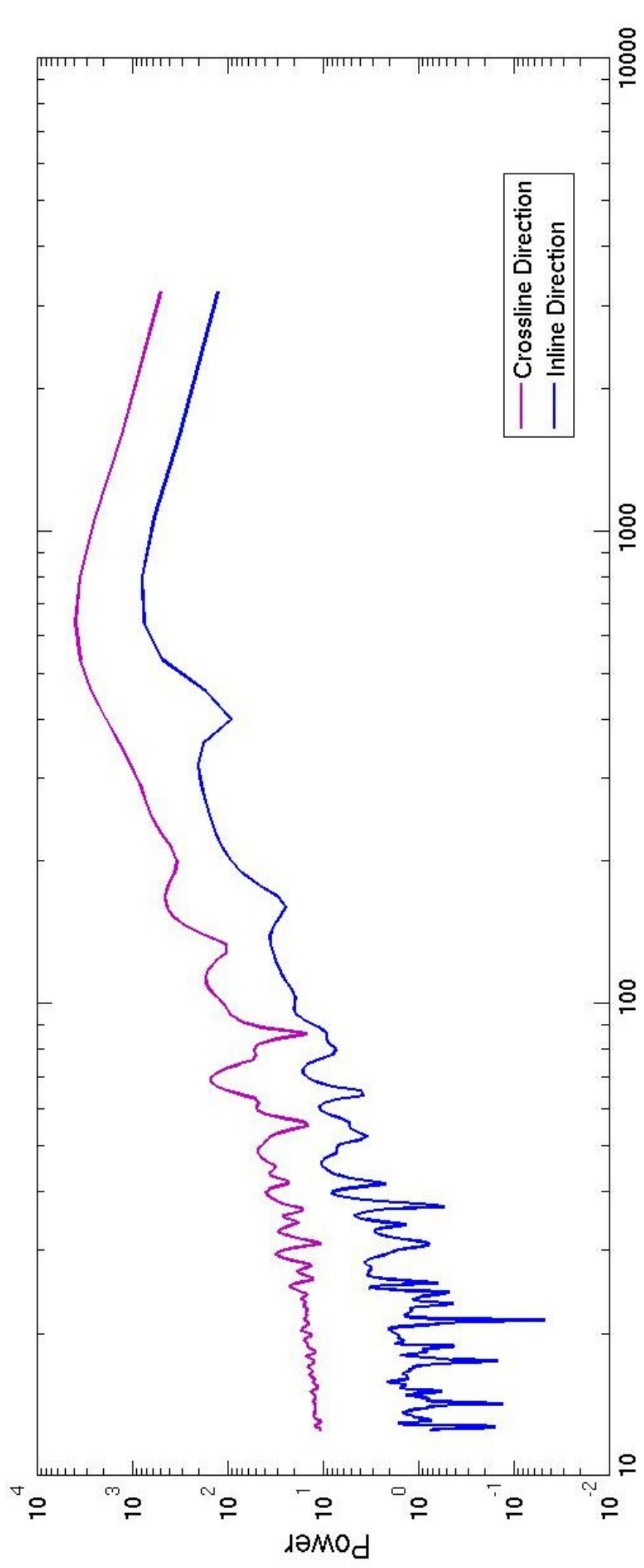

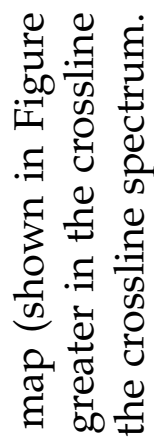

웜 은

节节

छृ छ छ

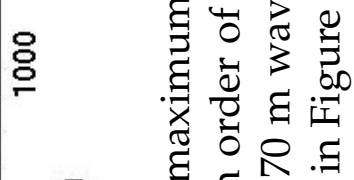

छ

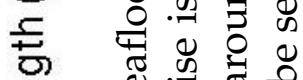

ब

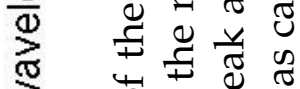

3 虫范

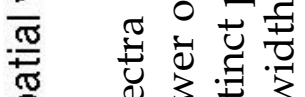

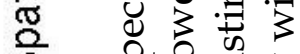

क के हो त्वे

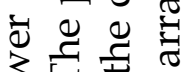

․․요

ᄃ ฮ च

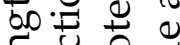

¿ี

元

उ

즈요

券寻: 㫕

के तै है

ర

麦:

¿्व

के ฮี छ

ن요용

\% :

เั้ 


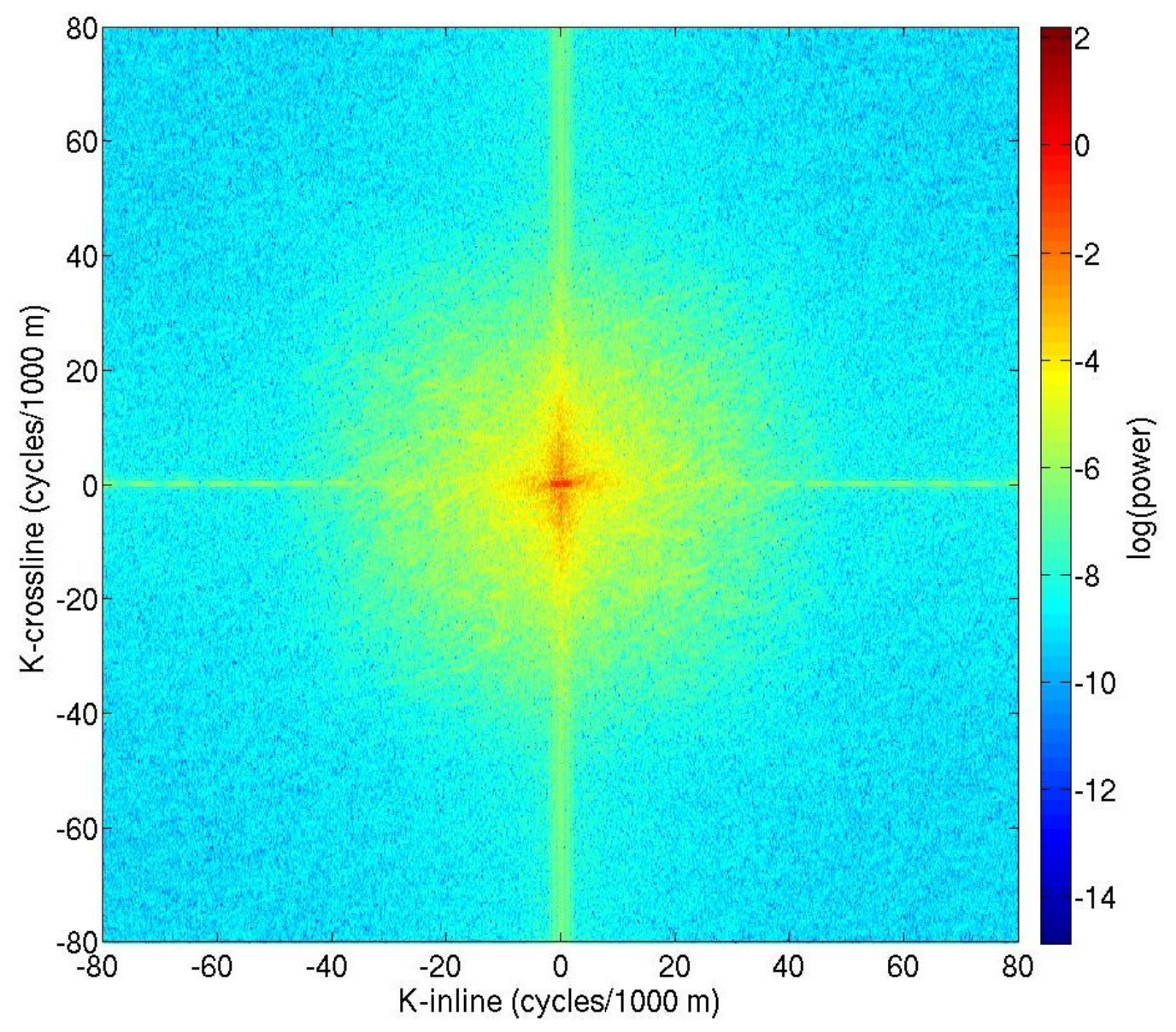

Figure 3.5: Plot of 2D spatial frequency domain of the RMS amplitude map shown in Figure 3.9. The $x$ and $y$ axes are inline wavenumber and crossline wavenumber respectively. The acquisition footprint is manifest as high-power noise in the crossline direction, over the entire crossline wavenumber spectrum for low inline wavenumbers. 


\subsubsection{Factors contributing to the footprint}

\section{Shooting direction}

One factor that may have introduced a systematic seafloor reflection characteristic bias is the shooting direction for each shot during acquisition. That is, the prevailing ocean currents and wind directions may have caused systematic differences in the seafloor reflection amplitudes depending on the directions the data were acquired in. As can be seen in Figure 3.6, where shooting direction is concerned, there are two distinct parts of the survey. The higher-amplitude southwestern half of the survey was conducted with the ship travelling to the southeast, and the lower-amplitude northeastern half with the ship travelling to the northwest. There is only a small section of overlap between these two sections, where lines shot in both directions exist.

\section{Acquisition geometry}

A detailed account of the acquisition geometry has been presented in Section 3.1. As a consequence of using trawl doors to spread the array out in a direction perpendicular to the ship's direction, middle-array streamers were towed farther below the sea surface than outer-array streamers. The differences in tow-depth would likely have been controlled primarily by the ship's speed relative to the prevailing water currents. The difference in arrival time between the seafloor ghost multiple and the primary seafloor reflection is a function of the streamer depth (the ghost is a reflection from the sea/air interface that arrives directly after the primary seafloor reflection, 'ghosting' the seafloor arrival). Therefore, the variation in the streamer depths perpendicular to the ship's direction would cause a variation in the arrival time of the ghost: the ghost multiple arrived a greater amount of time after the primary multiple for the middle-array streamers. This would cause variability in the way the primary seafloor reflection and the ghost interfere from streamer to streamer, providing a logical explanation for the variation in seafloor reflection waveform from streamer to streamer presented in section 3.2.2. 


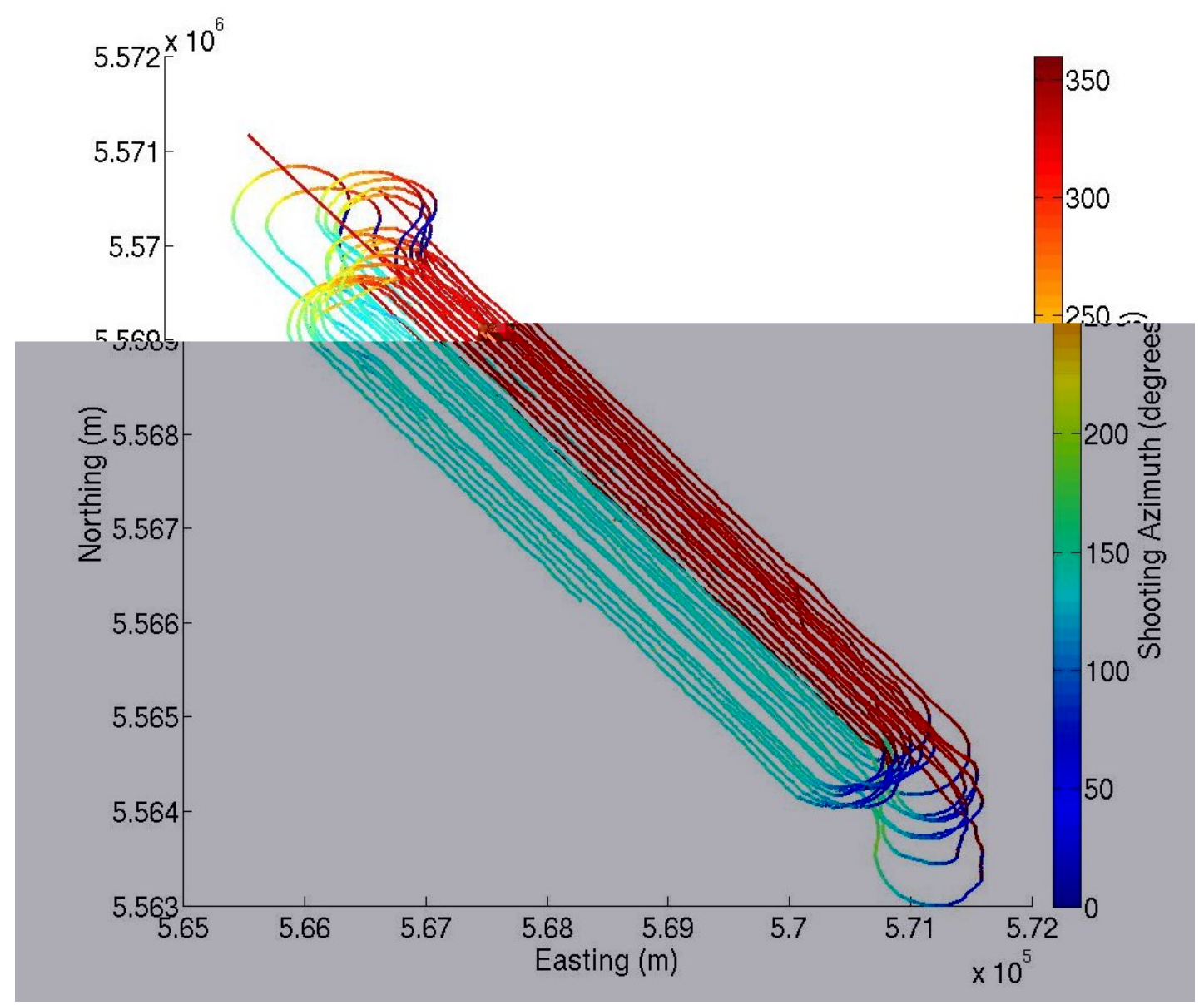

Figure 3.6: Omakere 3D seismic survey shotpoints coloured by shooting direction. Note the two distinct halves of the survey shot in opposite directions, with a small section of overlap. This diagram also demonstrates the 'racetrack' shooting style employed during the acquisition of the seismic data. 


\subsubsection{Footprint removal}

\section{Calculating RMS amplitude of the seafloor reflection}

The stripy artifact was very pronounced in the peak amplitude map (Figure 3.2). The investigation of the noise in the time domain showed that the centre-array streamers often recorded the seafloor reflection as a longer wavelet with double low-amplitude peaks, as opposed to the outer-array streamers that recorded the seafloor reflection as a shorter wavelet with one higher-amplitude peak. Therefore, calculating the RMS amplitude over the same time window for the two extremes in seafloor reflection waveform should attenuate some of the stripy artifact. The $20 \mathrm{~ms}$ RMS amplitude map was created to encompass the entire seafloor reflection waveform only for both the short, single-peak seafloor reflection waveform and the elongate, double-peak waveform. The signal from the seep sites is much more pronounced in the RMS amplitude maps than in the maximum and minimum seafloor amplitude maps and the stripy artifact appears to have been attenuated to some extent (see Figure 3.9 later in text). However, it is still a pronounced feature that will hinder interpretation.

\section{Spatial filtering of the seafloor horizon}

A commonly-used method for attenuating acquisition artifacts in 3D seismic datasets is 2D spatial filtering of horizon slices, to remove the artifact slice by slice (Sahai and Soofi, 2006; Chopra and Marfurt, 2007, 2008). The noise identified in Section 3.2.3 was removed in the $\mathrm{Kx}-\mathrm{Ky}$ domain by setting the noise-dominated matrix elements to zero (Figure 3.7). The data were transformed back into the spatial domain, showing that most of the crossline-directional amplitude striping had been attenuated (Figure 3.9).

The $\mathrm{Kx}-\mathrm{Ky}$ filtering removed much of the stripy artifact, but there was still low-frequency striping in the crossline direction (Figure 3.9). The frequency of this noise was too low to allow it to be filtered out by simply removing these frequencies from the $\mathrm{Kx}-\mathrm{Ky}$ domain and transforming back to the spatial domain. To remove this low-frequency noise, a stochastic approach was adopted. The remaining noise was sampled in the northwestern part of the $\mathrm{K} x-\mathrm{Ky}$-filtered 


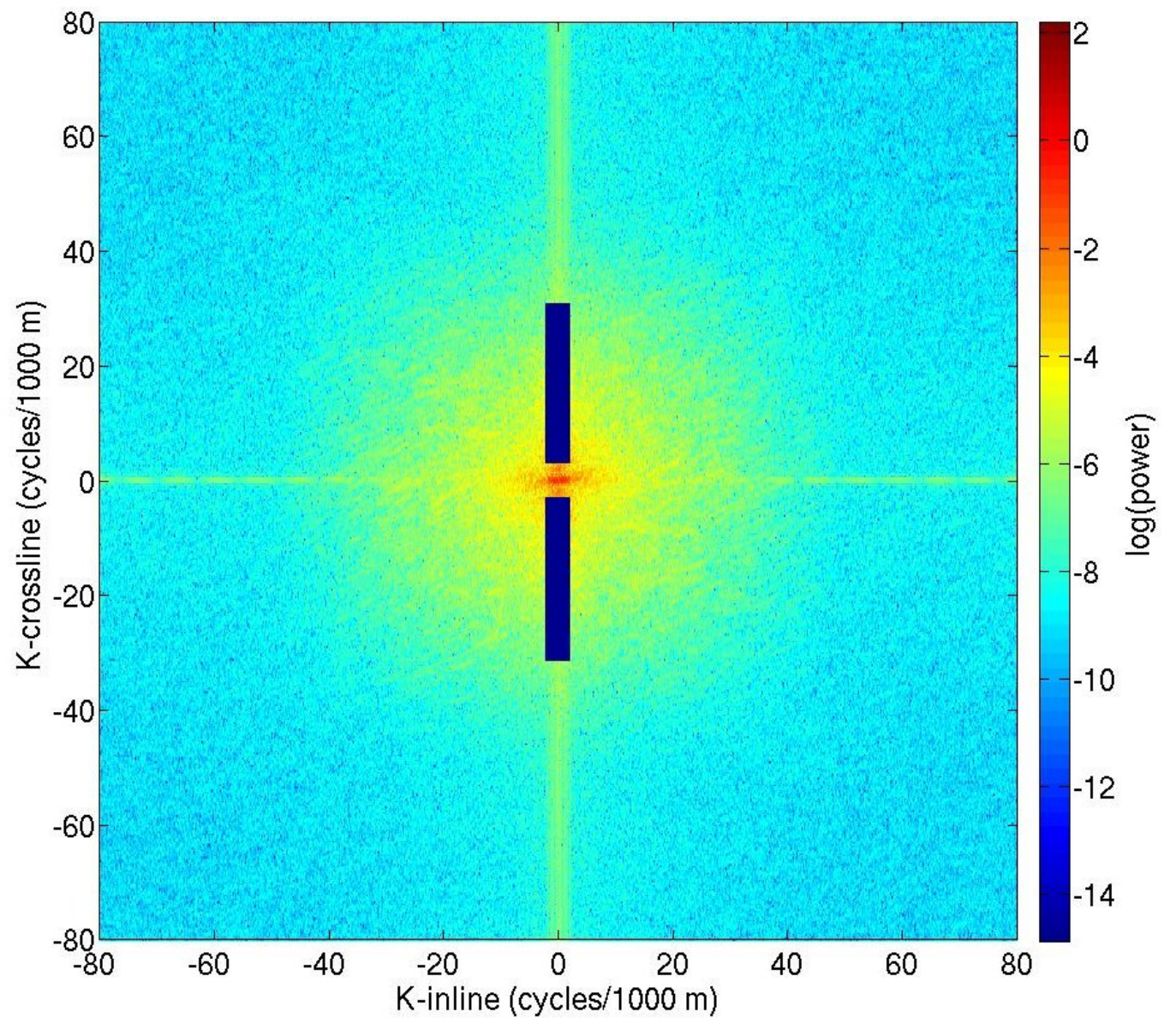

Figure 3.7: Plot of 2D spatial frequency domain showing the matrix elements that have been set to zero to remove the acquisition footprint noise. The $\mathrm{x}$ and $\mathrm{y}$ axes are inline wavenumber and crossline wavenumber respectively. Compare to the unfiltered 2D spatial frequency domain shown in Figure 3.5. To see the result of removing this section of the 2D spatial frequency domain before transforming back into the spatial domain, see Figure 3.9. 


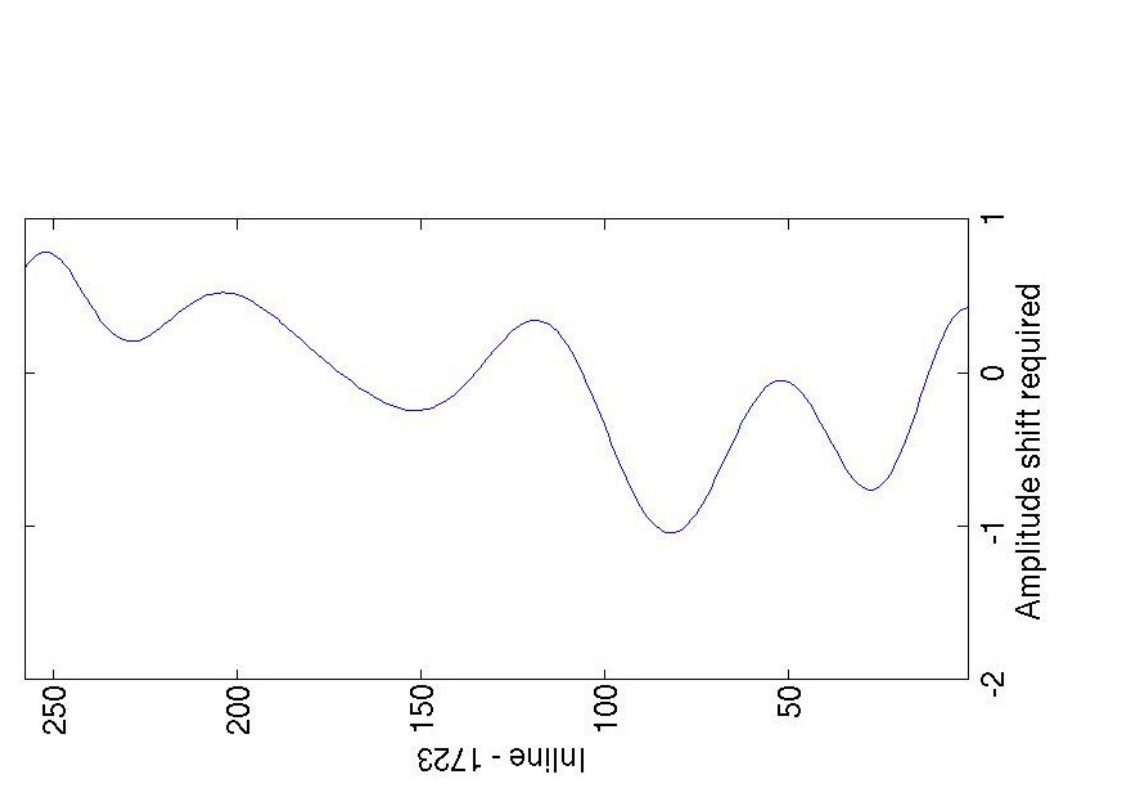

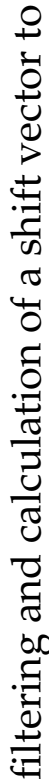
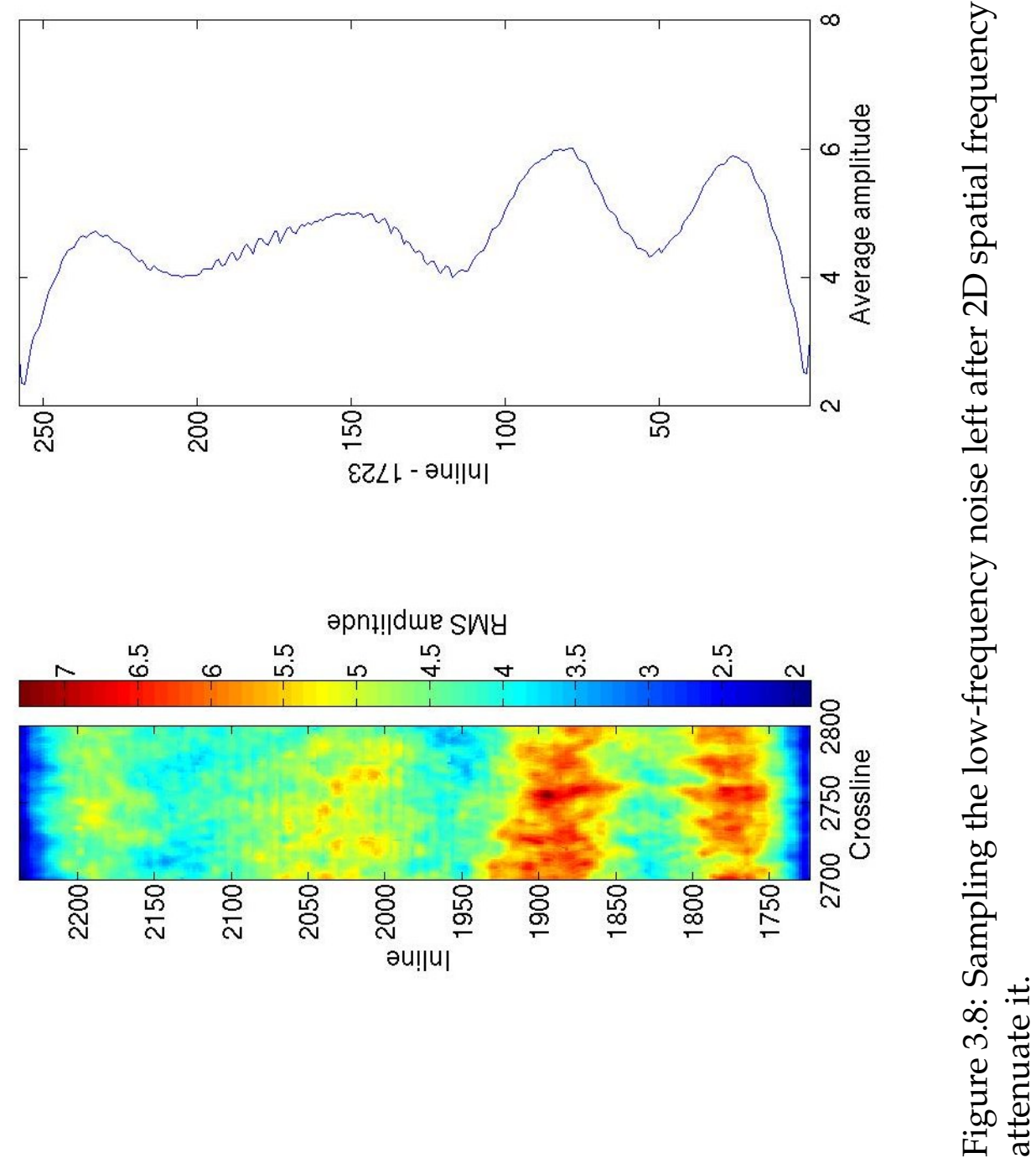
amplitude map, where the seafloor is homogeneous and no desired signal exists. The average amplitude of the sample area, $S_{A}$, was calculated, as well as the average amplitude for each inline, $I_{A}(i)$, within the sample area. A value for each inline was calculated to shift it to the sample area average (Figure 3.8). The shift value for each inline, $\operatorname{SHIFT}(i)$, was calculated as follows:

$$
\operatorname{SHIFT}(i)=S_{A}-I_{A}(i)
$$

The shift vector was smoothed, then added to each crossline column in the matrix. Much of the remaining low-frequency noise was removed (Figure 3.9).

\subsection{Seismic attributes}

\subsubsection{Seafloor reflection coefficient}

The reflection coefficient of any seismic reflection is a function of the acoustic impedance of the media above and below the reflecting interface. For a vertical reflection, the reflection coefficient is equal to:

$$
R=\frac{Z_{2}-Z_{1}}{Z_{2}+Z_{1}}
$$

where $Z_{1}$ and $Z_{2}$ are the acoustic impedances of the two media, which are equal to the product of acoustic velocity and density of the respective media (Sheriff and Geldart, 1995). In other words, the reflection coefficient is directly proportional to the acoustic impedance contrast.

To compute a seafloor reflection coefficient map, the reflection coefficient was calculated at several locations using the 2D migrated lines from the P-Cable survey. It was necessary to use the $2 \mathrm{D}$ migrated lines, as the seafloor multiple was truncated out of the preliminary 3D dataset during shipboard processing (explained in Section 3.1), and the seafloor multiple amplitude is a necessary piece of information in calculating the seafloor reflection coefficient, as explained below. The seafloor reflection coefficient was calculated using the following relationship, 


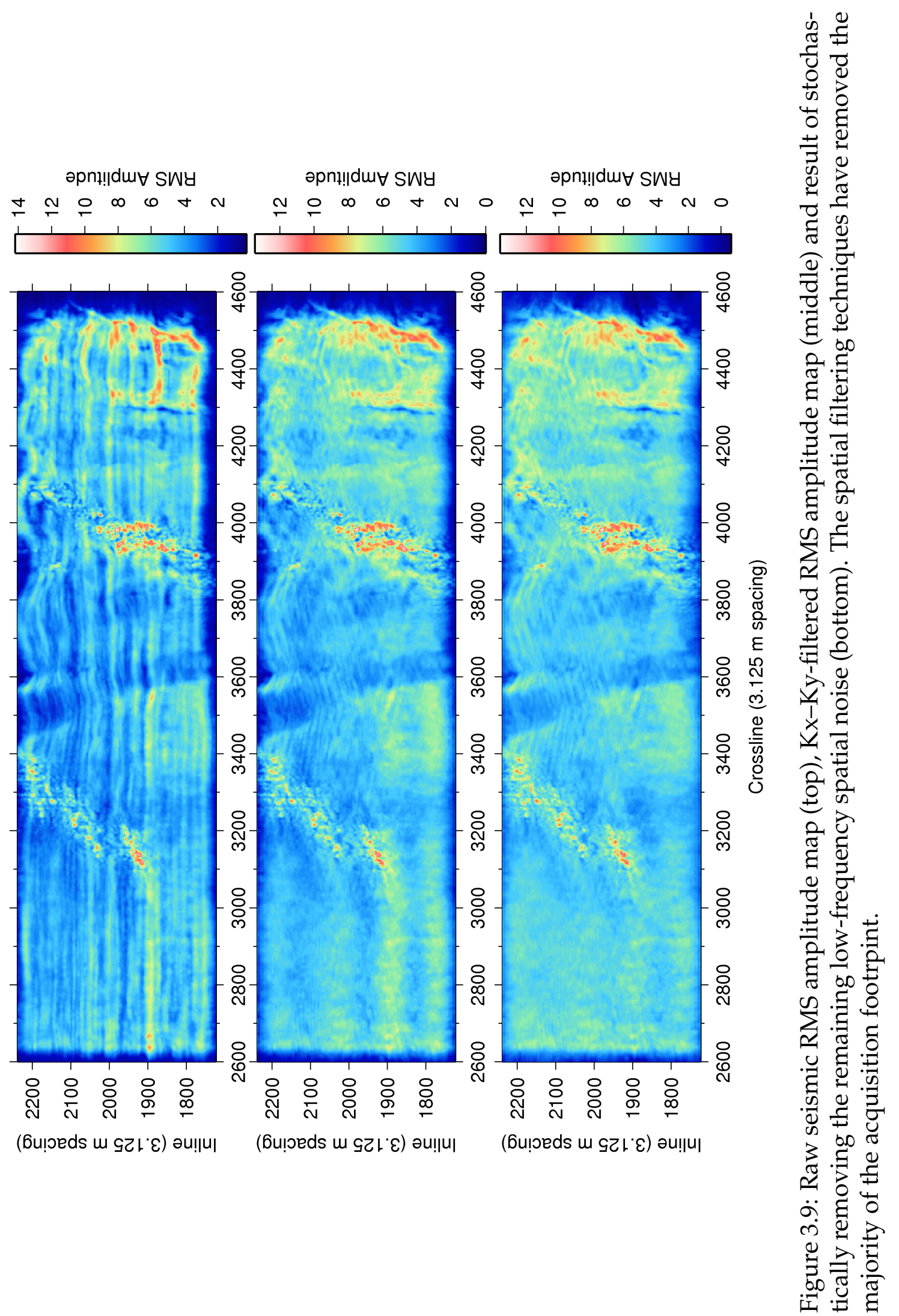


published in Yilmaz and Doherty (2001):

$$
R_{s}=-2 * \frac{A_{m u l}}{A_{s f l}}
$$

where $R_{s}$ is the seafloor reflection coefficient and $A_{m u l}$ and $A_{s f l}$ are the seafloor multiple and primary seafloor reflection amplitudes respectively (the factor of two in the equation accounts for linear amplitude loss with travel path, since the multiple reflection has twice the travel path as the primary seafloor reflection). An assumption of this method is that the sea/air reflection coefficient can be approximated to -1 , which is not always the case, especially for a rough sea state. Therefore, reflection coefficient values derived by this method should be considered a minimum estimate of the true seafloor reflection coefficient. A linear relationship was then calculated between reflection coefficient and seafloor 3D seismic amplitude for the filtered and smoothed seafloor amplitude map. An assumption of this method is that source strength remained constant throughout the survey, which it roughly should have (airgun pressure was maintained at 210 bar throughout the survey). The relationship between reflection coefficient and filtered 3D seismic amplitude was then used to transform the 3D seismic amplitude map into a reflection coefficient map. The advantage of calculating the seafloor reflection coefficient is that it is a survey-independent variable, unlike the primary reflection amplitude, which depends on source signal strength as well as reflection coefficient. This survey-independent parameter for quantifying reflection strength at the seep sites will allow future comparison with other seep sites in New Zealand and globally.

As described in Section 3.2, the RMS amplitude of the seafloor reflection was calculated as a first step in attenuating the acquisition artifact manifest in the maximum amplitude map. The disadvantage of an RMS amplitude is that it no longer has any polarity information. It is the RMS amplitude dataset that has undergone further filtering, and that has been converted into a reflection coefficient dataset. It should therefore be noted that this an absolute reflection coefficient dataset. It is possible that some areas of low absolute reflection coefficient presented in this thesis could represent areas of low negative acoustic impedance contrast, where the seafloor acoustic impedance is less than that of water due to very high gas concentrations (e.g. at Bear's Paw). However, in this study area, 
areas of high absolute reflection coefficient are almost certainly high positive reflection coefficient, as they correspond to areas of extensive carbonate build-ups of high acoustic impedance (e.g. at Moa Reef and Kea). Therefore, the fact that polarity information has been sacrificed does not significantly hinder interpretation of this dataset, especially when interpreted in conjunction with multibeam sonar backscatter data and Parasound ${ }^{\mathrm{TM}}$ sub-bottom profiler data.

\subsubsection{Seafloor seismic similarity}

Seismic 'similarity' is an algorithm available in OpenDtect ${ }^{\mathrm{TM}}$ for calculating coherence, where coherence is a measure of the similarity between waveforms of traces (Chopra and Marfurt, 2007). Quantifying the coherence of the seismic waveform from trace to trace is used to reveal subtle information in seismic data that is difficult to detect by looking at amplitude information alone. Coherence is particularly useful in identifying faults and fractures, which often cause abrupt changes in the seismic waveform (Chopra and Marfurt, 2007). There are many different methods for quantifying coherence (Chopra and Marfurt, 2007). Seismic 'similarity' in OpenDtect ${ }^{\mathrm{TM}}$ treats specified seismic trace segments as vectors in hyperspace, and quantifies the similarity as 1 minus the Euclidean distance between the vectors divided by the sum of the length of each vector ( $d G B$ Beheer B.V., 2011). In this way, trace segments with exactly the same waveform would have a similarity value of 1 , while trace segments that are totally dis-similar would have a similarity of 0 (dGB Beheer B.V., 2011). For the data presented in this thesis, seismic similarity was calculated at each CDP for a $20 \mathrm{~ms}$ window around the seafloor reflection and comparing the waveform to that of each of the 8 adjacent CDPs. The minimum similarity value of these 8 values was assigned to that CDP. 


\subsection{Results}

\subsubsection{Overview}

The seep sites mostly appear as features of high RMS seafloor reflection coefficient compared to the surrounding seafloor. The Moa Reef and Kea sites appear as regions of relatively consistent high reflection coefficient. Kaka and Kakapo are characterised by smaller patches of high reflection coefficient. The Bears Paw site appears as a patchy low-amplitude feature (Figure 3.10). To help quantify the reflection coefficient at each seep site, CDP percentage plots were created for areas encompassing each seep site (Figure 3.11). The areas encompassing each seep site were the same as those used to extract CDP percentage plots for sonar backscatter intensity (Figure 4.4 in Chapter 4 ). The seep sites all appear as low-similarity features, indicative of high variability in the seafloor reflection waveform from CDP to CDP (Figure 3.12). The seafloor seismic similarity map shows a number of linear low-similarity features towards the southeastern end of the survey area, which are related to an extensional fault network. In addition to the seafloor analyses, key inlines from the 3D seismic dataset have been selected to analyse the subsurface reflection characteristics beneath each seep site. As noted in Chapter 1 , these inlines and any interpretations drawn from them are preliminary only and a more thorough investigation will be conducted by Plaza-Faverola. The following subsections detail the observations at each seep site.

\subsubsection{Bear's Paw}

\section{Reflection Coefficient}

Bear's Paw is characterised by patches of predominantly low seafloor seismic reflection coefficient (Figure 3.10), with reflection coefficient values ranging from 0.10 to 0.35 with a modal value of 0.20 (Figure 3.11). The range of 0.25 and maximum reflection coefficient value of 0.35 are the lowest of all the seeps on Omakere Ridge. 


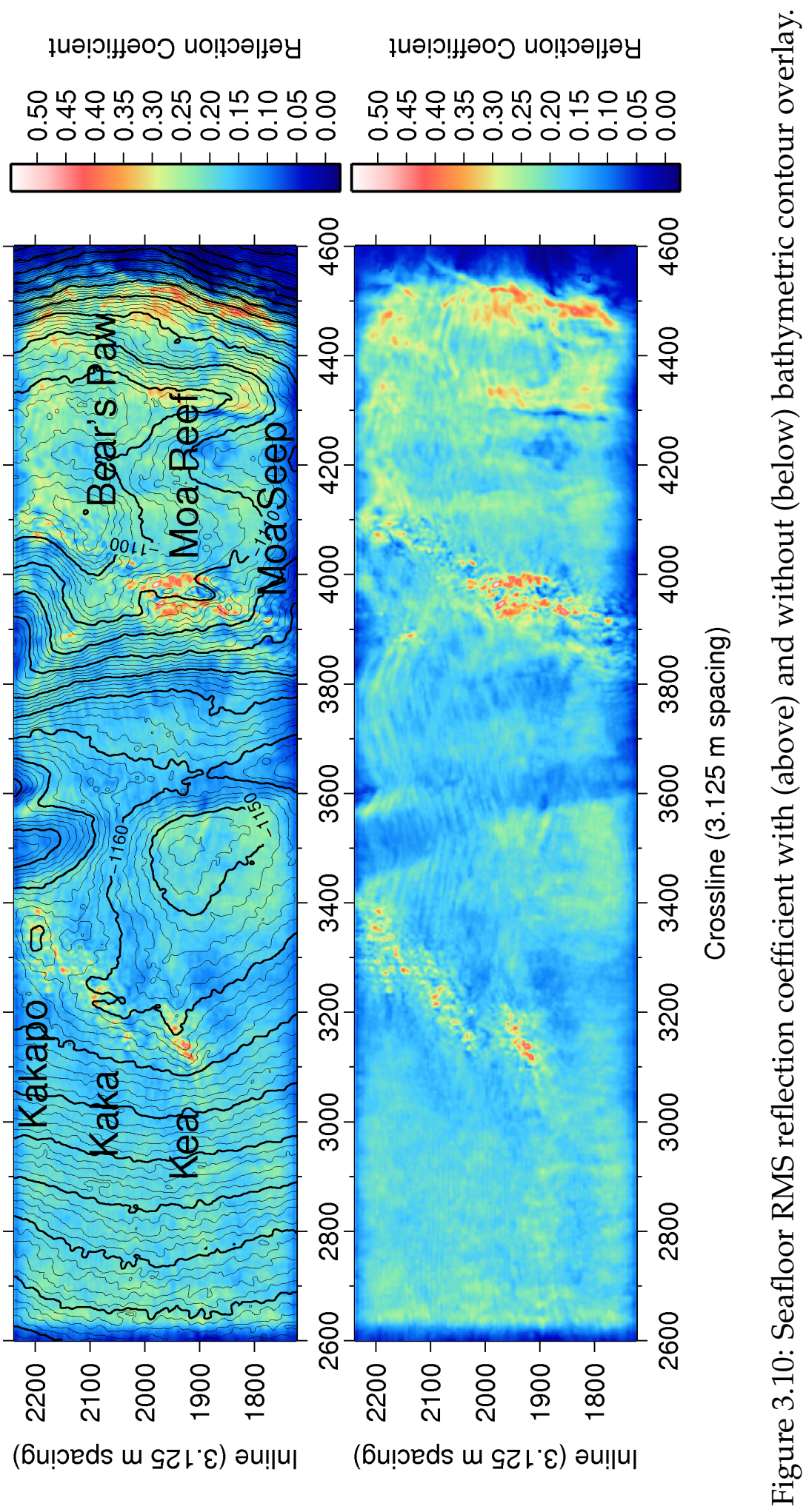



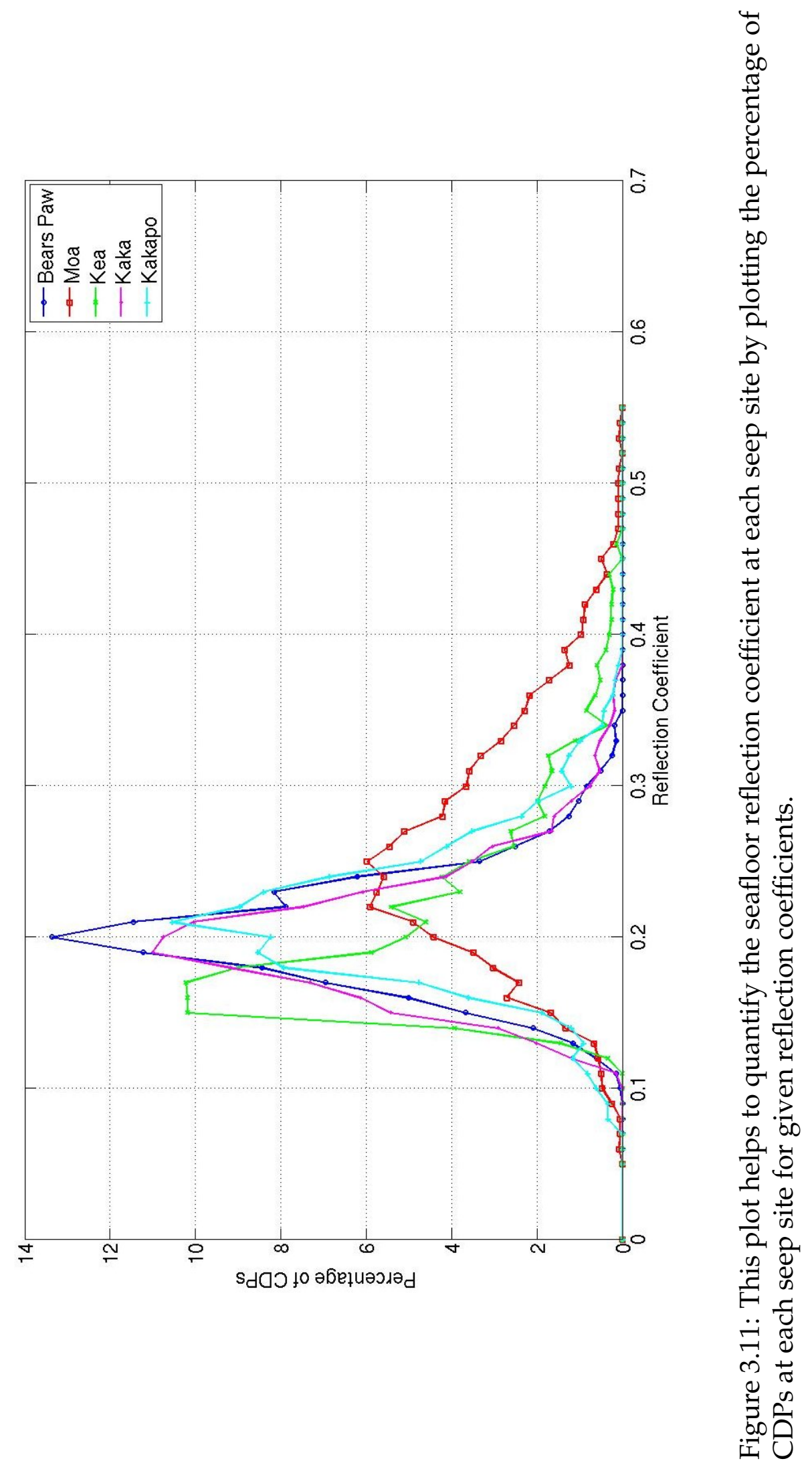


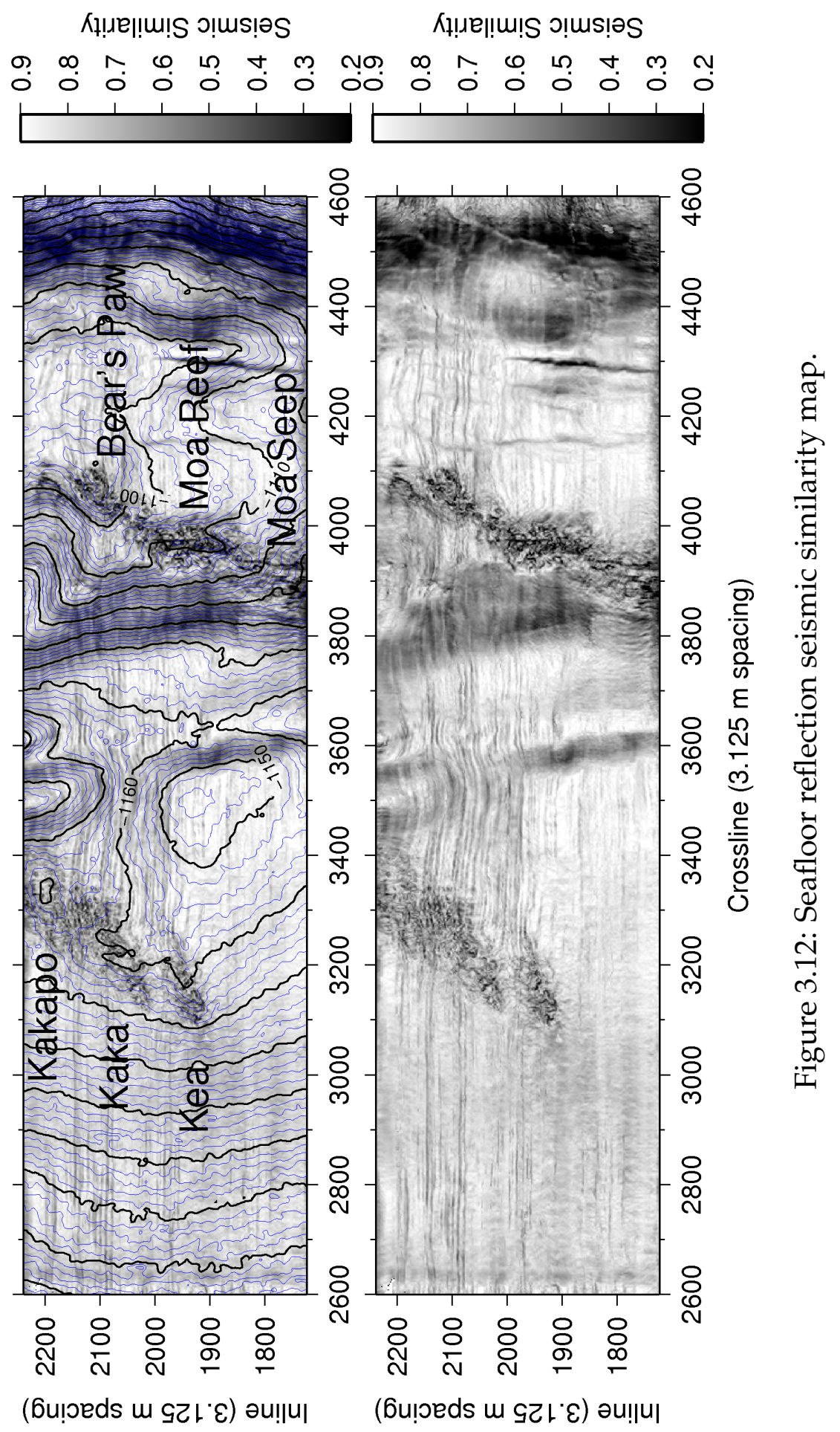




\section{Seismic Similarity}

The seafloor at Bear's Paw is characterised by low seismic similarity over the same region that exhibits patches of low reflection coefficient (Figure 3.12).

\section{D Seismic Subsurface}

The 3D seismic inline through Bear's Paw reveals a narrow vertical zone of disturbed reflectivity below the seep site. The bottom of this disturbed zone is not discernible, as it continues to the depth where the amplitude of the returned signal is too attenuated to detect reflections. Shallow reflection horizons beneath Bear's Paw and to the west of Bear's Paw are truncated and vertically offset due to extensional faulting beneath the ridge crest (Figure 3.15).

\subsubsection{Kea}

\section{Reflection coefficient}

Kea is characterised by a patch of reasonably uniform high seismic reflection coefficient, which is elongate in a WNW-ESE orientation (Figure 3.10). Reflection coefficient values at Kea range from 0.13 to 0.46 with a modal value of 0.17 (Figure 3.11). The maximum value of 0.46 at Kea is the second highest of the seep sites, lower only than the maximum of Moa Reef.

\section{Seismic similarity}

Kea exhibits low seismic similarity, also elongate in a WNW-ESE orientation over the same region that exhibits anomalous reflection coefficient (Figure 3.12).

\section{D seismic subsurface}

The key 3D seismic inline selected through Kea reveals a narrow vertical zone of anomalous reflectivity below the seep site, which extends down into a zone of high-amplitude reflections deeper in the subsurface. This zone of deep highamplitude reflections has an antiformal shape and is directly overlain by a zone of low amplitude response (Figure 3.14). 


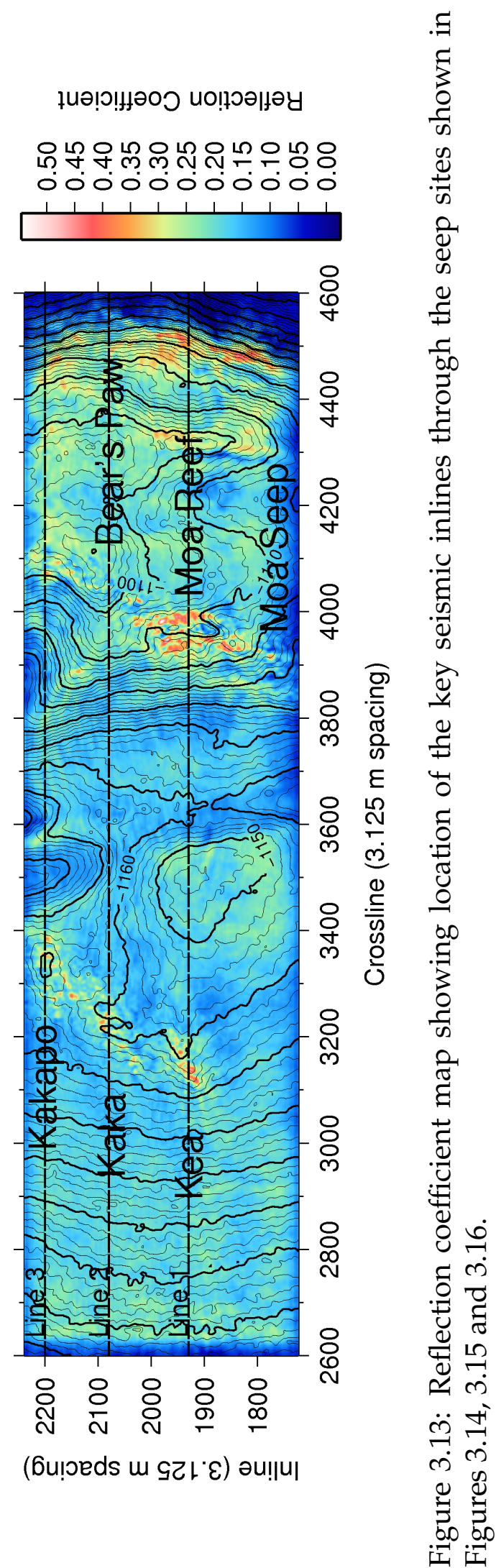



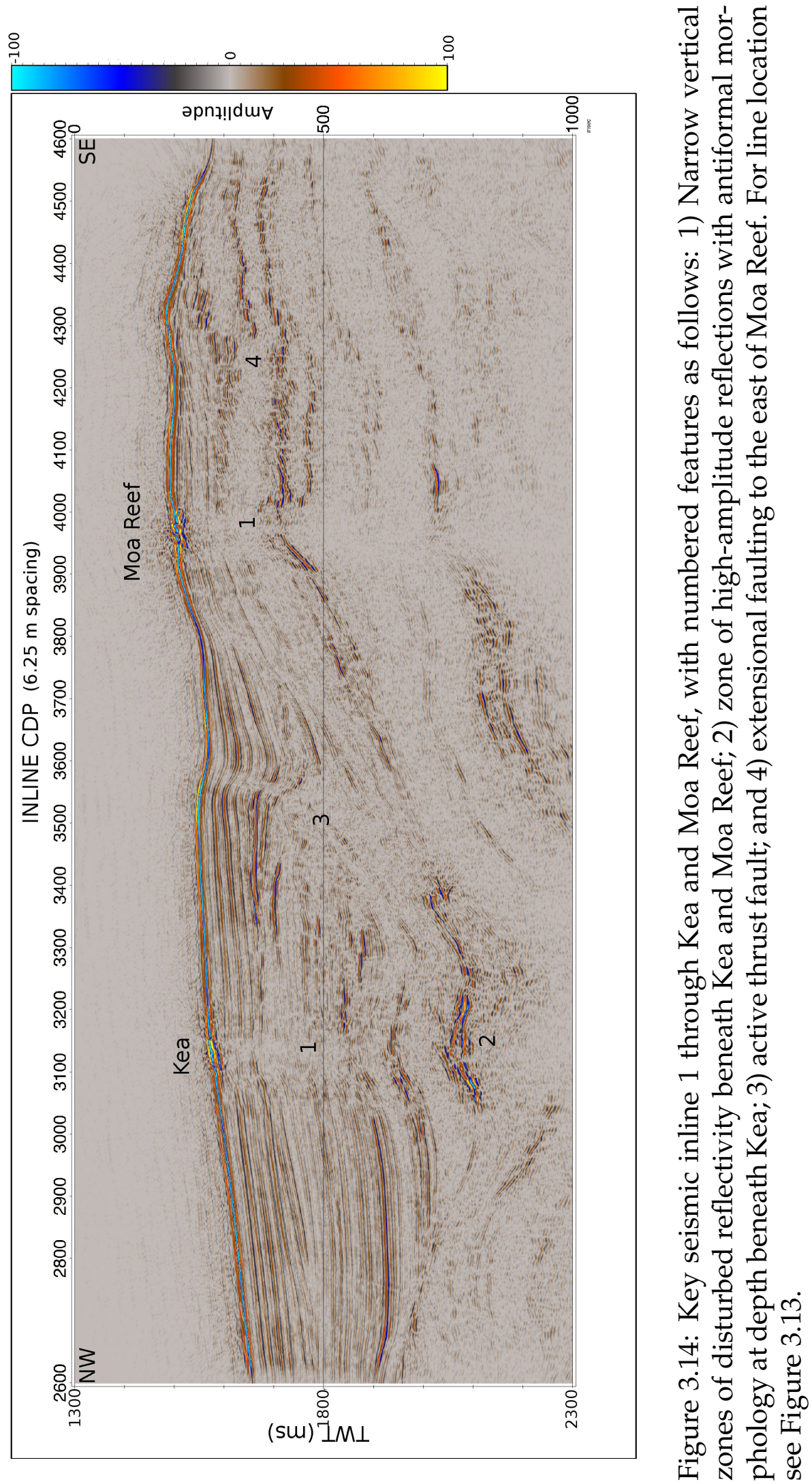


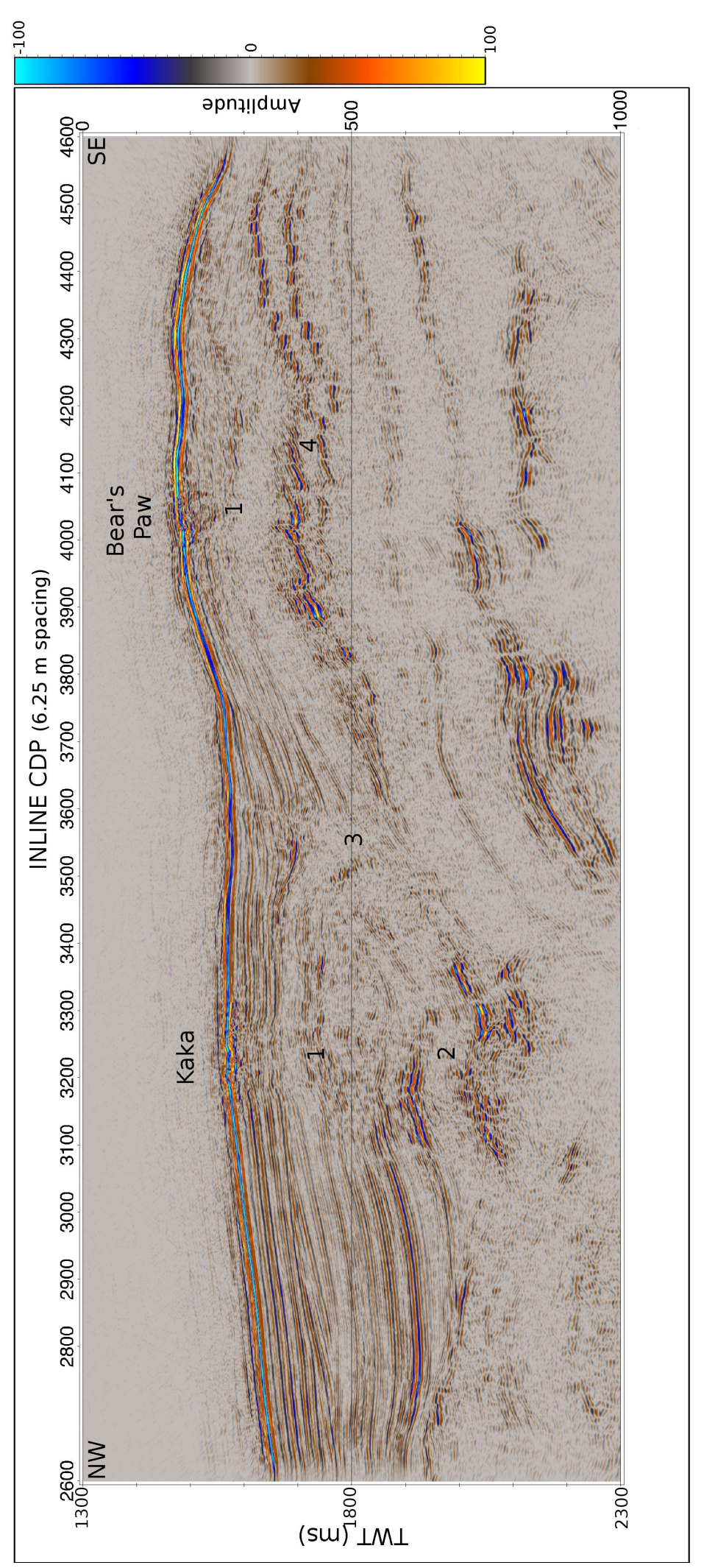

.

ธัธิ

$\ddot{\dot{\theta}}$

$\stackrel{0}{5}$

江

.$\varsubsetneqq$

g

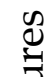

$\frac{7}{0}$

है

3

(n)

ฮี

ฮี

$\frac{\pi}{\sqrt{\pi}}$

50

ํㅣㄹ

N

Ð

萄

के

침

$\forall$ 江

ம்

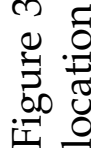




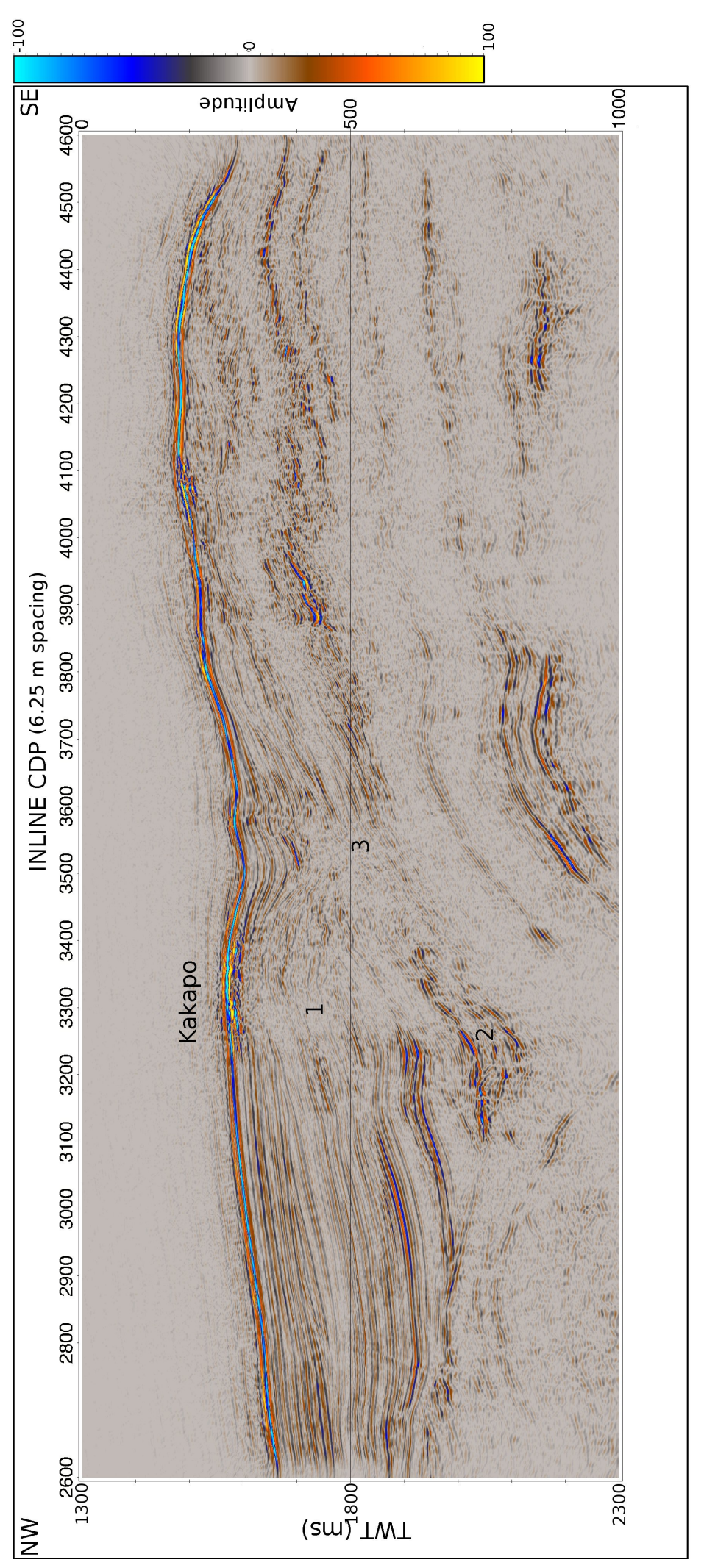

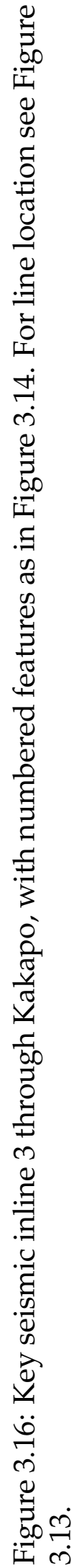




\subsubsection{Kaka}

\section{Reflection coefficient}

The Kaka seep is characterised by patches of high reflection coefficient interspersed by patches of low reflection coefficient. Like Kea, this heterogeneous zone of anomalous reflection coefficient is elongate in a WNW-ESE orientation (Figure 3.10). Reflection coefficient values at Kaka range from 0.11 to 0.38 with a modal value of 0.19 (Figure 3.11).

\section{Seismic similarity}

The seafloor at Kaka exhibits low seismic similarity elongate in a WNW-ESE orientation over the same region that exhibits anomalous reflection coefficient (Figure 3.12).

\section{D Seismic subsurface}

The key 3D seismic inline selected through Kaka reveals a narrow vertical zone of anomalous reflectivity below the seep site, which extends down into a zone of high-amplitude reflections deeper in the subsurface. This zone of deep highamplitude reflections has an antiformal shape and is directly overlain by a zone of low amplitude response, as observed at Kea (Figure 3.15).

\subsubsection{Kakapo}

\section{Reflection coefficient}

Like Kaka, the seafloor at Kakapo is characterised by patches of high reflection coefficient interspersed by patches of low reflection coefficient. Like Kea and Kaka, this heterogeneous zone of anomalous reflectivity is elongate in a WNWESE orientation (Figure 3.10). Reflection coefficient values at Kakapo range from 0.08 to 0.38 with a modal value of 0.21 (Figure 3.11).

\section{Seismic similarity}

Kakapo is characterised by low seafloor seismic similarity, elongate in a WNWESE orientation over the same region that exhibits anomalous reflection coeffi- 
cient (Figure 3.12).

\section{D seismic subsurface}

The key 3D seismic inline selected through Kakapo reveals a narrow vertical zone of anomalous reflectivity below the seep site, which extends down into a zone of high-amplitude reflections deeper in the subsurface. This zone of deep highamplitude reflections has an antiformal shape and is directly overlain by a zone of low amplitude response, as observed at Kea and Kaka (Figure 3.16).

\subsubsection{Moa Reef}

\section{Reflection coefficient}

The Moa Reef is characterised by a broad, uniform zone of very high seafloor reflection coefficient, elongate in a SW-NE direction (Figure 3.10). Reflection coefficient values at Moa Reef range from 0.06 to 0.55 with a modal value of 0.25 , exhibiting both the largest range and highest maximum value of all the Omakere Ridge seep sites (Figure 3.11).

\section{Seismic similarity}

Moa Reef appears as a region of low seismic similarity over the same region that is characterised by high reflection coefficient (Figure 3.12).

\section{D seismic subsurface}

The 3D seismic inline through Moa Reef reveals a narrow vertical zone of disturbed reflectivity beneath this site. The bottom of this disturbed zone is not visible, as it continues to the depth where the amplitude of the returned signal is too low to detect reflections. To the east of Moa, shallow reflection horizons are truncated and vertically offset by extensional faulting (Figure 3.14). 


\section{Chapter 4}

\section{Sonar Backscatter}

\subsection{Sonar backscatter theory}

Sonar backscatter theory is presented here in the context of backscattering from the seafloor and is a summary of principles published in Lurton (2002) that apply to the data presented in this thesis. Sonar waves incident on the seafloor are scattered by the seafloor in all directions. A portion of the incident waves is scattered back towards the transmitter/receiver. The intensity of the reflected signal $E_{L}$ received by the sonar system after backscattering is defined by Lurton (2002) with the formula:

$$
E_{L}=S_{L}-2 T_{L}+T_{S}=S_{L}-40 \log R-2 \alpha R+T_{S}
$$

where $S_{L}$ is the source intensity, $T_{L}$ is the transmission loss, $T_{S}$ is the target strength, $R$ is the propogation range and $\alpha$ is the absorption coefficient. Expressed in words, the echo intensity is equal to the source level minus transmission losses, minus absorption, plus the target strength.

The target strength $T_{S}$ is defined as the ratio of the signal intensity reflected back to the receiver to the incident intensity:

$$
T_{S}=10 \log \left(\frac{I_{b s}}{I_{i}}\right)
$$

(Lurton, 2002) where $I_{b s}$ is the intensity of the backscattered signal and $I_{i}$ is the 
intensity of the incident signal. $T_{S}$ differs from a reflection coefficient (described in Chapter 3) in that the incident plane wave is re-radiated from the target as if it were a new point source, whereas a reflection coefficient describes a reflected wave that is plane (Lurton, 2002). The backscattered signal strength from the seafloor $I_{b s}$ depends on the seafloor roughness (shape and size of small-scale irregularities), the contribution to backscattering by underlying volume heterogeneities down to a depth of several centimetres beneath the seafloor, the acoustic impedance contrast at the water/sediment interface, the frequency of the incident signal and the angle of incidence (measured from the normal to the seafloor) (Lurton, 2002).

The effect of seafloor roughness on backscattered signal strength depends on the frequency, angle of incidence and the scale of seafloor heterogeneity. Part of the incident wave is reflected away with no deformation at an angle equal to the angle of incidence on the surface (specular reflection), while the remainder is scattered in all angles, including back towards the source. Low interface roughness induces a high specular component and low scattered component distributed around the specular direction. High interface roughness strongly attenuates the specular component and results in high scattering in all directions (Lurton, 2002).

There are two main physical processes related to seafloor roughness that determine the backscattered signal intensity: facet backscattering and Bragg backscattering. At incidence angles up to approximately $20^{\circ}$, facet backscattering dominates the backscattered energy (Lurton, 2002). When a rough seafloor contains facets (small faces) that are inclined so that the normal to their surface is parallel to the angle of incidence, a strong backscatter response will be recorded. This is because the specular reflection is reflected back towards the receiver (Lurton, 2002). When the incidence angle is greater than around $20^{\circ}$, Bragg backscattering is dominant (Lurton, 2002). Bragg backscattering occurs when the scale of seafloor roughness is small relative to the acoustic wavelength, and the main contribution to backscattered signal strength at incident angle $\theta_{i}$, independent of the acoustic impedance contrast, comes from the scatterers with spacing $d$ such that $2 d \sin \theta_{i}=\lambda$, where $\lambda$ is the acoustic wavelength. Seafloor roughness at this scale results in constructive interference of the backscattered signal in the direction of 
the receiver, increasing the intensity of the received signal (Lurton, 2002). Consequently and ignoring acoustic impedance contrast and volume heterogeneities, the backscattered signal strength will be the greatest when seafloor irregularities are on a scale of roughly half the acoustic wavelength.

There are a number of models that attempt to quantify the exact angular dependence of sonar backscatter intensity on sediment physical properties such as grain size and fluid content (e.g. Lamarche et al., 2011), but such modelling is beyond the scope of this thesis, which aims for a purely qualitative approach to backscatter analysis.

Standard multibeam sonar backscatter processing techniques correct for the $\mathrm{Tx} / \mathrm{Rx}$ beam pattern (transimtter- and receiver-induced angular variation in signal strength) and the dependence of backscatter on angle of incidence, taking into account the bathymetry (e.g. Lamarche et al., 2011). During these corrections, the backscatter intensity of each beam in the swath is commonly statistically compensated to an arbitrary reference level (for example, the average backscatter intensity at an incidence angle of $45^{\circ}$ ) (Lamarche et al., 2011). After these corrections have been applied, the amplitude of the sonar data should depend only on the characteristics of the seafloor (roughness, grain size, acoustic impedance, volume heterogeneities). After such processing has been carried out, areas of high seafloor backscatter can be explained by (e.g. Lamarche et al., 2011):

- abundant seafloor irregularities on roughly the same order of magnitude as the acoustic wavelength;

- many optimally-oriented facets of a size below the spatial resolution of the bathymetry grid used in the backscatter processing;

- coarse-grained sediments;

- or a high acoustic impedance contrast at the interface between water column and seafloor;

while areas of low backscatter can be explained by:

- a smooth, homogeneous seafloor; 
- fine-grained sediments;

- or a low acoustic impedance contrast at the interface between water column and seafloor.

Gas bubbles in the sediment are known to be an essential component of seafloor backscattering (Lurton, 2002). The presence of gas lowers the acoustic impedance of the host sediments, lowering the acoustic impedance contrast between the water column and gas-charged seafloor sediments, and increasing the acoustic impedance contrast between gas-charged and non-gas-charged sediments. The presence of gas in sediments can therefore both decrease and increase reflection amplitude.

\subsection{Data acquisition}

The $12 \mathrm{kHz}$ Kongsberg EM120 ${ }^{\mathrm{TM}}$ multibeam sonar array was mounted on the hull of the RV Sonne. The system comprises two transducer arrays that are compensated for pitch, roll and yaw, and emit and receive successive frequency-coded signals between 11.25 and $12.6 \mathrm{kHz}$ in a swath of 191 beams. The swath spread out perpendicular to the ship's track on either side, with a total swath width of $120^{\circ}$ and across-track beam spacing of $2 \%$ of the water depth. Figure 4.1 shows the swath coverage of an individual sonar transect over the study area. The system recorded depth and backscattered signal amplitude. The depth information was determined automatically by the recording system using the two-way-traveltime and beam angle for each beam and taking into account beam refraction due to water velocity variations (Bialas, 2011). The recording system was set up so that a new transect was started every hour, where each new transect was automatically recorded as a separate Kongsberg ${ }^{\mathrm{TM}}$.all file (standard file format for Kongsberg ${ }^{\mathrm{TM}}$ sonar data, containing navigation, water depth and backscatter information for each beam). Each individual .all file could then be read into processing and interpretation software separately.

Multibeam sonar transects were collected over Omakere Ridge at the same time as the acquisition of the P-Cable 3D seismic dataset and a sidescan sonar dataset (Bialas, 2011). The 3D seismic survey involved racetrack shooting (see 


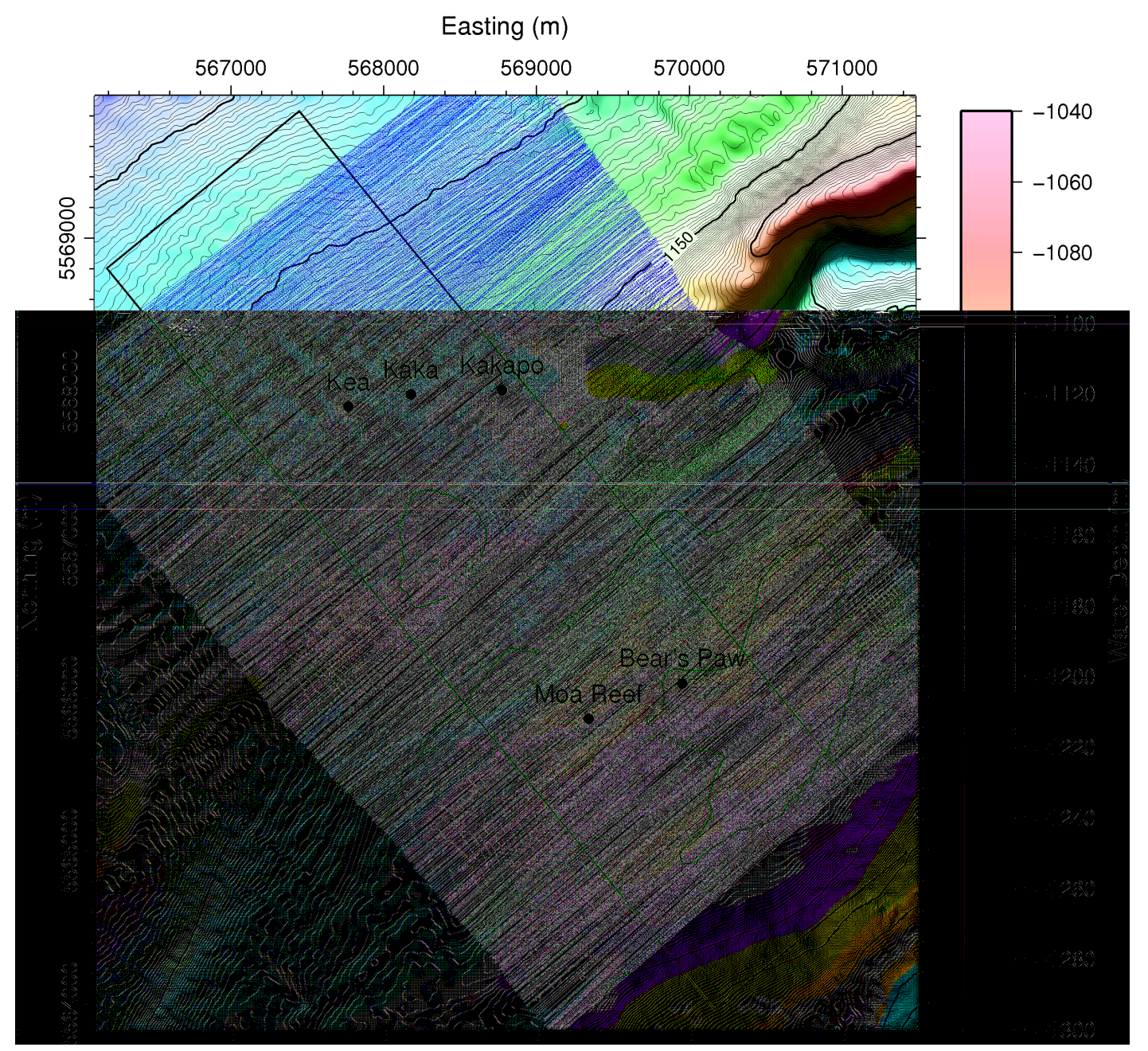

Figure 4.1: Swath coverage of an individual sonar transect. The location of the 3D seismic survey is shown as a reference (black rectangle). Each successive line of 191 blue dots represents the location of all 191 beams from an individual sounding on the seafloor. As the ship moved forward, successive soundings resulted in successive lines of readings. The multibeam system recorded both the depth and amplitude of the returned beams. 
Chapter 3), with long inlines perpendicular to the strike of the ridge. The majority of the sidescan sonar transects run parallel to the ridge. Overall, therefore, the multibeam sonar dataset comprises hundreds of transects such as the one depicted in Figure 4.1 over the study area, both perpendicular and parallel to the ridge's strike.

\subsection{Data Processing}

\subsubsection{Overview}

In order to produce an interpretable backscatter image over the study area, the data needed to be processed to account for $\mathrm{Tx} / \mathrm{Rx}$ amplitude effects and angular variation of backscatter with incidence angle, as discussed in Section 4.1. The processing was divided into separate bathymetry processing and backscatter processing phases. Both of these steps have been performed using the Fledermaus ${ }^{\mathrm{TM}}$ software suite. Because part of the backscatter processing sequence (determining the true beam incidence angles for correction of variation of backscatter with incidence angle) relied on having an accurate bathymetry grid, the bathymetry data were processed first. Once bathymetry-corrected, statistically-compensated sonar backscatter mosaics had been created in Fledermaus ${ }^{\mathrm{TM}}$, they were exported for additional processing using MATLAB ${ }^{\mathrm{TM}}$ scripts.

\subsubsection{Bathymetry}

The first stage in the bathymetry processing was to select a number of favourable transects over the study area to include in the bathymetry grid. The Fledermaus ${ }^{\mathrm{TM}}$ tool DMagic ${ }^{\mathrm{TM}}$ was used to plot all available transects, and a number of appropriate transects were identified and incorporated into the bathymetry grid. The raw bathymetry data, contained in the Kongsberg ${ }^{\mathrm{TM}}$.all files, contained a number of pings that recorded the seafloor depth erroneously. The bathymetry file was smoothed to a horizontal resolution of $10 \mathrm{~m}$ as a first step in removing noisy pings. The bathymetry file was then loaded into Fledermaus ${ }^{\mathrm{TM}}$ and anomalous pings were visually selected and removed from the dataset. Once all the erro- 
neous pings had been removed, the bathymetry grid was saved as a scalar grid file, which could be used to display the bathymetry of the study area and used in backscatter processing to determine the true angle of incidence of the sonar beams on the seafloor. The resulting bathymetry data are those seen in all detailed bathymetric maps of the Omakere Ridge study area presented in this thesis.

\subsubsection{Backscatter}

Once the bathymetry data had been processed, backscatter transects were chosen in DMagic ${ }^{\mathrm{TM}}$, ensuring they crossed over the target area. An important criterion for a good backscatter transect was that it did not include any ship turns. Backscatter data recorded during a ship turn is smeared-out and hinders interpretation (see Figure 4.2).
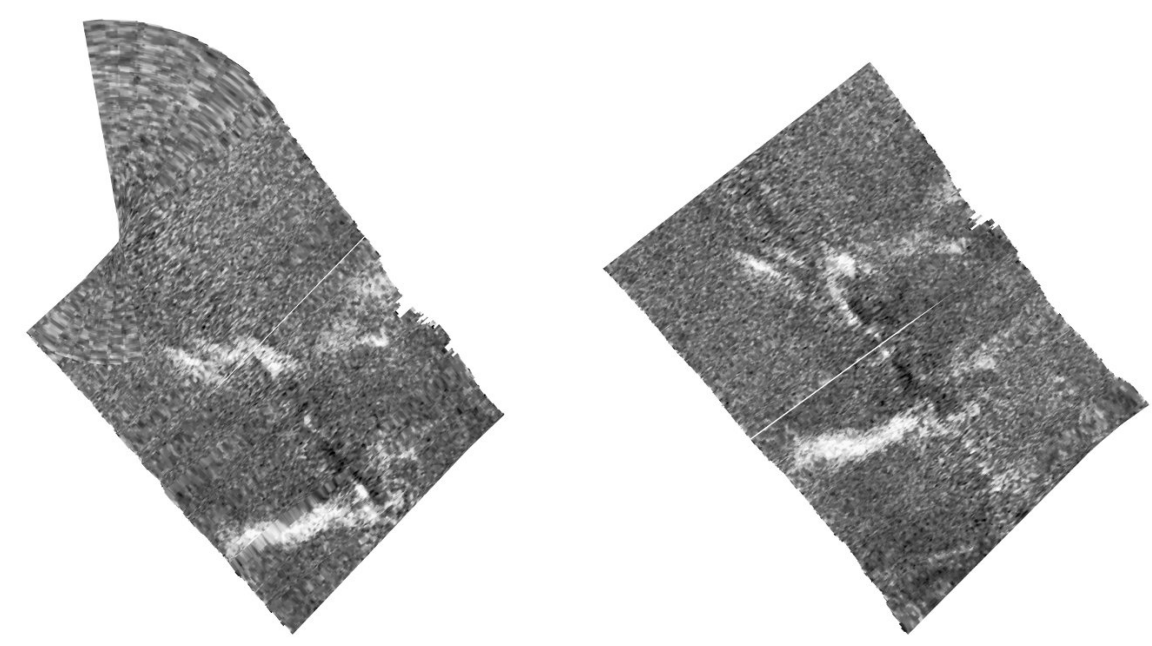

Figure 4.2: Omakere backscatter mosaics, showing the backscatter quality of a transect containing a ship turn (left) compared to a straight transect (right). This highlights the need to include only straight transects in backscatter mosaics.

Using FM Geocoder ${ }^{\mathrm{TM}}$, backscatter mosaics were created for each relevant transect and saved as screenshots for visual quality control. The highest-quality backscatter transects were identified and used in the final backscatter mosaics. The processing sequence employed for the backscatter data involved correcting 
for Tx/Rx amplitude variation based on a standard beam pattern for EM120 data, and the variation of backscatter with incidence angle, taking into account the bathymetry. This processing ensured that backscatter levels were statistically compensated across all beam angles, allowing the mosaics to be used for qualitative interpretation of the seafloor characteristics.

A common artifact that remains in many published sonar backscatter mosaics is the anomalous-backscatter normal-incident (nadir) beam, the effect of which is not entirely corrected for in backscatter processing sequences (e.g. Lamarche et al., 2011). This artifact commonly appears as a distinct line through the centre of a backscatter mosaic, parallel to the ship's direction of travel (Figure 4.2). The unwanted nadir artifact has been processed out of the Omakere Ridge backscatter mosaics, without resulting in any loss of seafloor backscatter coverage whatsoever. Because several tens of parallel backscatter transects were acquired, the Omakere Ridge multibeam backscatter dataset includes ample overlap between parallel multibeam transects to allow certain beam-angle ranges to be excluded from each transect. Only those beam angles of between $5^{\circ}$ and $55^{\circ}$ were included, and several parallel overlapping transects were combined to fill the gaps. Where the swaths overlapped, the average backscatter was calculated. In this way, seamless backscatter mosaics, without the nadir artifact, could be created for the entire area of interest, each constructed from two or three parallel transects (see Figure 4.4).

As previously mentioned, the racetrack shooting employed in the 3D seismic data acquisition resulted in several tens of parallel multibeam sonar transects being acquired over the seep sites. Six different sonar backscatter mosaics were created using the method described above, each from a different combination of parallel transects, using a total of 14 individual transects. Comparing the different backscatter mosaics over the seep sites allowed visual identification of the random noise present in each mosaic, which typically presented itself as a patch of anomalous high or low backscatter showing up in one mosaic but not others.

Each of the six sonar backscatter mosaics was mapped to the seismic CDP coordinate system to allow direct comparison with the seafloor seismic reflectivity data. One advantageous consequence of this was that six separate measurements 


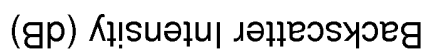

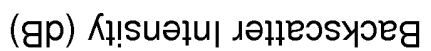

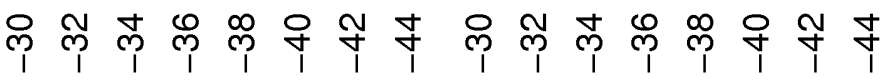

客

交范
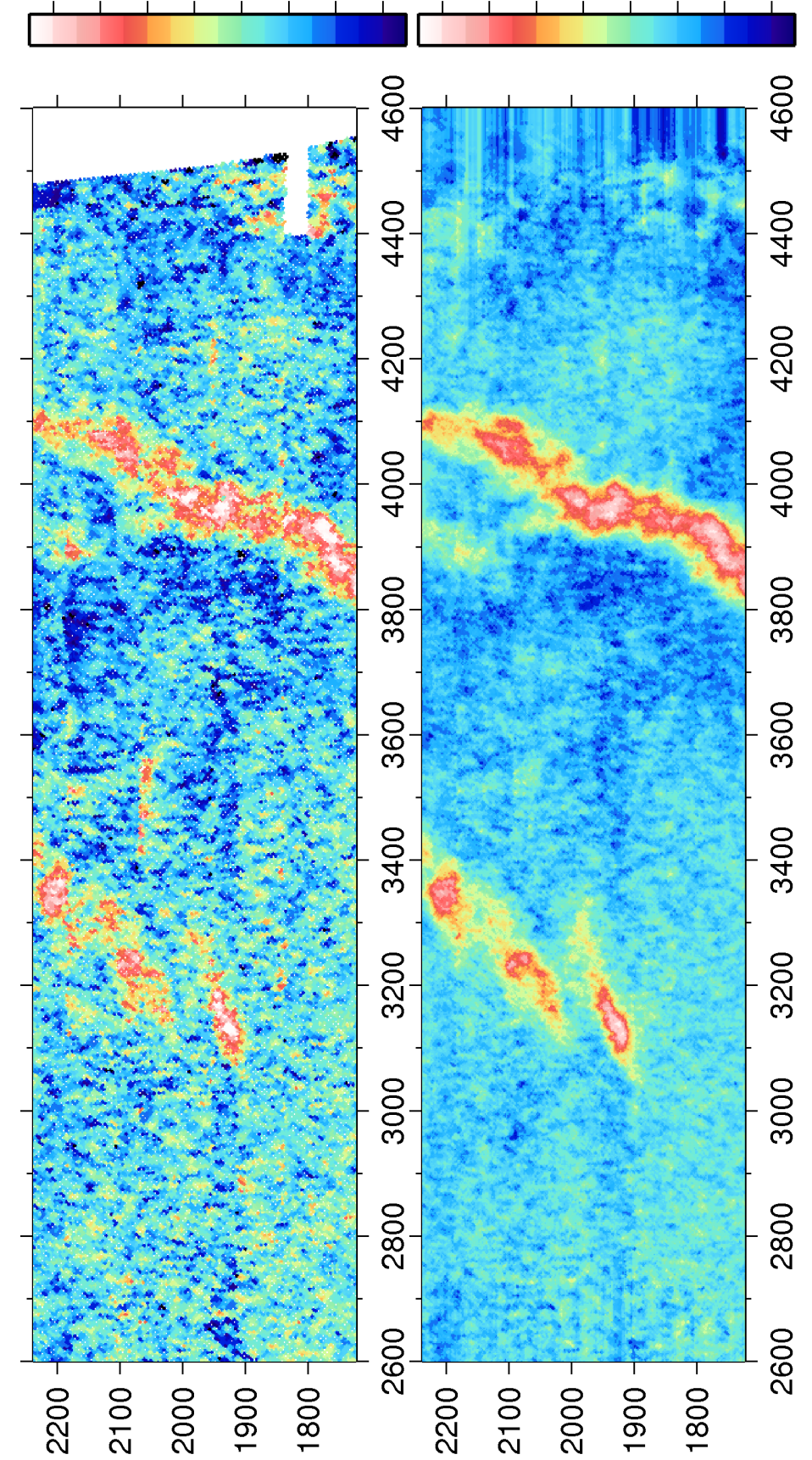

\&

$\stackrel{8}{+}$
ঃ
$\stackrel{+}{+}$
웅

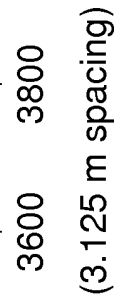

을

్ㅠ

चै ญ

के

.

ह

อั

苞

讨

웅

壱 స్తు

o 0

뭉 옹

㐫。

क त

$+5$

ठृ

$\overline{0}$

है

ชิ

(ब)

옹

원

.

ह

है

屯ี

䒕

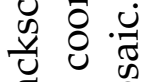

ลิ है

츨 즐

कิ

졸

웡

$\exists . \Xi$

लें है ठठ

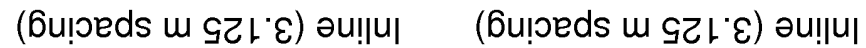


of sonar backscatter were assigned to each CDP location. By taking the average backscatter value at each CDP, a method akin to the well-established CDP stacking method used in seismic reflection processing was achieved. In effect, the six backscatter mosaics were stacked, yielding a six-fold sonar backscatter mosaic stack. The advantage of the stacking method is that it attenuates random noise while enhancing the signal. There is however a trade-off in that spatial resolution is somewhat decreased. The stacked backscatter mosaic exhibits much higher signal to noise ratio and is overall a more interpretable dataset than any one of the individual backscatter mosaics. The improvement of the stacked backscatter mosaic over an individual backscatter mosaic is illustrated in Figure 4.3.

\subsection{Results}

\subsubsection{Overview}

The stacked multibeam backscatter mosaic over the Kea, Kaka, Kakapo, Moa and Bear's Paw sites shows all seep sites as regions of high backscatter intensity compared to the surrounding seafloor. Some regions of steep bathymetric slope exhibit high backscatter, whereas others do not. This indicates that the bathymetry correction applied during the backscatter processing is working correctly, and that some areas of high bathymetric slope are hard and/or rough and therefore strong backscatterers. The Kea, Kaka and Kakapo seeps have a pronounced elongate shape oriented in a WNW-ESE direction, with higher backscatter intensity near their centres, which decreases towards either end of each seep. The Moa and Bear's Paw sites appear as more continuous patches of high sonar backscatter (Figure 4.4). To help quantify the backscatter intensity at each seep site, CDP percentage plots were created for areas encompassing the regions of elevated backscatter intensity at each seep site (Figure 4.5). The backscatter characteristics at each seep are described in detail below.

\subsubsection{Bear's Paw}

The Bear's Paw seep appears as a region of high sonar backscatter intensity compared to the surrounding seafloor, which is elongate in an E-W direction (Figure 4.4). Backscatter intensity at Bear's Paw ranges from $-38.5 \mathrm{~dB}$ to $-30.9 \mathrm{~dB}$ (Figure 


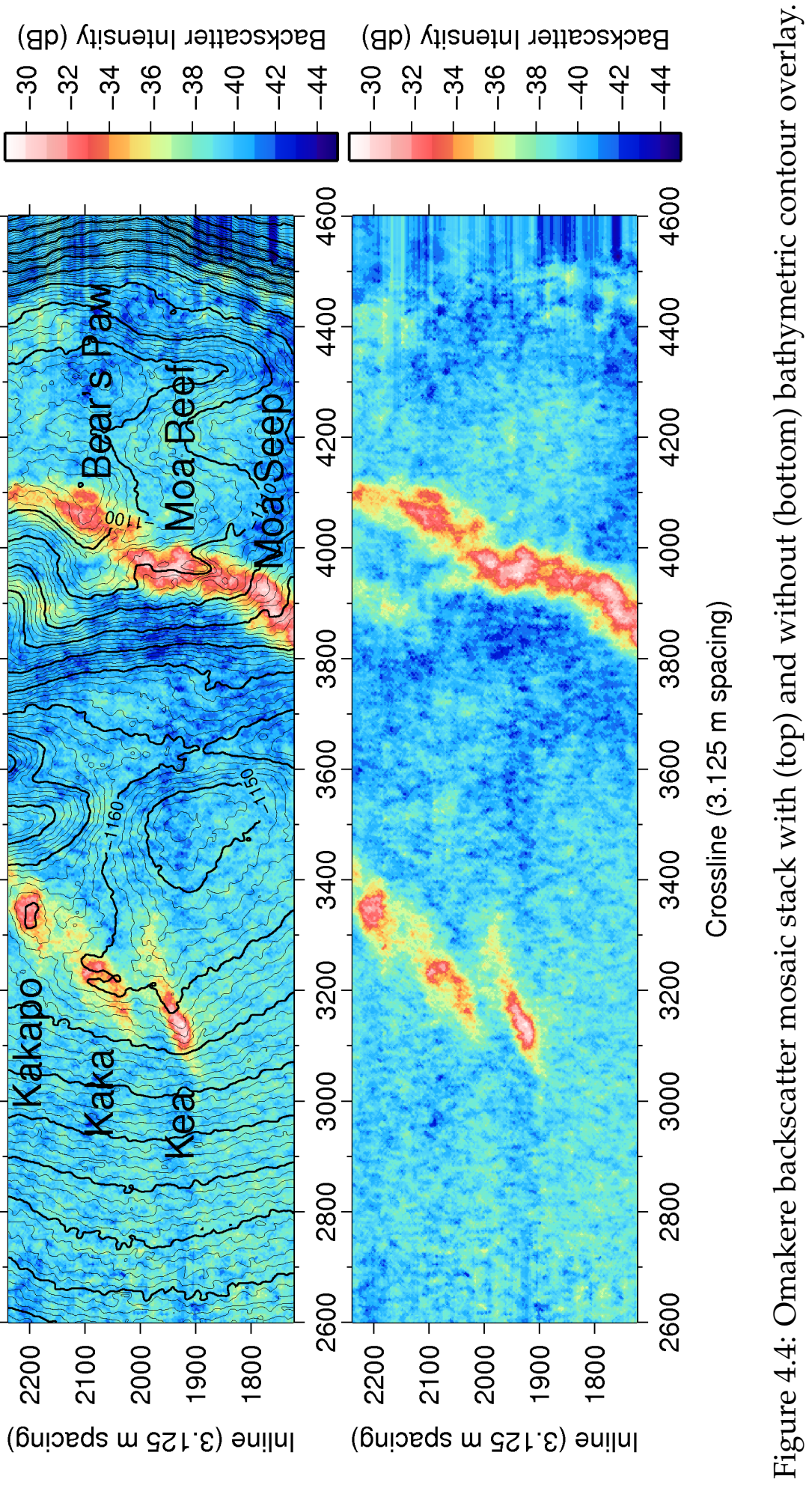




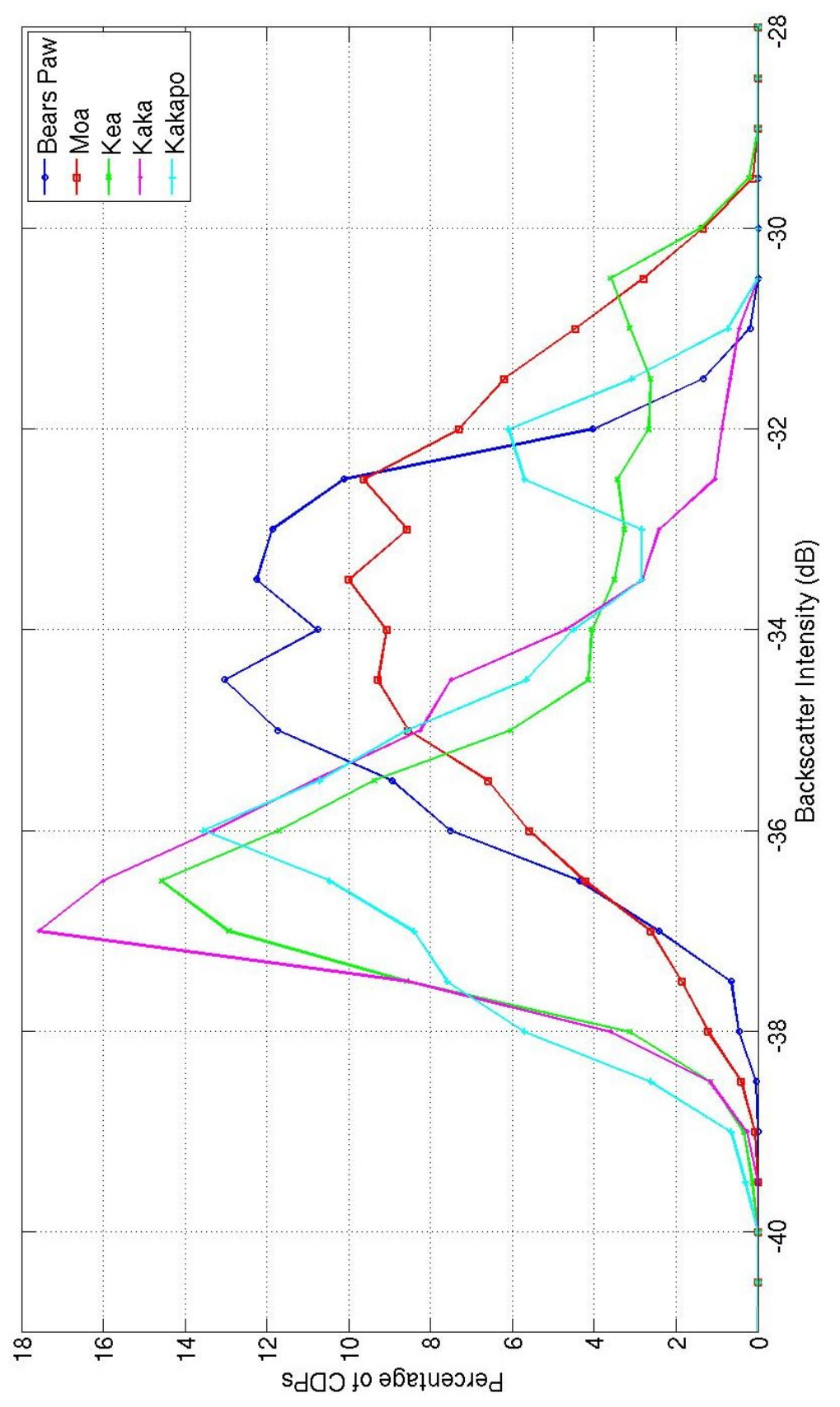

$\pi$
0
0
0
0
0

D.

ت゙્

这

$\stackrel{乛}{ \pm}$

草

을

छิ

ป

$+$

:

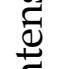

.

㐫

氙

บิ

\%

Ғ है

跣

롷

可

$\circ$ v

क :

ष्ट

항

은

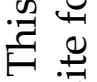

ம்

+

总 
4.5). The region of high sonar backscatter at Bear's paw is approximately $600 \mathrm{~m}$ long and $400 \mathrm{~m}$ wide at its widest point. The shape of this feature looks more like a crab's claw than a bear's paw (Figure 4.4).

\subsubsection{Kea}

Kea is characterised by a region of high sonar backscatter intensity compared to the surrounding seafloor. Backscatter intensity values at Kea range from $-39.5 \mathrm{~dB}$ to $-29.5 \mathrm{~dB}$ (Figure 4.5 ). The region of high backscatter has a very well-defined elongate shape, with the elongation oriented in a WNW-ESE direction and the highest backscatter intensity occurring in a continuous patch at the northwestern end of the feature. The region of high backscatter intensity is approximately $1 \mathrm{~km}$ long and is less than $200 \mathrm{~m}$ wide at its widest point in the very-high-backscatter zone in the northwestern part of the feature (Figure 4.4).

\subsubsection{Kaka}

The seafloor at Kaka exhibits high sonar backscatter intensity compared to the surrounding seafloor. Like Kea, the region of high backscatter intensity at Kaka is elongate in a WNW-ESE direction, with backscatter intensity values ranging from $-39.2 \mathrm{~dB}$ to $-30.8 \mathrm{~dB}$ (Figure 4.5). The centre of Kaka exhibits higher backscatter than the west-northwest and east-southeast ends of the feature. The region of high backscatter intensity is approximately $800 \mathrm{~m}$ long and $200 \mathrm{~m}$ wide at its widest point towards the centre of the feature (Figure 4.4).

\subsubsection{Kakapo}

The Kakapo seep is characterised by a region of high sonar backscatter intensity compared to the surrounding seafloor, with backscatter intensity values ranging from $-39.7 \mathrm{~dB}$ to $-30.8 \mathrm{~dB}$ (Figure 4.5). Like the Kea and Kaka sites, this region of high backscatter intensity is elongate in a WNW-ESE direction and backscatter is highest at the centre of the feature. The region of high backscatter intensity at Kakapo is approximately $600 \mathrm{~m}$ long and $200 \mathrm{~m}$ wide at its widest point towards the centre of the feature (Figure 4.4). 


\subsubsection{Moa Reef}

The Moa Reef is characterised by a region of high backscatter intensity compared to the surrounding seafloor, with backscatter intensity values ranging from -38.75 $\mathrm{dB}$ to $-29.5 \mathrm{~dB}$ (Figure 4.5). The region of high backscatter intensity is elongate in a SW-NE orientation and is approximately $800 \mathrm{~m}$ long and $300 \mathrm{~m}$ wide (Figure $4.4)$. 


\section{Chapter 5}

\section{Parasound}

\subsection{Acquisition}

Parasound ${ }^{\mathrm{TM}}$ sonar data were acquired continuously throughout the cruise, meaning they were collected simultaneously with the 3D seismic and multibeam backscatter datasets. The Parasound ${ }^{\mathrm{TM}}$ sub-bottom profiling system uses the parametric effect to create a narrow-beam $4 \mathrm{kHz}$ source signal from the simultaneous emission of an $18 \mathrm{kHz}$ signal and a $22 \mathrm{kHz}$ signal. The $4 \mathrm{kHz}$ signal is generated within the beam-spreading cone of the higher frequency signals, resulting in a 4 $\mathrm{kHz}$ beam with much smaller side-lobes than a standard $4 \mathrm{kHz}$ acoustic signal (Grant and Schreiber, 1990; Mosher and Simpkin, 1999). The beam-spreading angle for this dataset is approximately $4^{\circ}$ (Bialas, 2011). The advantage of this method is that unwanted out-of-plane reflections from the sides of a transect are reduced. The disadvantage is that because of the narrow spread of the beam, bathymetric slopes of much more than $4^{\circ}$ are not very well imaged as the entire beam is reflected away from the receiver. Therefore, amplitude information in areas where the seafloor is not very flat is unreliable. During shipboard processing, the $4 \mathrm{kHz}$ secondary signal was separated out from the primary $18 \mathrm{kHz}$ and $22 \mathrm{kHz}$ signals by the shipboard processing sequence, resulting in a dataset with a band-limited, 2-6 kHz sinusoidal wavelet with a dominant frequency of $4 \mathrm{kHz}$ (Bialas, 2011). The system recorded data continuously, saving a new file at the end of each day for both the $18 \mathrm{kHz}$ and $4 \mathrm{kHz}$ frequencies. The $4 \mathrm{kHz}$ dataset imaged the subsurface to a depth of $100 \mathrm{~m}$, while the $18 \mathrm{kHz}$ dataset imaged the water column. Only the $4 \mathrm{kHz}$ dataset is presented in this thesis. 


\subsection{Processing}

Each day's raw Parasound ${ }^{\mathrm{TM}}$ file was converted into SEGY (standard format for seismic data) format on board. The post-cruise processing that has been applied to the raw $4 \mathrm{kHz}$ SEGY files for each day involved the following steps and is a slight modification of the processing sequence described in Bialas (2011):

- segmentation of the daily SEGY files into separate SEGY files of 5000 traces;

- conversion of coordinates from arc milliseconds to UTM Zone 60S;

- application of a bandpass filter (2200-10000 kHz);

- application of Hilbert transform to convert to instantaneous amplitude;

- application of a despiking filter.

This was achieved using a combination of Seismic Unix ${ }^{\mathrm{TM}}$ and Globe Claritas ${ }^{\mathrm{TM}}$. Once this processing sequence had been applied to all the relevant Parasound ${ }^{\mathrm{TM}}$ data, the 5000-trace SEGY files were displayed in three dimensions with OpenDtect ${ }^{\mathrm{TM}}$. The majority of the SEGY files looped around the survey area several times, following the ship's path during 3D seismic acquisition. The Parasound ${ }^{\mathrm{TM}}$ data were further segmented into discrete lines over the study area to allow for the best display, analysis and interpretation of the data. A total of 43 such Parasound ${ }^{\mathrm{TM}}$ lines were created over the study area (locations shown in Figure 5.1). Once the data were segmented into lines, they were converted into geo-referenced image files (using Globe Claritas ${ }^{\mathrm{TM}}$ ) that could be displayed simultaneously with bathymetry, sonar backscatter and seismic reflection coefficient using Fledermaus ${ }^{\mathrm{TM}}$. By displaying the Parasound ${ }^{\mathrm{TM}}$ lines simultaneously with bathymetry, backscatter and reflection coefficient, the exact location of the seep sites could be identified on the Parasound ${ }^{\mathrm{TM}}$ lines, allowing more confident interpretation. Figure 5.2 shows how this was achieved.

\subsection{Results}

\subsubsection{Overview}

The processed Parasound ${ }^{\mathrm{TM}}$ transects reveal the shallow sub-seafloor acoustic reflection characteristics in the study area at a very high-resolution. With a $4 \mathrm{kHz}$ 


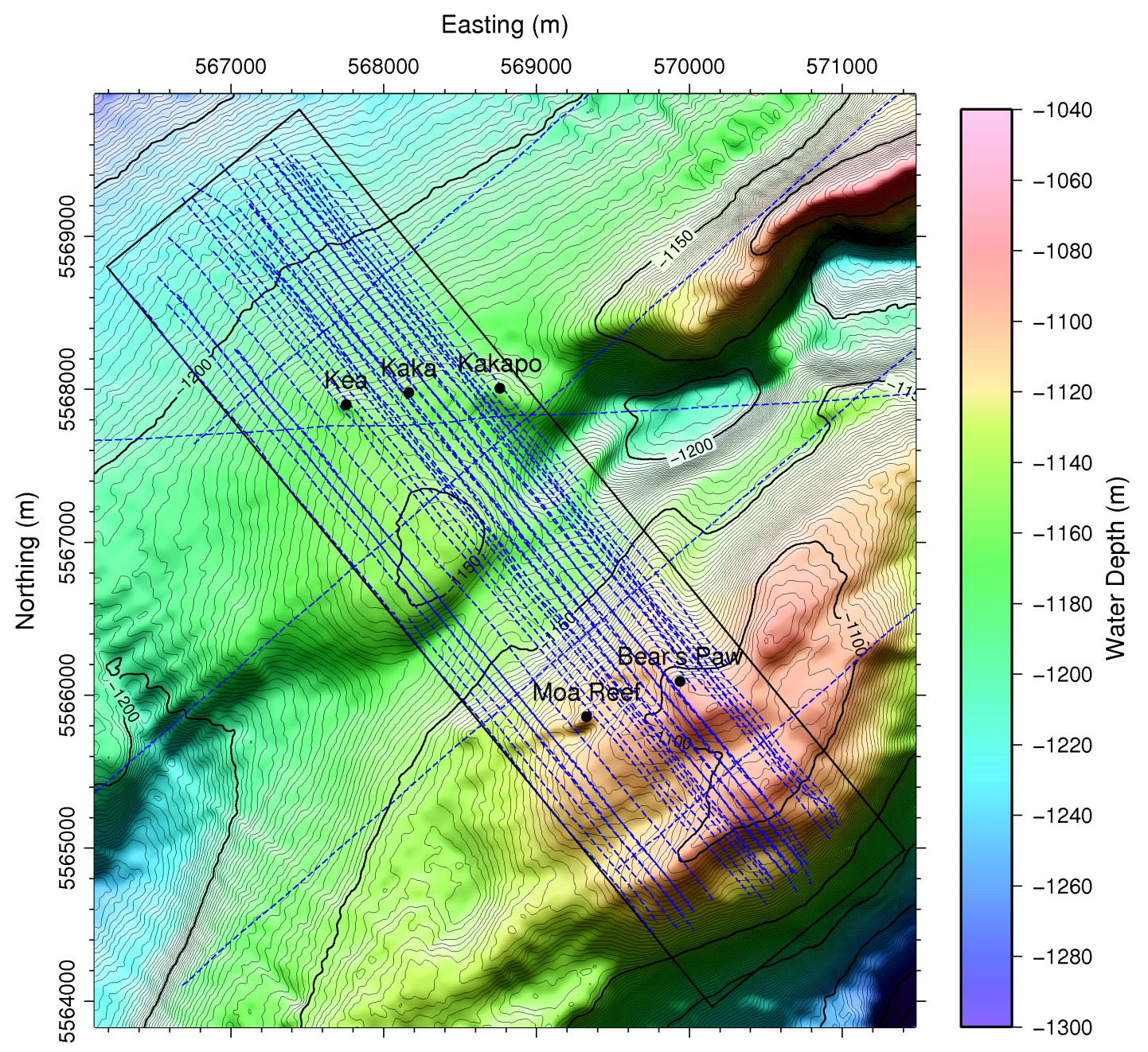

Figure 5.1: Map showing the locations (in blue) of all 43 processed Parasound ${ }^{\mathrm{TM}}$ lines over the study area. 

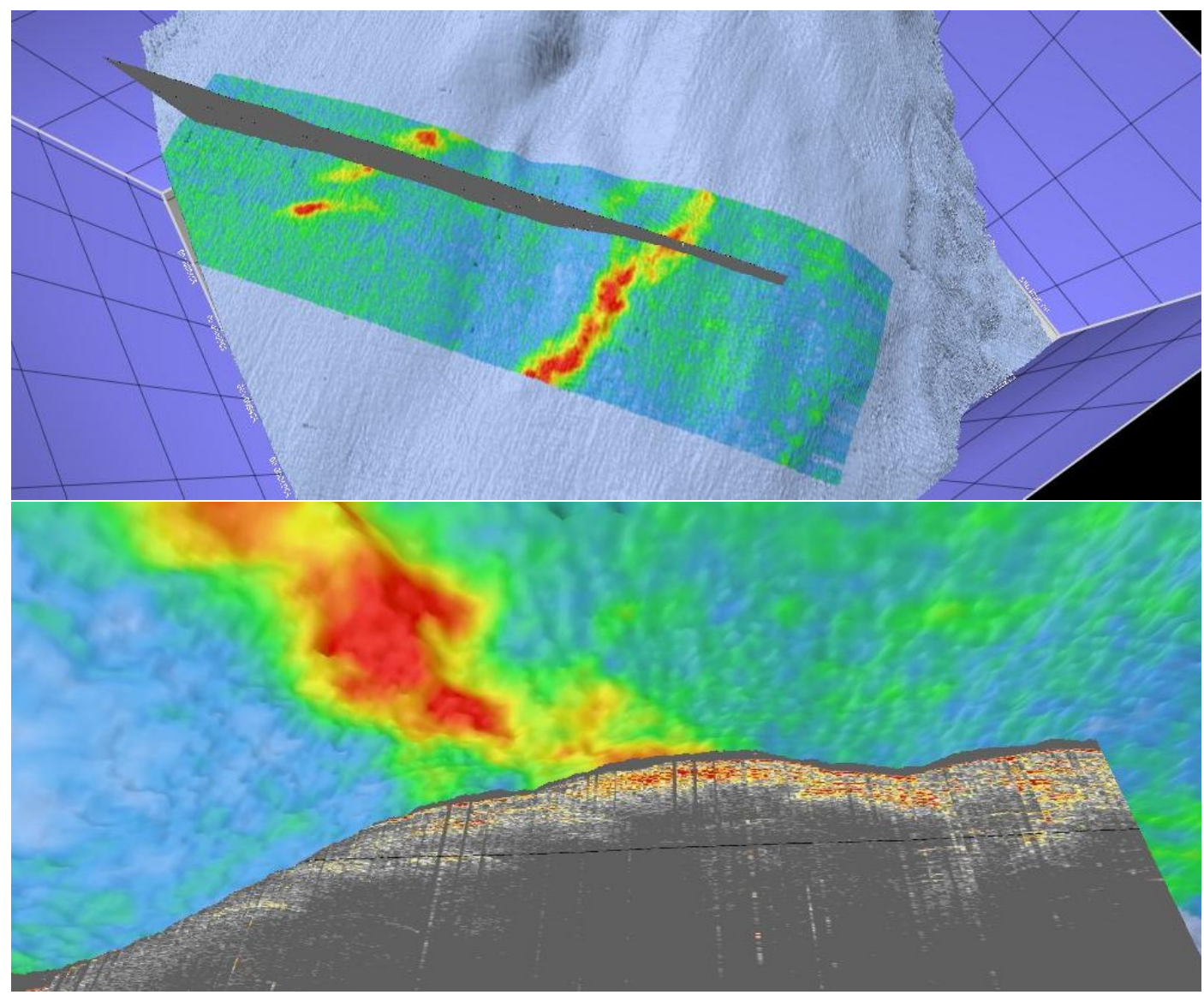

Figure 5.2: 3D visualisation of a Parasound ${ }^{\mathrm{TM}}$ transect and sonar backscatter intensity draped over seafloor bathymetry from above (top) and from below (bottom) using Fledermaus ${ }^{\mathrm{TM}}$. This Parasound ${ }^{\mathrm{TM}}$ transect crosses through Bear's Paw. Displaying the Parasound ${ }^{\mathrm{TM}}$ line and sonar backscatter simultaneously allows accurate location of the seep sites on the Parasound ${ }^{\mathrm{TM}}$ line. 
dominant frequency, features down to a vertical scale of $10 \mathrm{~cm}$ could theoretically be imaged (one quarter of the seismic wavelength at $1500 \mathrm{~m} / \mathrm{s}$ ), with depth penetration of up to $100 \mathrm{~m}$ where the seafloor is flat (see Figures 5.4, 5.5 and 5.6). Anomalous reflection characteristics have been observed beneath all the seep sites and are described in the following sections.

\subsubsection{Bear's Paw}

Parasound $^{\mathrm{TM}}$ sections through Bear's Paw reveal an extensive zone of high-amplitude reflections very close to the seafloor. The top of this high-amplitude zone extends to the seafloor, while the thickness of the zone is up to $10 \mathrm{~m}$ assuming a velocity of $1500 \mathrm{~m} / \mathrm{s}$ in the near-seafloor sediments. This high-amplitude feature is very similar to the high-amplitude feature beneath Kaka and Kakapo described below. Below the zone of high-amplitude reflections at Bear's Paw, not much signal is returned (Figure 5.5).

\subsubsection{Kea}

Kea is characterised by a localised high-amplitude patch near the seafloor, which exhibits a domed morphology at the seafloor. This high-amplitude patch is underlain by a distinctive, blanked zone, into which coherent reflections from sediment horizons are abruptly attenuated (Figure 5.4).

\subsubsection{Kaka}

Kaka is characterised by some diffractions / side reflections above higher-amplitude reflections close to the seafloor. These high-amplitude reflections are underlain by a thin low-amplitude zone, which is underlain by a much larger, more continuous zone of high-amplitude reflections. This zone of high-amplitude reflections is offset to the southeast of the seep location, and is underlain by a pronounced blank zone (Figure 5.5).

\subsubsection{Kakapo}

Parasound ${ }^{\mathrm{TM}}$ lines through Kakapo exhibit a patch of high-amplitude reflections near the seafloor, underlain by a thin low-amplitude zone, underlain by the same 


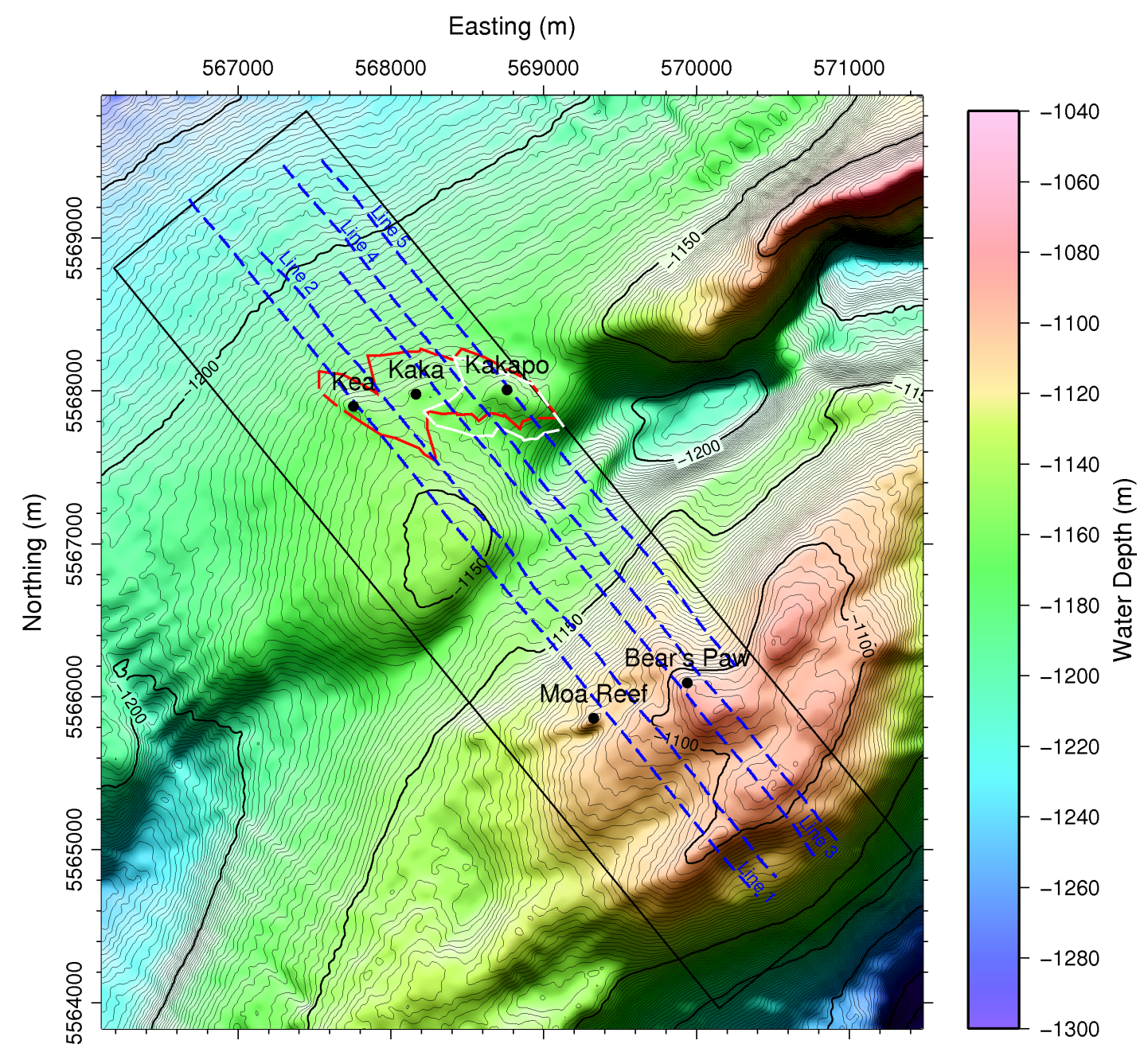

Figure 5.3: Bathymetric map showing the location of the five key Parasound ${ }^{\mathrm{TM}}$ lines through the seep sites. The red polygon marks the lateral extent of the blanked zone beneath Kea, Kaka and Kakapo at 25 ms TWT (see Figures 5.4, 5.5 and 5.6). The white polygon marks the lateral extent of the high-amplitude band beneath Kaka and Kakapo (see Figures 5.5 and 5.6). 

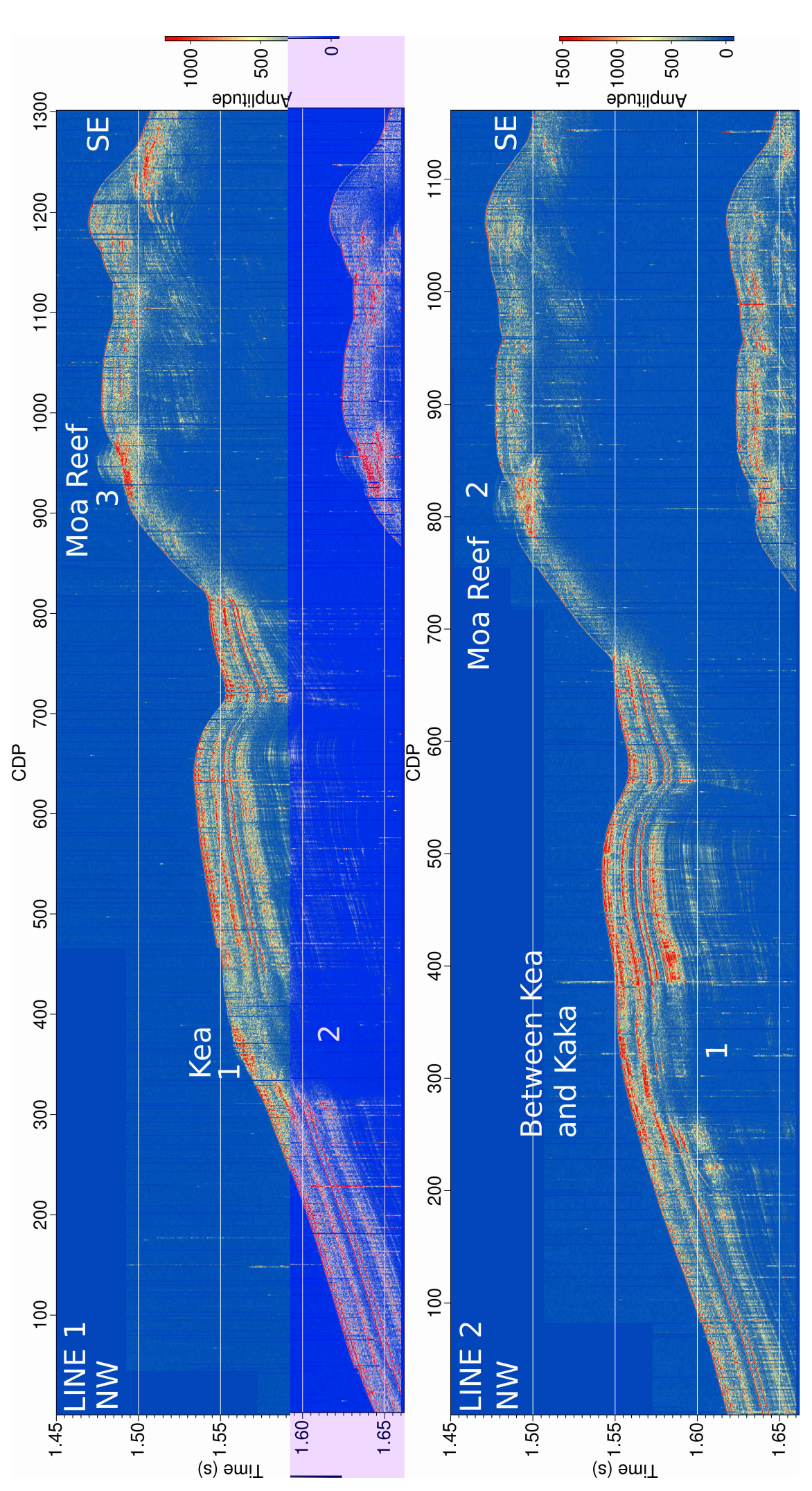

กิ उ. 웡 1 ข Q ¿ ए

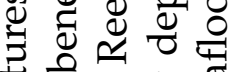

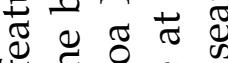
○ ర

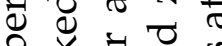

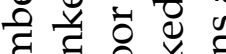

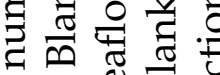
ᄃ $\widehat{\infty}$ 茫焉

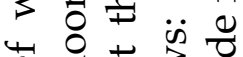
ष 뚀 $⿻$ 을 워 $\sum \pm \frac{d}{\pi} d \frac{1}{4}$ ¿ $\approx \stackrel{0}{0.00}$

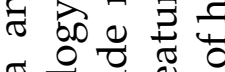
ஐ 0 원 $\forall$ 듬 듀유 ڤ उ छ त ठ

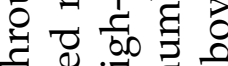
$\mp$ E્

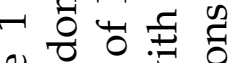
\& 3. 寻吉起范 $\sum$ 记

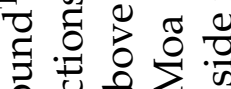
ठ प क्षै क्षै की ‡ ㅇ 0 웅 入

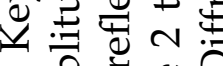
령

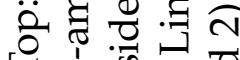
$\cdots$ क ㅂ. ம Ð

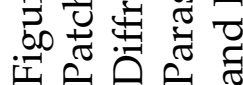



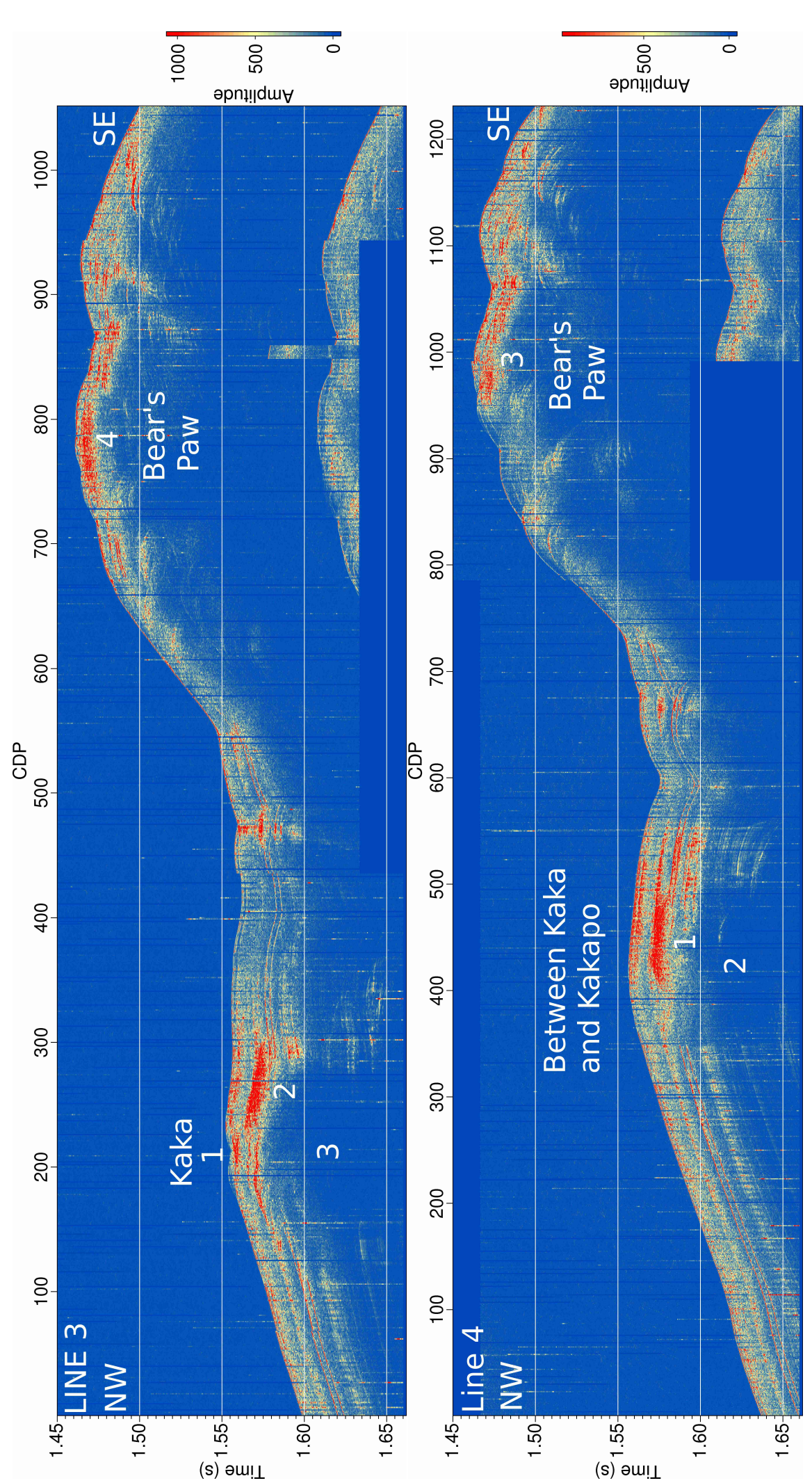

矛点矛芯

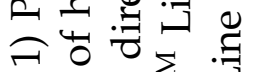

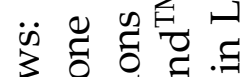

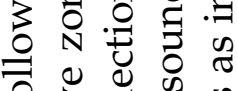

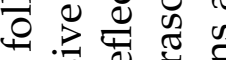

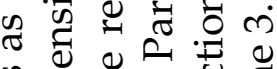
\& 妾

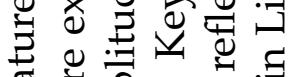
む రิ

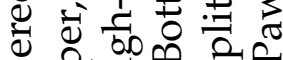
है छै.

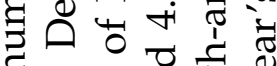
ปิ 䨌 3 ป $3 \underline{Z} \cong \approx$

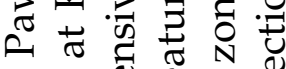

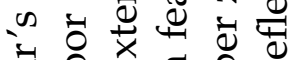
ฮี ० ๑ ฐ

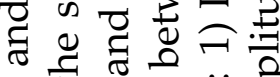
च \pm 五 光

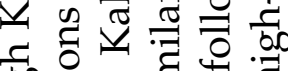

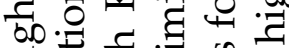

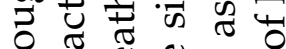

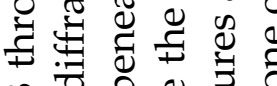
m 0 O Ð き

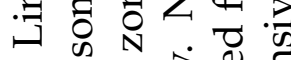
$\sum-0$ ¿ ठ ठ $\exists$ a 응 ฮี

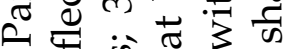
बे ट्ञ है के 讨 2. 을 क्षे के ஸ் छ ம

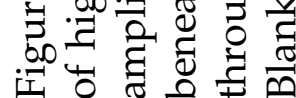




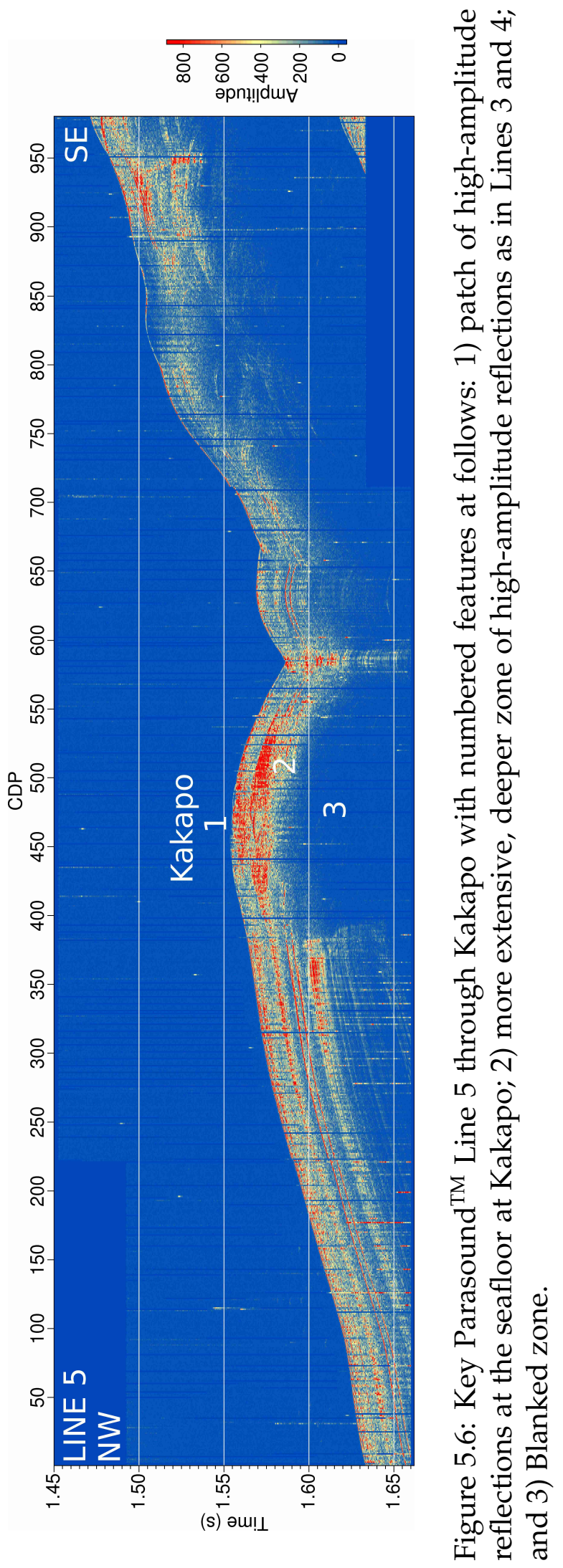


extensive zone of high-amplitude reflections observed beneath Kaka. Like at Kaka, this zone of high-amplitude reflections is underlain by a pronounced blanked zone (Figure 5.6).

\subsubsection{Moa Reef}

Through Moa Reef, Parasound ${ }^{\mathrm{TM}}$ lines reveal diffractions/side reflections above a localised patch of high-amplitude reflections at the seafloor and in the shallow subsurface. Below this patch of high-amplitude reflections, not much signal is returned (Figure 5.4).

\subsubsection{Blanked zone beneath Kea, Kaka and Kakapo}

The blanked zone beneath Kea, Kaka and Kakapo has been mapped to its full extent at 25 ms TWT below the seafloor reflection on all available Parasound ${ }^{\mathrm{TM}}$ lines. Its spatial extent is shown in Figure 5.3. The extent of the blanked zone in map view is greatest where the seep sites are centred and narrows in the regions between the seeps. A distinctive feature of the blanked zone is that coherent reflections from sediment horizons abruptly disappear in the blanked zone.

\subsubsection{Zone of high-amplitude reflections beneath Kaka and Kakapo}

The map-view extent of the high-amplitude reflection zone beneath Kaka and Kakapo is also shown in Figure 5.3. The feature is centred below the Kakapo seep and extends westward, to the south of the centre of seepage at Kaka. This feature is characterised by a zone of many individual high-amplitude reflections, that together create a distinctive high-amplitude feature in the Parasound ${ }^{\mathrm{TM}}$ sections (Figure 5.5). The top of this high-amplitude zone lies approximately $10 \mathrm{~m}$ below the seafloor and has a vertical thickness ranging from 5-10 m, assuming a velocity of $1500 \mathrm{~m} / \mathrm{s}$ in the near-seafloor sediments. It is very similar in character and spatial extent to the zone of high-amplitude reflections directly beneath the seafloor at Bear's Paw described above. 


\section{Chapter 6}

\section{Comparison of datasets}

\subsection{Summary of results}

This chapter draws together the results of Chapters 3,4 and 5. An overview of the results presented in these three chapters is provided first in this section for each seep site and includes a summary of the main observations at each seep site in Table 6.1. Section 6.2 then discusses the implications of these results in relation to authigenic carbonate build-ups at the seeps, subsurface gas distribution and fluid migration pathways, subsurface gas hydrates and the chronology of seepage at Omakere Ridge.

\subsubsection{Bear's Paw}

In contrast to the high seafloor seismic reflection coefficient of the other seep sites, Bear's Paw is characterised by a region of low reflection coefficient patches, with values similar to or lower than the surrounding seafloor. Some high reflection coefficient patches do exist towards the eastern end of the feature (Figure 6.1). This seep site appears as a region of high sonar backscatter intensity compared to the surrounding seafloor, which is elongate in an E-W direction. The region of high sonar backscatter at Bear's paw is approximately $600 \mathrm{~m}$ long and $400 \mathrm{~m}$ wide at its widest point (Figure 6.1). The maximum sonar backscatter intensity values reached at Bear's Paw are lower than the maximum values reached at all the other seeps. The seafloor at Bear's Paw is characterised by low seismic similarity over the same region that exhibits low reflection coefficient and elevated 


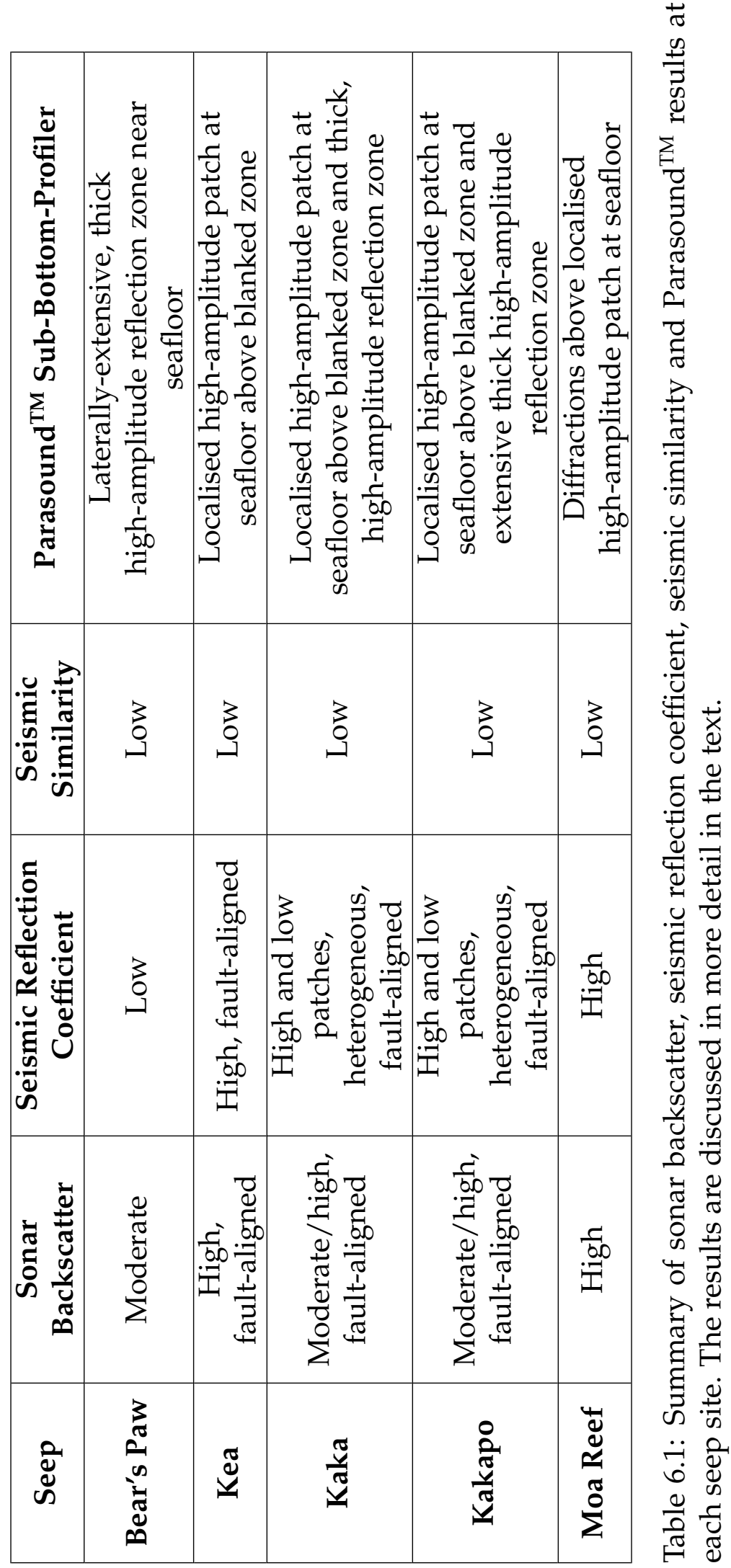


sonar backscatter (Figure 6.1). In the Parasound ${ }^{\mathrm{TM}}$ data, Bear's Paw is underlain by a laterally-extensive and vertically-thick (up to $10 \mathrm{~m}$ ) zone of high-amplitude reflections. Individual reflections within this high-amplitude zone are not laterally continuous. Rather, this zone appears to be comprised of a vast number of individual, separate reflections within a wider zone of distinct lateral and vertical extent (see Figure 5.5 in Chapter 5). The preliminary 3D seismic inline through Bear's Paw reveals a narrow vertical zone of disturbed reflectivity below the seep. The bottom of this disturbed zone is not visible, as it continues to the depth where the amplitude of the returned signal is too low to detect reflections. Shallow reflection horizons beneath Bear's Paw and further to the west are truncated and vertically offset by extensional faults (see Figure 3.15 in Chapter 3).

\subsubsection{Kea}

Kea appears as a reasonably continuous high reflection coefficient feature with some irregularities, and is elongate in a WNW-ESE direction. The reflection coefficient is highest towards southwestern end of the feature (Figure 6.1). This seep is characterised by a region of high sonar backscatter intensity compared to the surrounding seafloor. This region of high backscatter intensity has a very well-defined elongate shape, with the elongation oriented in a WNW-ESE direction and the highest backscatter intensity occurring in a continuous patch at the northwestern end of the feature (Figure 6.1). Kea exhibits low seismic similarity, elongate in a WNW-ESE orientation over the same region that exhibits anomalous seafloor seismic reflection coefficient and high sonar backscatter intensity (Figure 6.1). In the Parasound ${ }^{\mathrm{TM}}$ data, Kea is characterised by a localised highamplitude patch near the seafloor. This small high-amplitude patch is underlain by a distinctive blanked zone (Figure 5.4 in Chapter 5). The preliminary 3D seismic inline selected through Kea reveals a narrow vertical zone of anomalous reflectivity below the seep site, which extends down into a zone of high-amplitude reflections deeper in the subsurface. This zone of deep high-amplitude reflections has an antiformal shape and is directly overlain by a zone of low amplitude response (see Figure 3.14 in Chapter 3). 


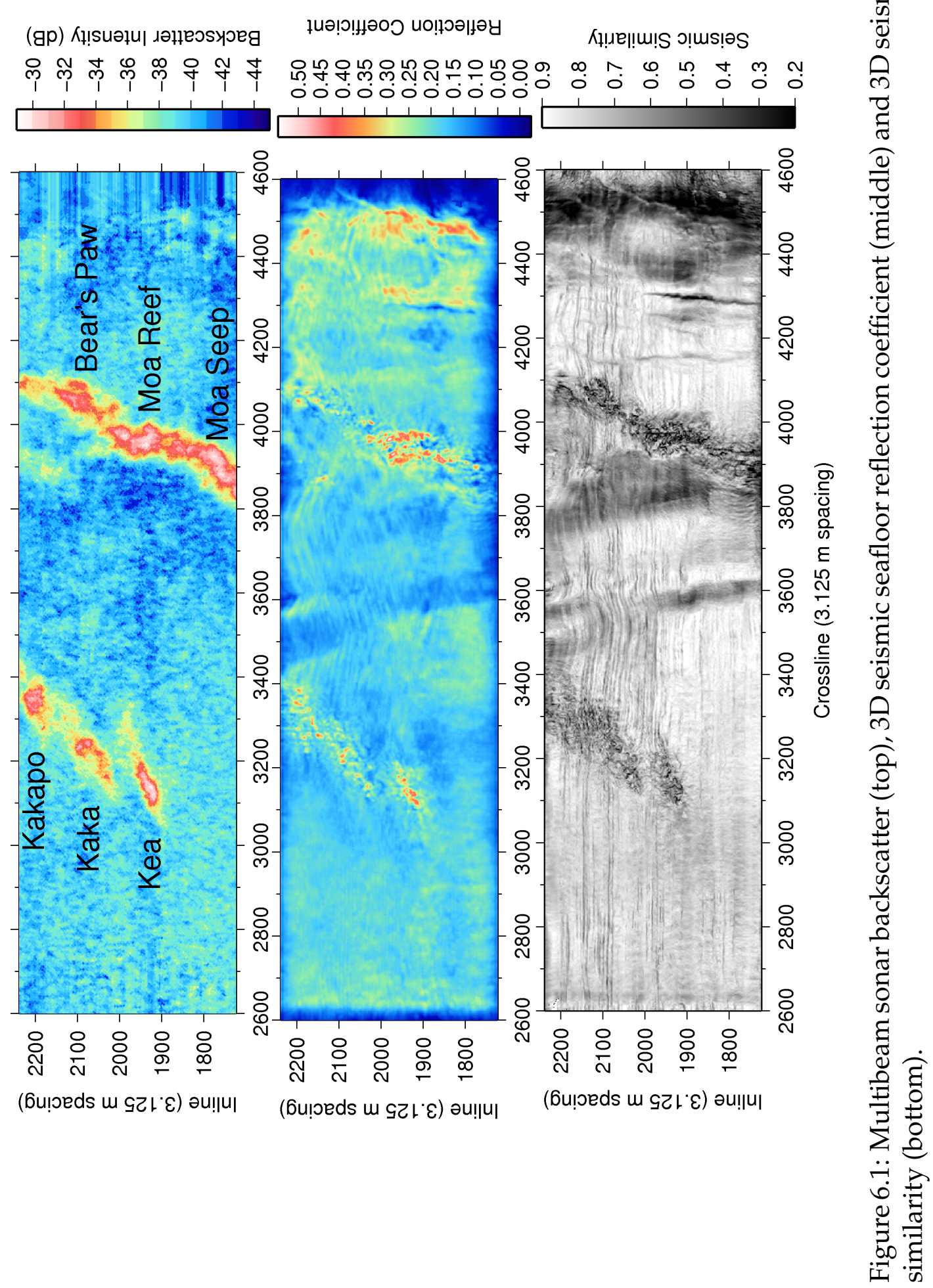




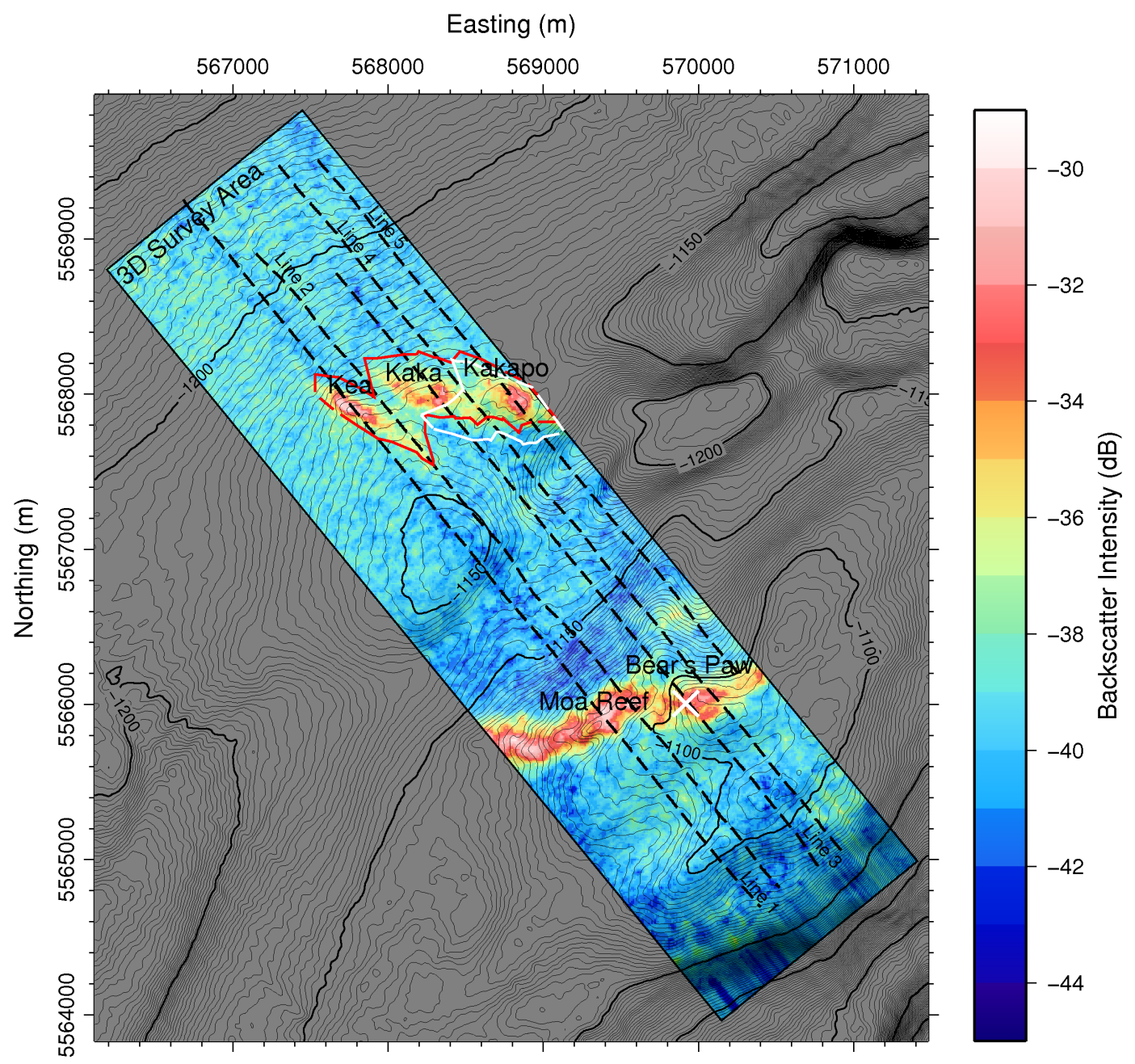

Figure 6.2: Sonar backscatter draped over bathymetry showing the location of the five key Parasound ${ }^{\mathrm{TM}}$ lines through the seep sites. The red polygon marks the lateral extent of the blanked zone beneath Kea, Kaka and Kakapo at $25 \mathrm{~ms}$ TWT (see Figures 5.4, 5.5 and 5.6 in Chapter 5). The white polygon marks the lateral extent of the high-amplitude reflection zone beneath Kaka and Kakapo (see Figures 5.5 and 5.6 in Chapter 5). These two features were mapped on all available Parasound ${ }^{\mathrm{TM}}$ lines. The white cross marks the location where gas hydrates were recovered at a depth of $1 \mathrm{~m}$ below the seafloor in 2007 (Bialas et al., 2007). 


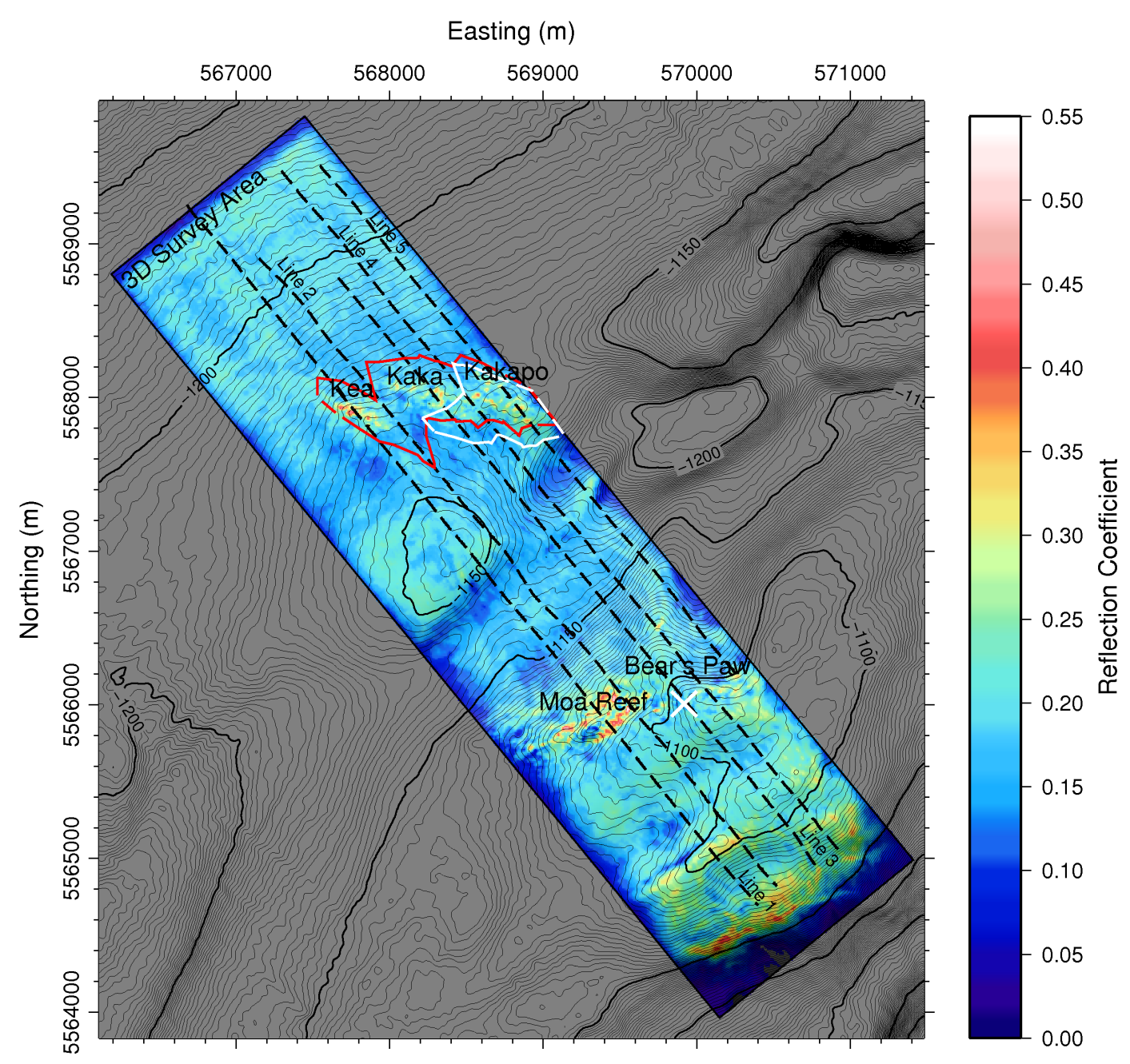

Figure 6.3: Seismic reflection coefficient draped over bathymetry showing the location of the five key Parasound ${ }^{\mathrm{TM}}$ lines through the seep sites. The red and white polygons and the cross are as described in Figure 6.2. 


\subsubsection{Kaka}

Kaka is manifest as a region of irregular high-reflection coefficient patches with an overall elongation in a WNW-ESE direction in the 3D seismic data. The highreflection coefficient patches are of highest amplitude towards the centre of the feature, where they are accompanied by conspicuous low amplitude patches (Figure 6.1). The seafloor at Kaka exhibits high sonar backscatter intensity compared to the surrounding seafloor. Like Kea, the region of high backscatter intensity at Kaka is elongate in a WNW-ESE direction. The centre of Kaka exhibits higher backscatter than the west-northwest and east-southeast ends of the feature (Figure 6.1). Kaka is characterised by low seismic similarity elongate in a WNW-ESE orientation over the same region that exhibits anomalous seafloor seismic reflection coefficient and high sonar backscatter intensity (Figure 6.1). Kaka is characterised by some diffractions/side reflections above higher-amplitude reflections close to the seafloor in the Parasound ${ }^{\mathrm{TM}}$ data. These high-amplitude reflections are underlain by a thin low-amplitude zone, which is underlain by a much larger, more continuous high-amplitude feature, offset to the southeast of the seep location. This larger, deeper high-amplitude feature is underlain by a pronounced blanked zone (see Figure 5.4 in Chapter 5). The preliminary 3D seismic inline selected through Kaka reveals a narrow vertical zone of anomalous reflectivity below the seep site, which extends down into a zone of high-amplitude reflections deeper in the subsurface. This zone of deep high-amplitude reflections is similar in character to the one beneath Kea described above (see Figure 3.15 in Chapter 3).

\subsubsection{Kakapo}

Kakapo is characterised by patches of high reflection coefficient interspersed with patches of low reflection coefficient. Like Kea and Kaka, this heterogeneous zone of anomalous reflectivity is elongate in a WNW-ESE orientation (Figure 6.1). This seep is characterised by a region of high sonar backscatter intensity compared to the surrounding seafloor. As at Kea and Kaka, this region of high backscatter intensity is elongate in a WNW-ESE direction and backscatter is highest at the centre of the feature (Figure 6.1). Kakapo is characterised by low seafloor seismic similarity, elongate in a WNW-ESE orientation over the same region that ex- 
hibits anomalous seafloor seismic reflection coefficient and high sonar backscatter intensity (Figure 6.1). In the Parasound ${ }^{\mathrm{TM}}$ data, Kakapo exhibits a patch of high-amplitude reflections near the seafloor, underlain by a thin low amplitude zone, underlain by the more extensive zone of high-amplitude reflections that is also observed beneath Kaka. This high amplitude feature is underlain by a pronounced blanked zone (see Figure 5.6 in Chapter 5). The preliminary 3D seismic inline selected through Kakapo reveals a narrow vertical zone of anomalous reflectivity below the seep site, which extends down into a zone of high-amplitude reflections deeper in the subsurface. This zone of deep high-amplitude reflections has an antiformal shape and is directly overlain by a zone of low amplitude response, as was observed beneath the Kea and Kaka seeps (see Figure 3.16 in Chapter 3).

\subsubsection{Moa Reef}

Moa Reef is characterised by a broad, relatively continuous zone of very high seafloor reflection coefficient, elongate in a SW-NE direction (Figure 6.1). Seafloor seismic reflection coefficient values at Moa reach levels higher than at any of the other seep sites. The region of high seafloor reflection coefficient coincides with a broad, continuous region of high sonar backscatter intensity compared to the surrounding seafloor (Figure 6.1). This region of high reflection coefficient and high backscatter intensity is also characterised by low seismic similarity (Figure 6.1). In the Parasound ${ }^{\mathrm{TM}}$ data, Moa Reef is characterised by diffractions/side reflections above more coherent high-amplitude reflections at and beneath the seafloor. Below these high-amplitude reflections, not much signal is returned (see Figure 5.4 in Chapter 5). The preliminary 3D seismic inline through Moa Reef reveals a narrow vertical zone of disturbed reflectivity beneath this site. The bottom of this disturbed zone is not visible, as it continues to the depth where the amplitude of the returned signal is too low to detect reflections. To the west of Moa, shallow reflection horizons are truncated and vertically offset by extensional faults (see Figure 3.14 in Chapter 3). 


\subsection{Discussion}

\subsubsection{Bear's Paw}

The extensive zone of high-amplitude reflections in the Parasound ${ }^{\mathrm{TM}}$ data extending from the seafloor to a depth of up to $10 \mathrm{~m}$ could be explained by any of three hypotheses: 1) a patchy distribution of gas in the sediments; 2) the presence of centimetre-scale bands of nodular carbonates throughout the sediment column; or 3) a patchy distribution of gas hydrates. Each of these hypotheses are geologically reasonable: methane is known to be actively seeping into the water column at Bear's Paw (Faure et al., 2010; Jones et al., 2010), nodular carbonates and carbonates with very large pore spaces were recovered from the seafloor at Omakere Ridge seep sites (Campbell et al., 2010) and gas hydrates were recovered from Bear's Paw at $1 \mathrm{~m}$ depth (Bialas et al., 2007).

The elevated sonar backscatter intensity at Bear's Paw could be caused by either of the following scenarios: 1) seafloor roughness at the sonar wavelength scale $(12.5 \mathrm{~cm})$; or 2$)$ high seafloor acoustic impedance. However, sonar backscatter at Bear's Paw does not reach the same high values of Kea and Moa. Even the maximum sonar backscatter intensities at Kaka and Kakapo are slightly higher than the maximum values at Bear's Paw. The fact that seismic similarity at Bear's Paw is as low as at Moa Reef, and lower than at Kea, Kaka and Kakapo indicates that the seafloor at Bear's Paw is at least as rough as at the other seep sites on the seismic CDP scale $(6.25 \mathrm{~m})$. Assuming that seismic similarity at the $6.25 \mathrm{~m}$ scale is also some indication of the relative seafloor roughness of the seep sites at the sonar wavelength scale, the lower sonar backscatter intensity at Bear's Paw compared to the other seep sites is best explained by low seafloor acoustic impedance caused by high gas concentrations in the near-seafloor sediments.

Using the geological hypotheses presented above to explain the features observed in the Parasound ${ }^{\mathrm{TM}}$, sonar backscatter and 3D seismic similarity datasets as guidelines, the low seafloor acoustic impedance observed in the 3D seismic dataset is consistent with the following scenarios: 1) high gas concentrations in the near-seafloor sediments; 2$)$ a lack of indurated carbonates thicker than one quarter of the seismic wavelength ( 6-7 m); and 3) a patchy distribution of gas 


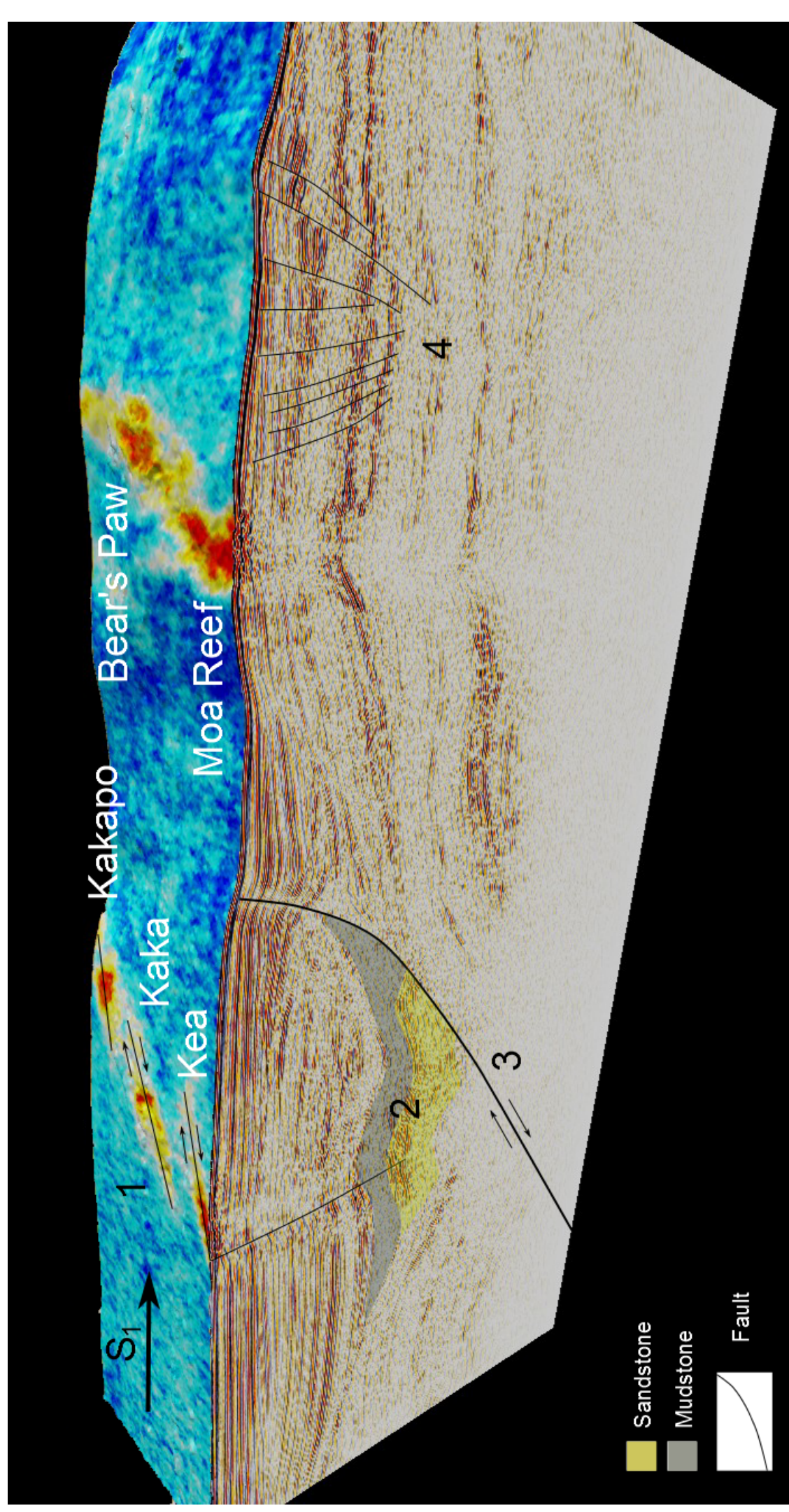

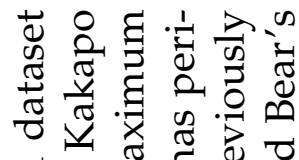

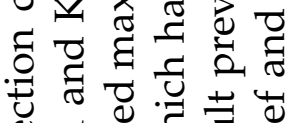

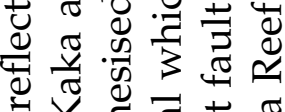

บ

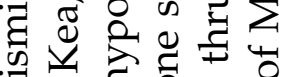

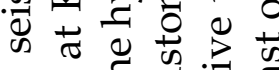

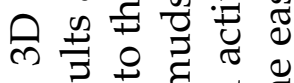

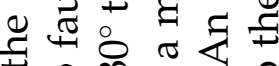

દํㅠ

过良

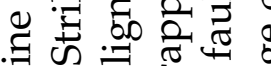

ఏ

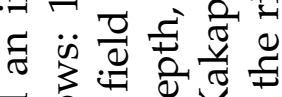

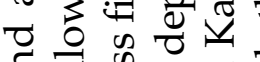

ฮิ

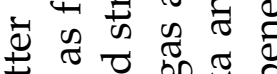

चु

की

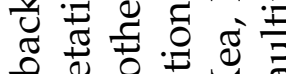

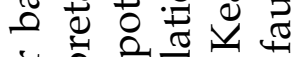

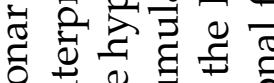

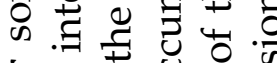

రั రृ.

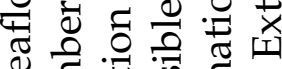

का छ क्व

Ч

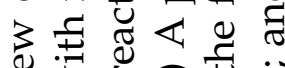

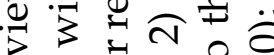

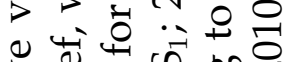

\& च

芷

की

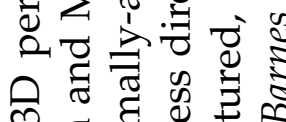

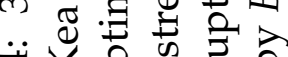

붕

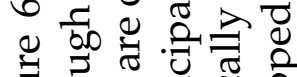

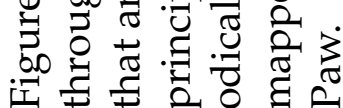


hydrates in the shallow subsurface. In scenario 1, high gas concentrations would lower the acoustic impedance of the near-seafloor sediments, which would in turn lower the acoustic impedance contrast between seawater and the seafloor, resulting in a reduction in reflection coefficient. Gas often increases the amplitude of the seafloor reflection in soft sediments by causing a high negative impedance contrast, but for indurated sediments such as those at Hikurangi Margin seep sites, it has been shown that the impedance contrast decreases and stays positive, leading to a low-amplitude reflection of positive polarity (e.g. Crutchley et al., 2010). In scenarios 2 and 3, if the vertical extent of indurated carbonate structures / zone of uniform gas hydrate distribution is less than one quarter of the seismic wavelength (in this case 6-7 m), destructive interference between reflections from the top and base of the carbonate build-up will result in a low-amplitude reflection and an apparent low reflection coefficient (Chopra and Marfurt, 2007). Both centimetre-scale bands of nodular carbonates and centimetre-scale patches of gas hydrates in the shallow subsurface of Bear's Paw would not significantly alter the bulk acoustic properties of the sediments at the seismic wavelength scale.

What the data suggest is that thick, indurated carbonate deposits are not present at Bear's Paw. If they were, then they would have shown up as highamplitude features in the 3D seismic data. Any carbonate deposits in the subsurface at Bear's Paw must be such that they do not significantly increase the average acoustic impedance of near-seafloor sediments on the seismic wavelength scale. However, bands of nodular carbonates are large enough to cause high-amplitude reflections in the higher-frequency Parasound ${ }^{\mathrm{TM}}$ data. High gas concentrations in the shallow subsurface at Bear's Paw are consistent with all observations presented above and appear to be higher at Bear's Paw than at any of the other Omakere Ridge seeps. The presence of many discrete centimetre-scale patches of gas hydrate in the sediments beneath Bear's Paw is also consistent with all of the observations presented above, following the same reasoning presented above for the nodular carbonates hypothesis.

\subsubsection{Kea, Kaka and Kakapo}

High and relatively continuous seafloor seismic reflection coefficient and sonar backscatter intensity at Kea are most likely the result of an extensive build-up of 
authigenic carbonate, at least 6-7 $\mathrm{m}$ in vertical thickness. At Kaka and Kakapo, while the respective regions of elevated sonar backscatter intensity are also relatively continuous, the seafloor seismic reflection coefficient is high only in a number of much smaller patches. This suggests that the authigenic carbonate thickness reaches 6-7 m only in a few localised patches within the overall seep locations. Below this thickness, seismic reflection waveform interference would reduce the amplitude of the returned waves (Chopra and Marfurt, 2007). The presence of more extensive carbonates at Kea suggests that methane seepage has been occurring over a longer period of time here than at Kaka and Kakapo (cf. Judd and Hovland, 2007). This supports the previously published suggestion that seepage at Omakere Ridge has been migrating eastward over time (Jones et al., 2010).

The blanked zone in the Parasound ${ }^{\mathrm{TM}}$ data beneath Kea, Kaka and Kakapo is most likely caused by the presence of gas in the sediments, and represents the migration pathway of gas to the seeps (e.g. Jones et al., 2010). The distinct linear morphology of these three seep sites and their strike of approximately $30^{\circ}$ to the hypothesised local maximum principal stress direction suggest that the gas is migrating vertically along strike-slip faults that are optimally oriented for reactivation in the local stress regime (e.g. Sibson, 1985) (Figure 6.4). It is known that such optimally-oriented faults that are constantly reactivated act as permeability conduits (e.g. Hooper, 1991; Sibson and Scott, 1998), which explains the seepage along such faults at Kea, Kaka and Kakapo. These faults may have formed through hydraulic fracturing of a mudstone seal above a gas-charged sandstone once gas pressure reached a critical level. The deep zone of high-amplitude reflections associated with an antiformal structure observed in the preliminary 3D seismic inlines may be caused by such a gas accumulation. Such hydraulic fractures may have coalesced into strike-slip faults, with their current orientation owing to the local stress regime. The lateral extent of the blanked zone in the Parasound ${ }^{\mathrm{TM}}$ data indicates that the gas has migrated laterally up to $300 \mathrm{~m}$ from the faults into the surrounding sediments (Figures 6.2 and 6.3).

The extensive zone of high-amplitude reflections in the Parasound ${ }^{\mathrm{TM}}$ data beneath Kaka and Kakapo could be explained by three possible scenarios: 1) the presence of buried carbonates; 2) a patchy distribution of gas in the sediments; or 3) a patchy distribution of gas hydrates in the sediments. A deep accumulation 
of carbonates beneath Kaka and Kakapo could have been formed during a previous phase of seepage that has since ceased and the carbonates have subsequently been buried by sedimentation. The lack of a deeper zone of high-amplitude reflections beneath Kea suggests one of the following three scenarios: 1) the absence of a deeper accumulation of carbonates beneath Kea; 2) a different distribution of gas in the sediments beneath Kea compared to that beneath Kaka and Kakapo; or 3) gas hydrates are not as abundant beneath Kea as they are beneath Kaka and Kakapo.

\subsubsection{Moa Reef}

The extensive region of very high seafloor seismic reflection coefficient and sonar backscatter intensity at Moa Reef is likely due to a laterally and vertically extensive accumulation of authigenic carbonate. This is consistent with previous research: Jones et al. (2010) observed carbonates of higher relief at Moa Reef than at any of the other seeps on Omakere Ridge. It is a safe assumption that authigenic carbonate has a higher acoustic impedance than the surrounding muddy seafloor sediments. To produce such a continuous zone of high seafloor seismic reflection coefficient, the carbonate build-up at Moa must be at least 6-7 $\mathrm{m}$ thick over a broad area. 


\section{Chapter 7}

\section{Conclusions}

\subsection{Summary}

The three datasets that have been analysed in this thesis have proved suitable for addressing the goals set out in Chapter 1, which are presented again here:

- to determine the extent of authigenic carbonate build-ups at the seep sites;

- to determine the distribution of gas in shallow sediments at the seep sites;

- to identify the shallow subsurface migration pathways of methane to the seep sites;

- to determine the relative ages of the seep sites;

- and to determine seep initiation mechanisms.

The 3D seismic dataset has proved useful in determining the extent of thick authigenic carbonate structures and the presence of gas in the top $25 \mathrm{~m}$ of sediment (seafloor reflection coefficient), and in determining the extent of any carbonates on the seafloor (seismic similarity). Sonar backscatter data have been useful in determining the extent of carbonates on the seafloor. The Parasound ${ }^{\mathrm{TM}}$ subbottom profiler data have provided a high-resolution picture of the distribution of carbonates and gas in the subsurface, to a depth of up to $100 \mathrm{~m}$. A preliminary interpretation of the deeper 3D seismic data has provided the first glimpse into how the seeps are connected to deeper fluid migration pathways and how the seeps may have formed. A summary of the interpretation flow applied to the 
3D seismic reflection coefficient, sonar backscatter intensity and Parasound ${ }^{\mathrm{TM}}$ reflection characteristics is provided in Figure 7.1. Summaries of the findings of this thesis in relation to each of the goals above are provided in the following sections. These interpretations are based on the interpretation flow presented in Figure 7.1 and the deeper 3D seismic reflection characteristics (discussed in more detail in Chapter 6). This Chapter concludes with proposed future research at Omakere Ridge.

\subsection{Distribution and nature of carbonates}

The likely distribution and nature of authigenic carbonates in the top $50 \mathrm{~m}$ of sediment at Omakere Ridge has been determined by comparing the 3D seismic, multibeam sonar backscatter and Parasound ${ }^{\mathrm{TM}}$ datasets. Areas of high seafloor seismic reflection coefficient are indicative of indurated authigenic carbonate structures of at least 6-7 $\mathrm{m}$ thickness on the seafloor and in the shallow subsurface down to $25 \mathrm{~m}$ (seismic wavelength). Carbonates of such thickness are most developed at Moa Reef, where a broad area of high seismic reflection coefficient indicates a broad area of thick carbonates. A smaller, but still broad area of high reflection coefficient at Kea indicates that thick carbonates are also present here. Thick carbonates only exist in small patches at Kaka and Kakapo, and don't appear to exist at all at Bear's Paw. However, a zone of high-amplitude reflections in the Parasound ${ }^{\mathrm{TM}}$ data suggests that nodular carbonates may be present in the sediments beneath Bear's Paw down to a depth of up to $10 \mathrm{~m}$. A zone of highamplitude reflections beneath Kaka and Kakapo of similar vertical and lateral extent, from 10-20 m beneath the seafloor, may indicate the presence of carbonates at depth beneath these seeps.

\subsection{Distribution of gas and migration pathways}

Areas of low seismic reflection coefficient at Bear's Paw, Kaka and Kakapo may be caused in part by high concentrations of gas in the near-seafloor sediments (as well as by the absence of thick build-ups of authigenic carbonate as discussed above). If reflection coefficient is proportional to gas concentration, then Bear's Paw has the highest levels of gas in the near-seafloor sediments (consistent with 

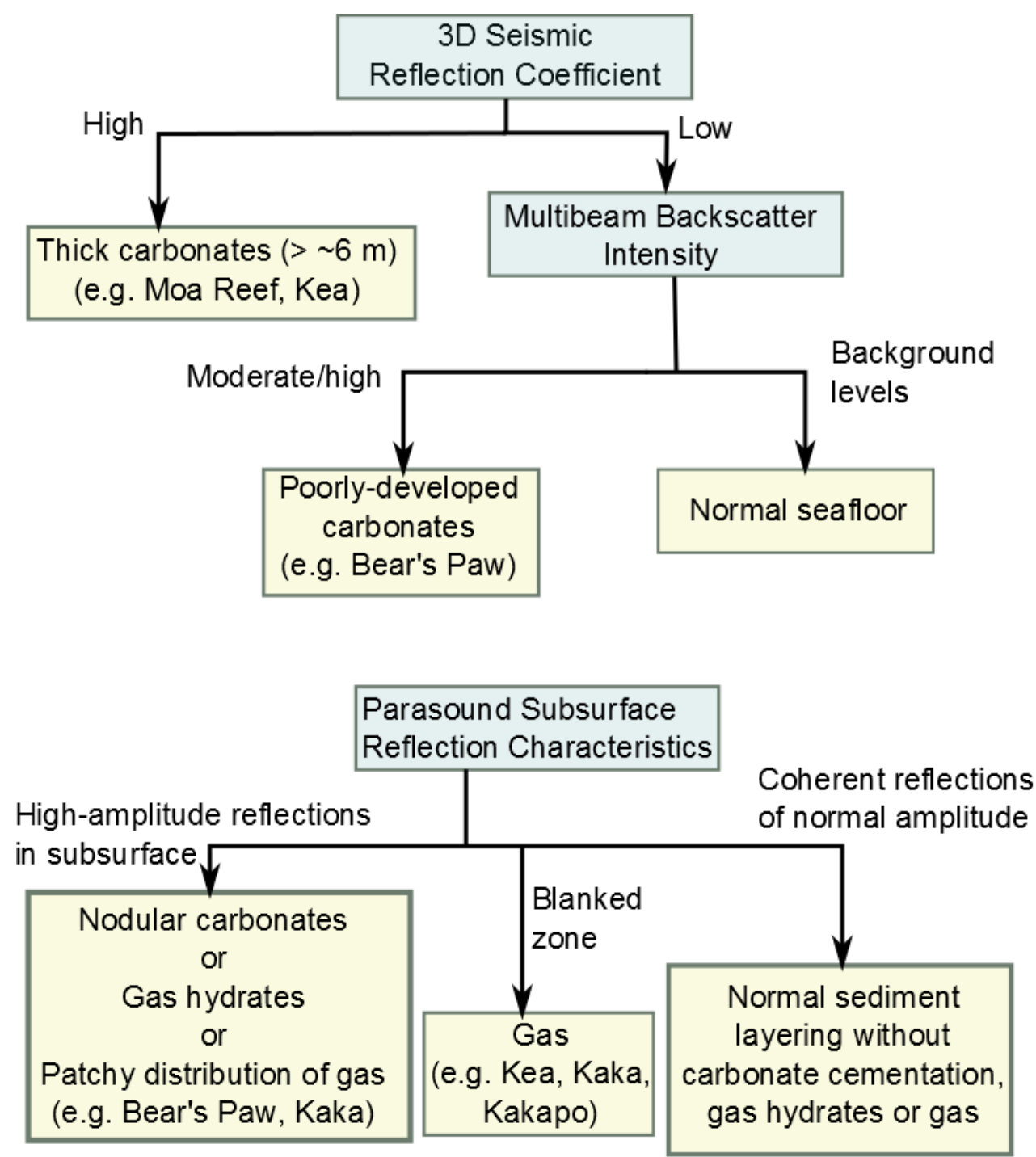

Figure 7.1: Interpretation flow diagram summarising how the 3D seismic reflection coefficient, multibeam backscatter intensity and Parasound ${ }^{\mathrm{TM}}$ reflection characteristics have been interpreted. Datasets are in blue boxes, observations of these datasets are written along the flow branches, and interpretations are given in the yellow boxes. 
Faure et al., 2010; Jones et al., 2010), followed by Kaka and Kakapo, Kea and finally Moa Reef. The fact that multibeam backscatter intensity at Bear's Paw did not reach values as high as those at any of the other seeps may also be indicative of higher gas concentrations.

The methane migration pathways to the Kea, Kaka and Kakapo seeps have been identified by the distinct blanked zone in the Parasound ${ }^{\mathrm{TM}}$ data, which is most likely caused by the presence of gas in the sediments. This blanked zone has been imaged down to a depth of approximately $50 \mathrm{~m}$ in the Parasound ${ }^{\mathrm{TM}}$ data. The distinct linear alignment of carbonates on the seafloor as observed in the sonar backscatter and 3D seismic data at each of these seeps suggests that methane is migrating along faults that crop out at the seafloor. In this top $50 \mathrm{~m}$ of sediment, gas appears to be prevalent up to a lateral distance of 200-300 m from these faults, indicating that gas has migrated laterally from the faults into undisturbed sediment layers, or that these faults are associated with broader areas of permeable fracture networks. Beneath and to the southeast of Bear's Paw and Moa Reef, an extensional fault network can be seen in the seismic sections. This fault network likely plays an integral role in facilitating fluid migration to these seeps.

\subsection{Chronology of seepage}

As discussed in Chapter 2, the extent of carbonate accumulations at a seep site is related to the age of the seep. The more extensive the carbonate accumulation is, the longer seepage has occurred at that location. Following this reasoning, Kea is probably older than Kaka and Kakapo due to more extensive build-up of authigenic carbonates, as observed by the broader area of high reflection coefficient in the 3D seismic data. Bear's Paw is likely to be the youngest seep site on Omakere Ridge, due to the least-developed carbonates as observed by the lowest seismic reflection coefficient values in the 3D seismic data. Moa, with the broadest area of high reflection coefficient in the 3D seismic data, indicative of the most extensive build-up of carbonates out of all the Omakere Ridge seep sites, is most likely to be the oldest seep site. This chronology of seepage is consistent with the hypothesis 
presented by Jones et al. (2010) based on the chemosynthetic faunal communities at each of the seep sites. The hypothesised deeper accumulation of carbonates beneath Kaka and Kakapo, as discussed above, might be related to an earlier phase of seepage in the area. These carbonates may have formed near the seafloor, such as the carbonates currently in the shallow subsurface at Kea, Kaka and Kakapo, and been subsequently buried by sedimentation.

\subsection{Seepage initiation mechanisms}

Initiation of seepage at Kea, Kaka and Kakapo appears to be related to an accumulation of gas at depth, above which strike-slip faults, that act as conduits from this reservoir to the seafloor, have formed. Each of these strike-slip faults crops out at the seafloor at the Kea, Kaka and Kakapo seep sites respectively, with the elongate distribution of carbonates at these three seeps owing to the linear nature of the fault traces on the seafloor. These three faults have a strike of approximately $30^{\circ}$ to the hypothesised maximum principal stress direction at Omakere Ridge. The initiation of each of these faults may have been triggered by fracturing of a sealing lithology over a gas accumulation at depth due to a build-up of excessive pore fluid pressure. Their strike of $30^{\circ}$ to the maximum principal stress direction makes them optimally aligned for reactivation and therefore permeable, enabling sustained seepage at the seafloor.

\subsection{Proposed future research}

The zone of high-amplitude reflections in the Parasound ${ }^{\mathrm{TM}}$ data beneath Kaka and Kakapo at 10-20 m depth should be investigated using the 3D seismic data. The amplitude of any reflection related to this feature should determine whether it is caused by small features in the sediments such as nodular carbonates (as has been proposed for the shallower high-amplitude reflection zone beneath Bear's Paw described above), or thick, indurated carbonates such as those exposed on the seafloor at Moa Reef and Kea, while the phase of the seismic reflection should distinguish between gas (negative polarity reflection expected) and thick carbonates/hydrates (positive polarity reflection expected). 
The only way to be sure of which geological phenomena are causing the features observed in the geophysical datasets presented in this thesis is to drill and core these features. The zones of high-amplitude reflections observed in the Parasound $^{\mathrm{TM}}$ data beneath Bear's Paw and the deeper zone of high-amplitude reflections beneath Kaka and Kakapo provide interesting drilling targets, as they could be caused by carbonates, gas hydrates or gas. Determining what is causing these zones of high-amplitude reflections in the Parasound ${ }^{\mathrm{TM}}$ data will increase our knowledge of the seep system at Omakere Ridge, as well as improve our ability to relate these features observed in Parasound ${ }^{\mathrm{TM}}$ data to geological phenomena. Proposed drilling sites and depths targeting the high-amplitude zones beneath Bear's Paw and Kaka and Kakapo are presented in Figure 7.2.

Geochemical analysis, stable carbon and oxygen isotope analysis (e.g. Campbell et al., 2010) and U/Th dating (e.g. Liebetrau et al., 2010) of any carbonates recovered in the cores from the proposed drilling sites will determine the geochemical environment and chronology of formation of such buried carbonates. Through the research proposed above, there is more that can be learned from Omakere Ridge about the history of methane seepage on the Hikurangi Margin. 


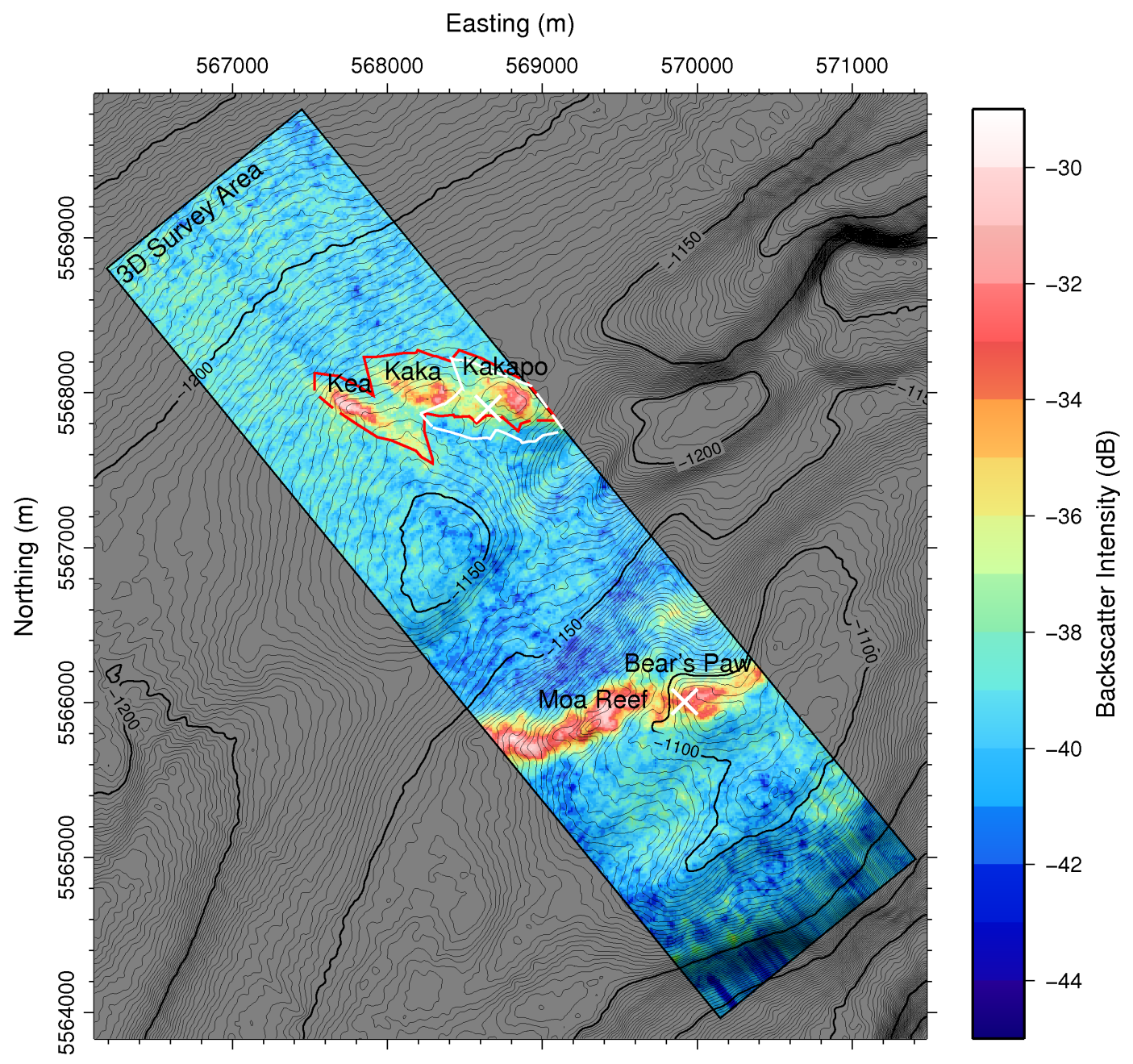

Figure 7.2: Sonar backscatter draped over bathymetry showing the location of two proposed drilling sites, targeting high-amplitude reflections observed in Parasound ${ }^{\mathrm{TM}}$ sub-bottom profiler sections (could be caused by buried carbonates, gas, or gas hydrates). The white polygon marks the lateral extent of the high-amplitude reflection zone beneath Kaka and Kakapo, and the red polygon marks the lateral extent of the blanked zone at 25 ms TWT (see Figures 5.5 and 5.6 in Chapter 5). The white crosses mark the locations of the proposed drilling sites, with coordinates as follows (NZ UTM Zone 60S Easting, Northing, Depth): Bear's Paw 569915.33, 5566005.14, 15 m; Kaka/Kakapo 568650, 5567900, 30 m. 


\section{Bibliography}

Baco, A. R., A. A. Rowden, L. A. Levin, C. R. Smith, and D. A. Bowden (2010), Initial characterization of cold seep faunal communities on the New Zealand Hikurangi margin, Marine Geology, 272(14), 251 - 259, doi:10.1016/j.margeo. 2009.06.015.

Bangs, N. L. B., D. S. Sawyer, and X. Golovchenco (1993), Free gas at the base of the gas hydrate zone in the vicinity of the Chile triple junction, Geology, 21(10), $905-908$.

Barker, D. H. N., R. Sutherland, S. Henrys, and S. Bannister (2009), Geometry of the Hikurangi subduction thrust and upper plate, North Island, New Zealand, Geochemistry Geophysics Geosystems, 10.

Barnes, P. M., G. Lamarche, J. Bialas, S. Henrys, I. Pecher, G. L. Netzeband, J. Greinert, J. J. Mountjoy, K. Pedley, and G. Crutchley (2010), Tectonic and geological framework for gas hydrates and cold seeps on the Hikurangi subduction margin, New Zealand, Marine Geology, 272(1-4), 26 - 48, doi:10.1016/j. margeo.2009.03.012.

Bayon, G., G. Henderson, and M. Bohn (2009), U-Th stratigraphy of a cold seep carbonate crust, Chemical Geology, 260(12), 47 - 56, doi:10.1016/j.chemgeo.2008. 11.020 .

Bialas, J. (2011), FS SONNE Fahrtbericht/Cruise Report SO-214, Tech. Rep. 47, IFM-GEOMAR.

Bialas, J., J. Greinert, P. Linke, and O. Pfannkuche (2007), FS SONNE Fahrtbericht/Cruise Report SO-191, Tech. Rep. 9, IFM-GEOMAR. 
Boswell, R. (2009), Is gas hydrate energy within reach?, Science, 325(5943), 957958, doi:10.1126/science.1175074.

Campbell, K. (2006), Hydrocarbon seep and hydrothermal vent paleoenvironments and paleontology: Past developments and future research directions, Palaeogeography, Palaeoclimatology, Palaeoecology, 232(24), 362 - 407, doi:10.1016/ j.palaeo.2005.06.018.

Campbell, K. A., D. A. Francis, M. Collins, M. R. Gregory, C. S. Nelson, J. Greinert, and P. Aharon (2008), Hydrocarbon seep-carbonates of a Miocene forearc (East Coast Basin), North Island, New Zealand, Sedimentary Geology, 204(34), 83 105, doi:10.1016/j.sedgeo.2008.01.002.

Campbell, K. A., C. S. Nelson, A. C. Alfaro, S. Boyd, J. Greinert, S. Nyman, E. Grosjean, G. A. Logan, M. R. Gregory, S. Cooke, P. Linke, S. Milloy, and I. Wallis (2010), Geological imprint of methane seepage on the seabed and biota of the convergent Hikurangi Margin, New Zealand: Box core and grab carbonate results, Marine Geology, 272(1-4), 285 - 306, doi:10.1016/j.margeo.2010.01. 002.

Chopra, S., and K. Marfurt (2007), Seismic Attributes for Prospect Identification and Reservoir Characterization, Society of Exploration Geophysicists.

Chopra, S., and K. Marfurt (2008), Gleaning meaningful information from seismic attributes, First Break, 26, 43-53.

Collett, T. S., A. H. Johnson, C. C. Knapp, and R. Boswell (2009), Natural gas hydrates: A review, AAPG Special Volumes, AAPG Memoir 89: Natural gas hydrates energy resource potential and associated geologic hazards, 146-219.

Crutchley, G. J., I. A. Pecher, A. R. Gorman, S. A. Henrys, and J. Greinert (2010), Seismic imaging of gas conduits beneath seafloor seep sites in a shallow marine gas hydrate province, Hikurangi Margin, New Zealand, Marine Geology, 272(14), 114 - 126, doi:10.1016/j.margeo.2009.03.007.

Davey, F., M. Hampton, J. Childs, M. Fisher, K. Lewis, and J. Pettinga (1986), Structure of a growing accretionary prism, Hikurangi margin, New Zealand, Geology, 14, $663-666$. 
Davy, B. (1992), Seismic reflection profiling on southern lake Rotorua - evidence for gas-charged lakefloor sediments, Geothermics, 21(12), 97 - 108, doi:10.1016/ 0375-6505(92)90071-G.

Davy, B., I. Pecher, R. Wood, L. Carter, and K. Gohl (2010), Gas escape features off New Zealand: Evidence of massive release of methane from hydrates, Geophysical Research Letters, 37, 21,309, doi:10.1029/2010GL045184.

dGB Beheer B.V. (2011), OpenDtect User Documentation version 4.2, dGB Earth Sciences.

Faure, K., J. Greinert, J. S. von Deimling, D. F. McGinnis, R. Kipfer, and P. Linke (2010), Methane seepage along the Hikurangi Margin of New Zealand: Geochemical and physical data from the water column, sea surface and atmosphere, Marine Geology, 272(1-4), 170 - 188, doi:10.1016/j.margeo.2010.01.001.

Field, B., and C. Uruski (1997), Cretaceous-Cenozoic Geology and Petroleum Systems of the East Coast Region, New Zealand, Institute of Geological and Nuclear Sciences monograph, vol. 19.

Grant, J. A., and R. Schreiber (1990), Modern swathe sounding and sub-bottom profiling technology for research applications: The Atlas Hydrosweep and Parasound Systems, Marine Geophysical Research, 12, 9-19, 10.1007/BF00310559.

Greinert, J., G. Bohrmann, and E. Suess (2001), Gas hydrate-associated carbonates and methane-venting at Hydrate Ridge: classification, distribution, and origin of authigenic lighologies, in Natural Gas Hydrates: Occurrence, Distribution, and Detection, Geophysical Monograph, vol. 124, edited by C. Paull and P. Dillon, pp. 99-113, American Geophysical Union.

Greinert, J., K. Lewis, J. Bialas, I. Pecher, A. Rowden, D. Bowden, M. D. Batist, and P. Linke (2010), Methane seepage along the Hikurangi Margin, New Zealand: Overview of studies in 2006 and 2007 and new evidence from visual, bathymetric and hydroacoustic investigations, Marine Geology, 272(1-4), 6 - 25, doi: 10.1016/j.margeo.2010.01.017.

Henrys, S., S. Ellis, and C. Uruski (2003), Conductive heat flow variations from bottom simulating reflectors on the Hikurangi margin, New Zealand, Geophysical Research Letters, 30, doi:10.1029/2002GL015772. 
Hooper, E. C. D. (1991), Fluid migration along growth faults in compacting sediments, Journal of Petroleum Geology, 14, 161-180, doi:10.1111/j.1747-5457.1991. tb00360.x.

Hovland, M., H. Svensen, C. F. Forsberg, H. Johansen, C. Fichler, J. H. Foss, R. Jonsson, and H. Ruesltten (2005), Complex pockmarks with carbonate-ridges off mid-Norway: Products of sediment degassing, Marine Geology, 218(14), 191 206, doi:10.1016/j.margeo.2005.04.005.

Jones, A., J. Greinert, D. Bowden, I. Klaucke, C. Petersen, G. Netzeband, and W. Weinrebe (2010), Acoustic and visual characterisation of methane-rich seabed seeps at Omakere Ridge on the Hikurangi Margin, New Zealand, $\mathrm{Ma}$ rine Geology, 272(1-4), 154 - 169, doi:10.1016/j.margeo.2009.03.008.

Judd, A., and M. Hovland (2007), Seabed fluid flow, Cambridge University Press.

Kamp, P., and K. Furlong (2006), Neogene plate tectonic reconstructions and geodynamics of North Island sedimentary basins: implications for the petroleum systems, in New Zealand Petroleum Conference Proceedings, Auckland.

Katz, H.-R. (1981), Probable gas hydrate in continental slope east of the North Island, New Zealand, Journal of Petroleum Geology, 3(3), 315-324, doi:10.1111/j. 1747-5457.1981.tb00933.x.

Kvenvolden, K. A. (1993), Gas hydrates - geological perspective and global change, Reviews of Geophysics, 31(2), 173-187.

Kvenvolden, K. A., G. D. Ginsburg, and V. A. Soloviev (1993), Worldwide distribution of subaquatic gas hydrates, Geo-Marine Letters, 13, 32-40, $10.1007 /$ BF01204390.

Lamarche, G., X. Lurton, A.-L. Verdier, and J.-M. Augustin (2011), Quantitative characterisation of seafloor substrate and bedforms using advanced processing of multibeam backscatter-Application to Cook Strait, New Zealand, Continental Shelf Research, 31(2, Supplement 1), S93 - S109, doi:10.1016/j.csr.2010.06.001.

Lewis, K., and J. Pettinga (1993), The emerging, imbricate frontal wedge of the Hikurangi margin, in South Pacific Sedimentary Basins, Sedimentary Basins of the World, vol. 2, edited by P. Balance, pp. 225 - 250, Elsevier. 
Lewis, K. B., and B. A. Marshall (1996), Seep faunas and other indicators of methane-rich dewatering on New Zealand convergent margins, New Zealand Journal of Geology and Geophysics, 39(2), 181-200.

Liebetrau, V., A. Eisenhauer, and P. Linke (2010), Cold seep carbonates and associated cold-water corals at the Hikurangi Margin, New Zealand: New insights into fluid pathways, growth structures and geochronology, Marine Geology, 272(1-4), 307 - 318, doi:10.1016/j.margeo.2010.01.003.

Lurton, X. (2002), An Introduction to Underwater Acoustics, Springer.

MacDonald, I. R., W. W. Sager, and M. B. Peccini (2003), Gas hydrate and chemosynthetic biota in mounded bathymetry at mid-slope hydrocarbon seeps: Northern Gulf of Mexico, Marine Geology, 198(1-2), 133 - 158, doi: 10.1016/S0025-3227(03)00098-7.

Mazzullo, S. (2000), Organogenic dolomitization in peritidal to deep-sea sediments, Journal of Sedimentary Research, 70(1), 10-23, doi:10.1306/ 2DC408F9-0E47-11D7-8643000102C1865D.

Milkov, A. (2000), Worldwide distribution of submarine mud volcanoes and associated gas hydrates, Marine Geology, 167(12), 29 - 42, doi:10.1016/ S0025-3227(00)00022-0.

Mosher, D. C., and P. G. Simpkin (1999), Status and trends on marine highresolution seismic reflection profiling: data acquisition, Geoscience Canada, 25, 174-188.

Naehr, T. H., P. Eichhubl, V. J. Orphan, M. Hovland, C. K. Paull, W. Ussler III, T. D. Lorenson, and H. G. Greene (2007), Authigenic carbonate formation at hydrocarbon seeps in continental margin sediments: A comparative study, Deep Sea Research Part II: Topical Studies in Oceanography, 54(1113), 1268 - 1291, doi: 10.1016/j.dsr2.2007.04.010.

Netzeband, G., A. Krabbenhoeft, M. Zillmer, C. Petersen, C. Papenberg, and J. Bialas (2010), The structures beneath submarine methane seeps: Seismic evidence from Opouawe Bank, Hikurangi Margin, New Zealand, Marine Geology, 272(14), 59 - 70, doi:10.1016/j.margeo.2009.07.005. 
Nyman, S. L., C. S. Nelson, and K. A. Campbell (2010), Miocene tubular concretions in East Coast Basin, New Zealand: Analogue for the subsurface plumbing of cold seeps, Marine Geology, 272(14), 319 - 336, doi:10.1016/j.margeo.2009.03. 021.

Paull, C. K., and W. Ussler III (2008), Re-evaluating the significance of seafloor accumulations of methane-derived carbonates: seepage or erosion indicators?, in Proc. 6th International Conference on Gas Hydrates, Vancouver, Britich Columbia, Canada.

Pecher, I., S. Henrys, S. Ellis, S. Chiswell, and N. Kukowski (2005), Erosion of the seafloor at the top of the gas hydrate stability zone on the Hikurangi Margin, New Zealand, Geophysical Research Letters, 32, L24,603, doi:10.1029/ 2005 GL024687.

Pecher, I., J. Bialas, GHR Working Group, and NEMESYS Working Group (2011), Gas hydrates research in New Zealand, overview on latest results, in Proc. 7th International Conference on Gas Hydrates, Edinburgh.

Pecher, I. A., and S. Henrys (2003), Potential gas reserves in gas hydrate sweet spots on the Hikurangi Margin, New Zealand, Tech. Rep. 23, GNS Science.

Pecher, I. A., S. A. Henrys, and H. Zhu (2004), Seismic images of gas conduits beneath vents and gas hydrates on Ritchie Ridge, Hikurangi margin, New Zealand, New Zealand Journal of Geology and Geophysics, 47(2), 275-279, doi: 10.1080/00288306.2004.9515054.

Pecher, I. A., S. A. Henrys, W. T. Wood, N. Kukowski, G. J. Crutchley, M. Fohrmann, J. Kilner, K. Senger, A. R. Gorman, R. B. Coffin, J. Greinert, and K. Faure (2010), Focussed fluid flow on the Hikurangi Margin, New Zealand Evidence from possible local upwarping of the base of gas hydrate stability, Marine Geology, 272(14), 99 - 113, doi:10.1016/j.margeo.2009.10.006.

Plaza-Faverola, A., S. Buenz, and J. Mienert (2011), Repeated fluid expulsion through sub-seabed chimneys offshore Norway in response to glacial cycles, Earth and Planetary Science Letters, 305(34), 297 - 308, doi:10.1016/j.epsl.2011.03. 001. 
Rait, G., F. Chanier, and D. W. Waters (1993), Landward- and seaward-directed thrusting accompanying the onset of subduction beneath New Zealand, Geology, 19(3), $230-233$.

Roberts, H. H., B. A. Hardage, W. W. Shedd, and J. Hunt, Jesse (2006), Seafloor reflectivity-An important seismic property for interpreting fluid/gas expulsion geology and the presence of gas hydrate, The Leading Edge, 25(5), 620-628, doi:10.1190/1.2202667.

Sager, W. W., I. R. MacDonald, and R. Hou (2003), Geophysical signatures of mud mounds at hydrocarbon seeps on the Louisiana continental slope, northern Gulf of Mexico, Marine Geology, 198(1-2), 97 - 132, doi:10.1016/S0025-3227(03) 00097-5.

Sahai, S. K., and K. A. Soofi (2006), Use of simple 2-D filters to reduce footprint noise in seismic data, Geohorizons, 14.

Sheriff, R. E., and L. P. Geldart (1995), Exploration Seismology, Cambridge University Press.

Sibson, R. (1985), A note on fault reactivation, Journal of Structural Geology, 7(6), 751 - 754, doi:10.1016/0191-8141(85)90150-6.

Sibson, R., and J. Scott (1998), Stress/fault controls on the containment and release of overpressured fluids: Examples from gold-quartz vein systems in Juneau, Alaska; Victoria, Australia and Otago, New Zealand, Ore Geology Reviews, 13(15), 293 - 306, doi:10.1016/S0169-1368(97)00023-1.

Sloan, E. (1998), Clathrate hydrates of natural gases, CRC Press.

Tissot, B., and D. Welte (1978), Petroleum formation and occurrence: a new approach to oil and gas exploration, Springer-Verlag, New York, NY.

Townend, J. (1997), Estimates of conductive heat flow through bottom-simulating reflectors on the Hikurangi and southwest Fiordland continental margins, New Zealand, Marine Geology, 141(14), 209 - 220, doi:10.1016/S0025-3227(97) 00073-X. 
Whiticar, M., E. Faber, and M. Schoell (1986), Biogenic methane formation in marine and freshwater environments: $\mathrm{CO}_{2}$ reduction vs. acetate fermentationIsotope evidence, Geochimica et Cosmochimica Acta, 50(5), 693 - 709, doi:10.1016/ 0016-7037(86)90346-7.

Wood, R., and B. Davy (1994), The Hikurangi Plateau, Marine Geology, 118(12), 153 - 173, doi:10.1016/0025-3227(94)90118-X.

Yilmaz, O., and S. Doherty (2001), Seismic data analysis: processing, inversion and interpretation of seismic data, vol. 1, Society of Exploration Geophysicists. 